University of Nebraska - Lincoln

DigitalCommons@University of Nebraska - Lincoln

Mechanical (and Materials) Engineering --

Dissertations, Theses, and Student Research

Mechanical \& Materials Engineering,

Department of

Summer 8-2011

\title{
ARTICULATED MECHANISM DESIGN AND KINEMATICS FOR NATURAL ORIFICE TRANSLUMENAL ENDOSCOPIC SURGERY ROBOT
}

Wei Jian Chin

University of Nebraska-Lincoln, jianchin@gmail.com

Follow this and additional works at: https://digitalcommons.unl.edu/mechengdiss

Part of the Mechanical Engineering Commons

Chin, Wei Jian, "ARTICULATED MECHANISM DESIGN AND KINEMATICS FOR NATURAL ORIFICE TRANSLUMENAL ENDOSCOPIC SURGERY ROBOT" (2011). Mechanical (and Materials) Engineering -Dissertations, Theses, and Student Research. 22.

https://digitalcommons.unl.edu/mechengdiss/22

This Article is brought to you for free and open access by the Mechanical \& Materials Engineering, Department of at DigitalCommons@University of Nebraska - Lincoln. It has been accepted for inclusion in Mechanical (and Materials) Engineering -- Dissertations, Theses, and Student Research by an authorized administrator of DigitalCommons@University of Nebraska - Lincoln. 


\title{
ARTICULATED MECHANISM DESIGN AND KINEMATICS FOR NATURAL ORIFICE TRANSLUMENAL ENDOSCOPIC SURGERY ROBOT
}

by

Wei Jian Chin

\author{
A THESIS \\ Presented to the Faculty of \\ The Graduate College at the University of Nebraska \\ In Partial Fulfillment of Requirements \\ For the Degree of Master of Science
}

Major: Mechanical Engineering

Under the Supervision of Professor Carl A. Nelson

Lincoln, Nebraska

August, 2011 


\title{
ARTICULATED MECHANISM DESIGN AND KINEMATICS FOR NATURAL ORIFICE TRANSLUMENAL ENDOSCOPIC SURGERY ROBOT
}

\author{
Wei Jian Chin, M.S. \\ University of Nebraska, 2011
}

Advisor: Carl A. Nelson

Natural Orifice Translumenal Endoscopic Surgery (NOTES) is a fairly recent surgical approach that eliminates the need for external incisions on the patient. NOTES takes the minimally invasive surgery paradigm a step further by using a natural orifice as the pathway to transport surgical tools to the surgical site and completely eliminating the need for even the smallest incision on the skin. Although the concept of NOTES has been in existence for the past decade, technological deficiencies prevent it from being widely accepted in human surgeries. A novel multifunctional robot for NOTES has been developed to overcome these limitations and make the approach a feasible one.

The NOTES robot comprises a multifunctional robotic manipulator and a steerable and articulating drive mechanism. The robotic manipulator carries three interchangeable surgical tool tips in a cartridge that enables tool changing without removing the robot from the patient. A stereovision camera is attached at the tip of the robotic manipulator to provide real-time video feedback to the surgeon. A steerable articulating drive mechanism is connected to the robotic manipulator to guide the robot and navigate through a natural orifice. Besides its guiding capabilities, the drive mechanism is also shape-lockable which provides a stable platform for the robotic manipulator to perform surgeries. 
The design process and engineering analysis for the articulating drive mechanism are discussed in detail in this thesis. The first-generation drive mechanism is designed and built as a proof of concept. Bench-top tests show that the design achieves the purpose of guiding and positioning the robotic manipulator. It is believed that the articulating drive mechanism can provide freedom of movement to the robotic manipulator and help circumvent some of the difficulties faced by approaches such as typical minimally invasive surgery (MIS). The second generation of the articulating drive mechanism is presented next, whereby the overall size of the drive mechanism is reduced significantly and the components in part of the drive transmission are also altered.

Phantom Omni joysticks from SensAble Technologies are used as control consoles for the drive mechanism. The programming for the drive mechanism controls has been developed and is presented in this thesis.

Although further improvements are necessary to the current iteration of the robot, bench-top testing results show promise of continued success for the multifunctional robot for NOTES. 


\section{Table of Contents}

Chapter 1. Introduction .................................................................................................................. 6

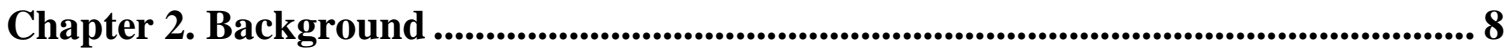

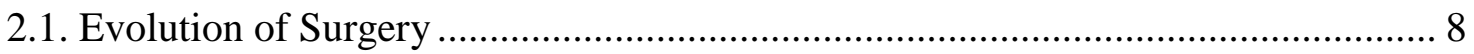

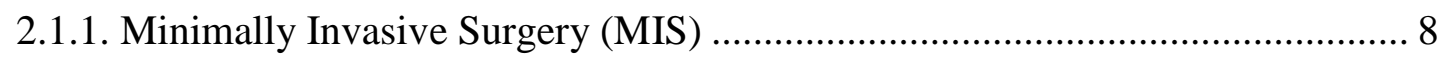

2.1.2. Laparoendoscopic Single-Site Surgery (LESS) ............................................. 9

2.1.3. Natural Orifice Translumenal Endoscopic Surgery (NOTES) ....................... 10

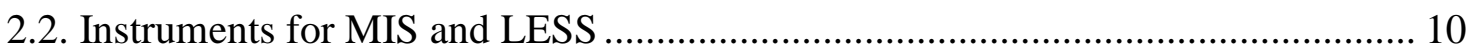

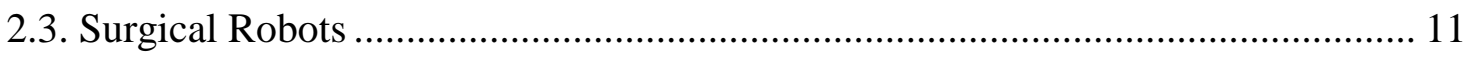

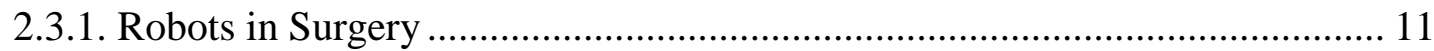

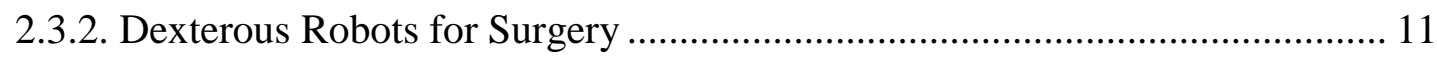

Chapter 3. NOTES Robot Motivation ................................................................................ 14

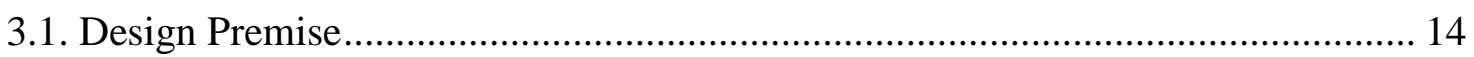

3.2. Design Requirements .............................................................................. 14

Chapter 4. Articulating Drive Mechanism ........................................................................... 19

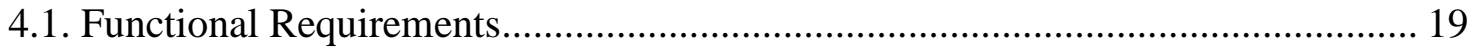

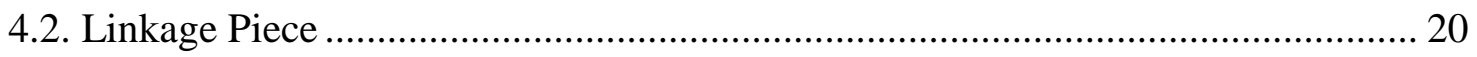

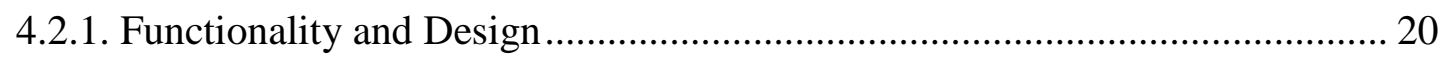

4.2.2. Linkage Piece First Generation ................................................................ 21

4.2.3. Linkage Piece Second Generation ................................................................. 24

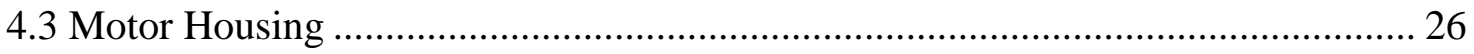

4.3.1. Functionality and Design ......................................................................... 26

4.3.2. Motor Housing First Generation................................................................. 27

4.3.3. Motor Housing Second Generation ................................................................ 29

4.3.4. Motor Housing Third Generation ............................................................... 30

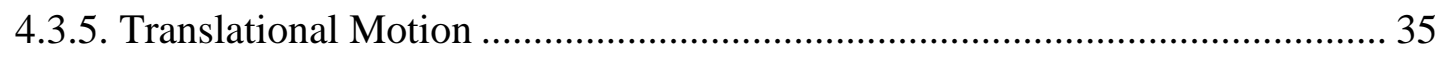

Chapter 5. Kinematic Analysis ....................................................................................... 39

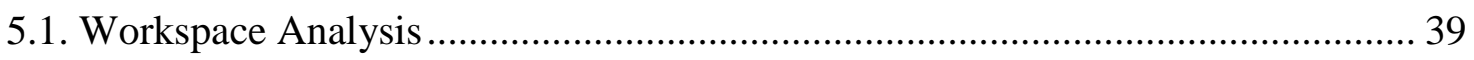

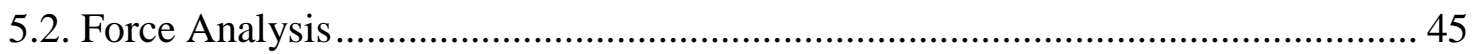

Chapter 6. Bench-Top Testing............................................................................................ 49

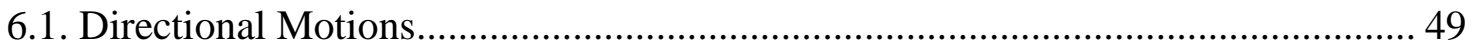

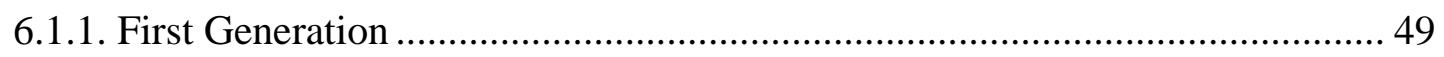

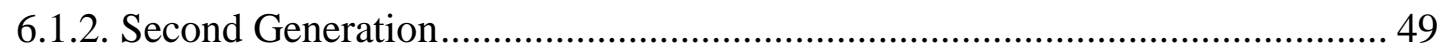

6.1.3. Third Generation........................................................................................ 50

Chapter 7. Curvature Function ....................................................................................... 67 
Chapter 8. Summary and Conclusion...................................................................................... 78

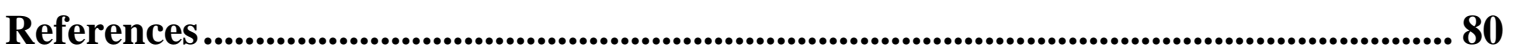

Appendix A. Drive Mechanism Design Supporting Materials ........................................ 84

Appendix B. Matlab ${ }^{\circledR}$ Workspace Codes ............................................................................... 93

Appendix C. Matlab ${ }^{\circledR}$ Curvature Code................................................................................... 98

Appendix D. Faulhaber Motor Data Sheet........................................................................... 100

Appendix E. Faulhaber Planetary Gearhead Data Sheet ................................................ 102 


\section{List of Figures}

Figure 1. Overview of natural orifice surgery with articulated drive mechanism .............. 7

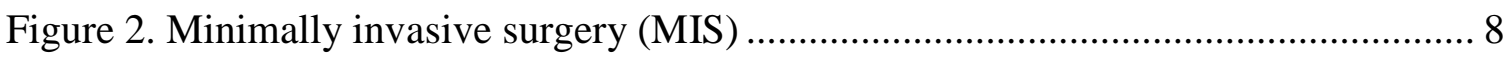

Figure 3. Laparoendoscopic single-site surgery (LESS) [3] ......................................... 9

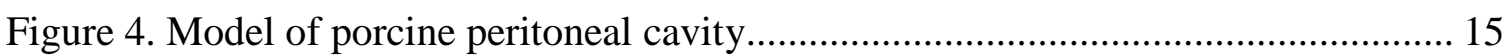

Figure 5. Model of human peritoneal cavity............................................................... 15

Figure 6. Bending angle of Olympus LF-DP laryngoscope ........................................ 17

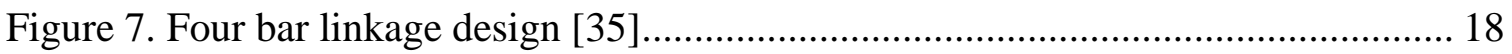

Figure 8. Lead scew multi-revolute joints design [35] ................................................ 18

Figure 9. Tendon actuated multi-spherical joints design [35] .................................... 18

Figure 10. Early conceptual designs for linkage piece …….......................................... 20

Figure 11. CAD model of first generation linkage piece ................................................ 22

Figure 12. Angular displacement between two linkage pieces ........................................ 22

Figure 13. Cross sections of linkage piece with wire cable locations ............................. 23

Figure 14. Wire actuation for drive mechanism articulation ......................................... 24

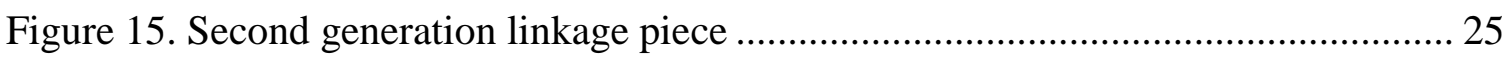

Figure 16. Comparison between first and second generations of linkage piece ............... 26

Figure 17. Change of directions in wire arrangement................................................... 28

Figure 18. Chain and sprocket design for second generation motor housing .................. 29

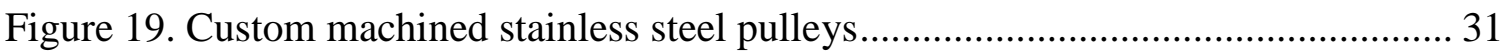

Figure 20. Chain and sprocket for wire manipulation ................................................ 32

Figure 21. Overall arrangement of motors in housing ................................................. 33

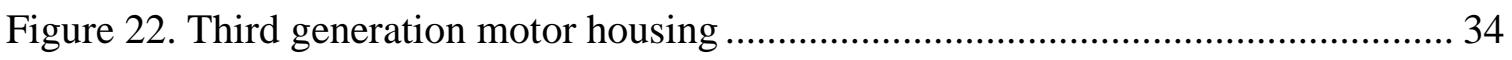

Figure 23. Prototype of third generation motor housing.................................................. 34

Figure 24. Track roller guidance system for translational motion.................................... 36

Figure 25. Threaded shaft and hex nut to drive translation ............................................. 36

Figure 26. Overall translational system with motor housing ......................................... 37

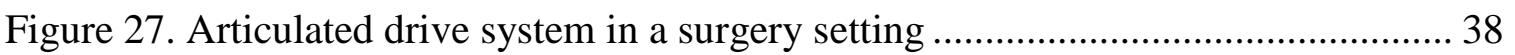

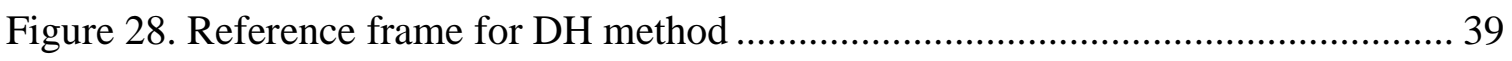

Figure 29. Graphical interpretation of drive mechanism workspace................................ 42

Figure 30. Workspace of drive mechanism without translational motion in peritoneal

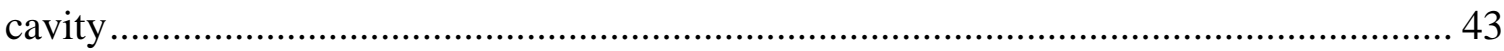

Figure 31. Workspace area with four linkage pieces ...................................................... 43

Figure 32. Workspace area with five linkage pieces .................................................... 44

Figure 33. Drive mechanism workspace with robotic manipulator workspace................. 44

Figure 34. Cantilever model for tension analysis ........................................................... 45

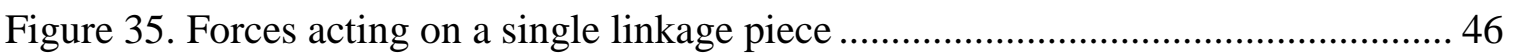

Figure 36. Pressure acting on surface of spherical top of linkage piece........................... 47 
Figure 37. (a) Drive mechanism at horizontal starting position (b) Drive mechanism articulated to the left (c) Drive mechanism articulated to the right 52

Figure 38. Drive mechanism articulation sequence from extreme left to extreme right position..... 54

Figure 39. (a) Starting position for drive mechanism (b) Drive mechanism lifted up...... 55

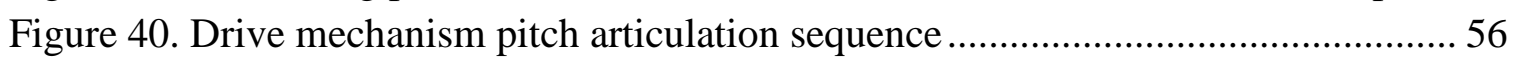

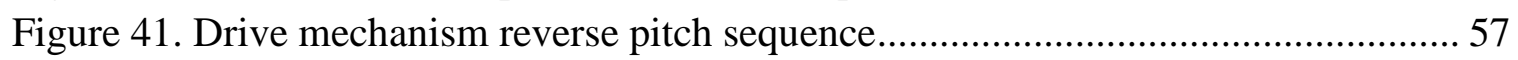

Figure 42. Comparison between actual and theoretical workspace of drive mechanism . 58

Figure 43. Comparison between actual 3D workspace with theoretical workspace........ 59

Figure 44. Articulation sequence with lubricated linkage pieces .................................. 61

Figure 45. (a) Curvature for 18 pieces (b) Curvature for 14 pieces (c) Curvature for 10

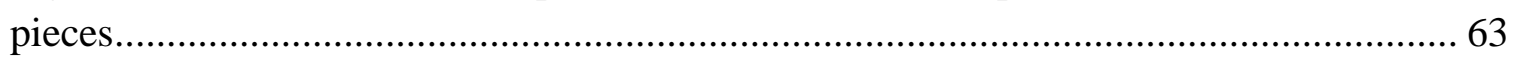

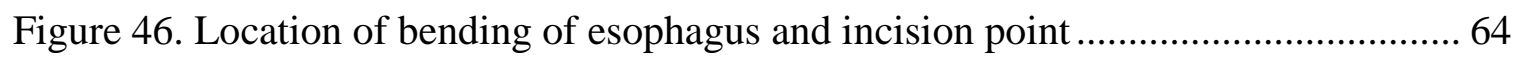

Figure 47. Cartesian coordinates of six positions of drive mechanism .......................... 68

Figure 48. Discretized curve for finite-difference method with constant interval h........ 69

Figure 49. Plots of xy coordinates, radius of curvature, and curvature for drive

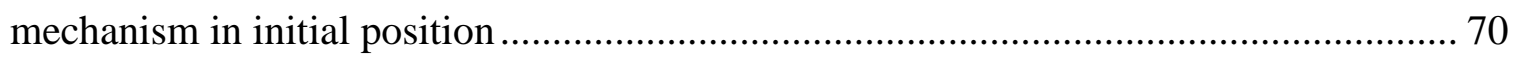

Figure 50. Plots of xy coordinates, radius of curvature, and curvature for drive

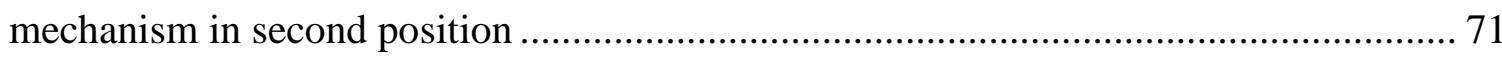

Figure 51. Plots of xy coordinates, radius of curvature, and curvature of drive mechanism

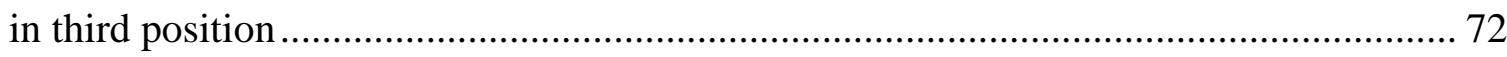

Figure 52. Plots of xy coordinates, radius of curvature, and curvature of drive mechanism

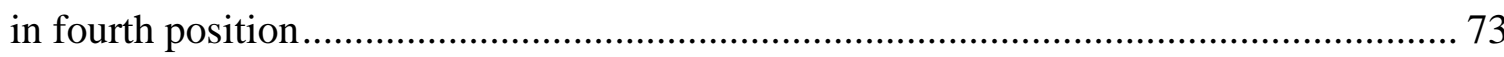

Figure 53. Plots of xy coordinates, radius of curvature, and curvature of drive mechanism

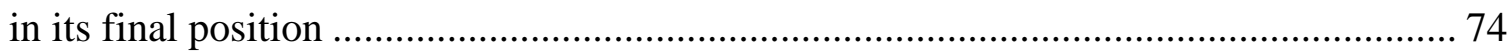

Figure 54. Curve of drive mechanism separated into two portions (yellow and red) for

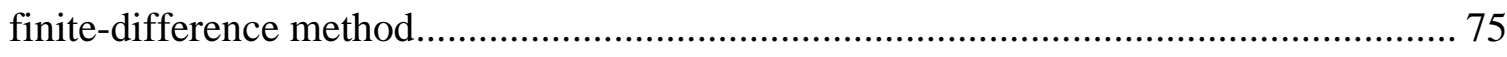

Figure 55. Plots of xy coordinates, radius of curvature, and curvature for the first portion of upward articulation 76

Figure 56. Plots of xy coordinates, radius of curvature, and curvature for the second portion of upward articulation 


\section{List of Tables}

Table 1. Tensile properties of the human esophagus ...................................................... 16

Figure 28. Reference frame for DH methodTable 2. Denavit-Hartenberg parameters .... 39

Table 3. Link parameter value and joint variables working range ................................... 40

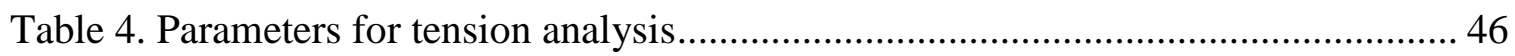

Table 5. Additional parameters for tension analysis....................................................... 47

Table 6. Number of linkage pieces and corresponding length of drive mechanism......... 63

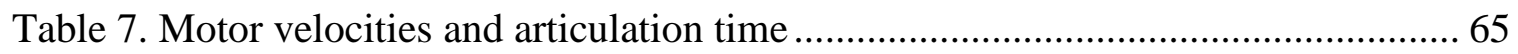




\section{Chapter 1. Introduction}

Advances in surgical technology in the past few decades have seen surgeries become less invasive. Many surgical procedures that were traditionally performed through "open" approaches have been replaced by minimally invasive surgery (MIS). This method has become the new standard in healthcare due to its many benefits, including reduction in patient recovery time and improved aesthetics. However, minimally invasive surgery is limited by the reduced maneuverability of surgical instruments due to the small surgical incisions through which they are inserted. It is also difficult to maintain consistent visual feedback in MIS procedures. Many specialized surgical tools have been manufactured to overcome this difficulty, with positive but not perfect results.

Natural Orifice Translumenal Endoscopic Surgery (NOTES) has taken minimally invasive surgery a step further by eliminating external incisions. By passing surgical instruments into the abdominal cavity through natural orifices such as the esophagus, the problem of limited tool manipulation is addressed. NOTES also offer the same benefits of minimally invasive procedures. This advancement in surgical technology has brought forth complications like size constraints. Currently most instruments for NOTES utilize flexible endoscopic tools that are wire-actuated from outside the patient's body. Although this method addresses the issue of size constraints by avoiding the introduction of actuators inside the body, it has compromised on tool manipulation and force transmission. 
This thesis presents a novel robotic platform for NOTES where issues mentioned above are addressed. The steerable and articulating drive mechanism is actively controlled to navigate a multifunctional robotic manipulator through the curves of a natural orifice and provide a stable platform for surgery once it reaches the surgical site. This design moves away from the cable-force transmission paradigm by placing actuators directly in the robotic manipulator.

The articulated drive mechanism is controlled remotely using a joystick. Although it still utilizes wire cables for steering purposes, by removing the need to pass surgical instruments through the drive mechanism, this allows it to have greater freedom of movement to better position the robotic manipulator. When the articulated drive mechanism and the robotic manipulator are combined, the overall system provides an improved tool manipulation and force transmission for NOTES, as shown in Figure 1.

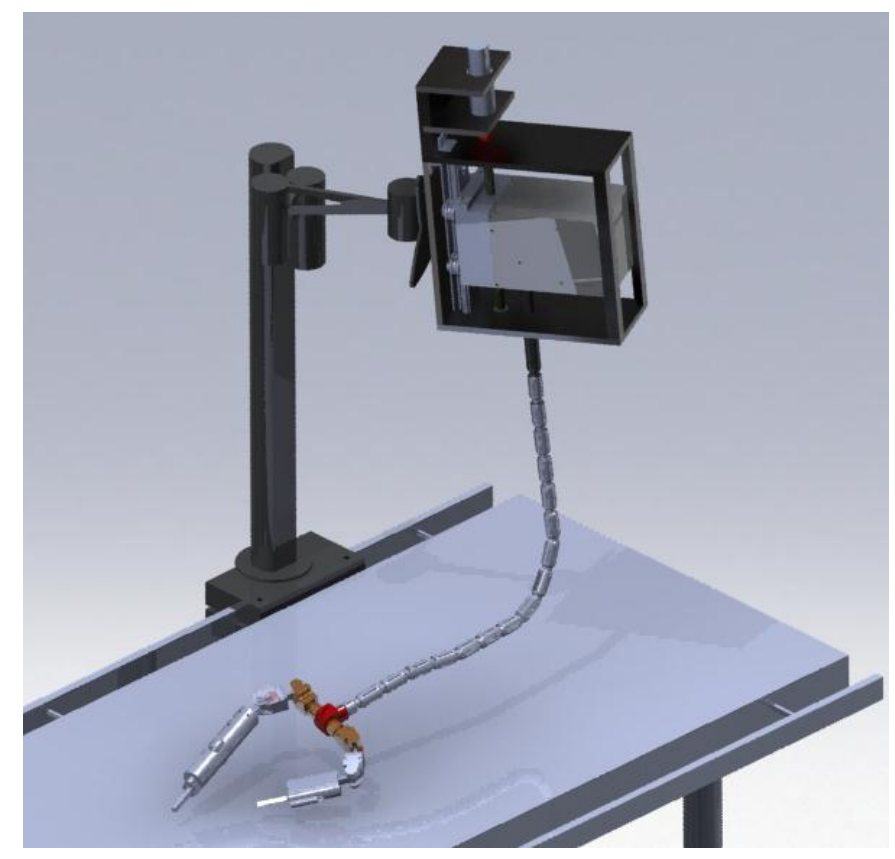

Figure 1. Overview of natural orifice surgery with articulated drive mechanism 


\section{Chapter 2. Background}

\subsection{Evolution of Surgery}

\subsubsection{Minimally Invasive Surgery (MIS)}

Prior to the 1990s, surgical procedures such as colonoscopic polypectomy and cholecystectomy were commonly performed with traditional open approaches. However, advancements in surgical technology in the 1990s brought forth a shift in surgical procedures to minimally invasive surgery (MIS). Since open surgeries have been known to cause damage to the peritoneum and also cause more adhesions which can lead to problems like infertility, chronic abdominal pain, increased risk of repeat surgery, and increased morbidity [1], MIS swiftly became the standard of health care. It has been found that MIS improves patient recovery time and lessens patient trauma [2] due to the fact that it reduces the size of surgical openings from a traditional $20 \mathrm{~cm}$ cut to $1 \mathrm{~cm}$ incisions. Figure 2 shows a typical MIS procedure and tool arrangements.

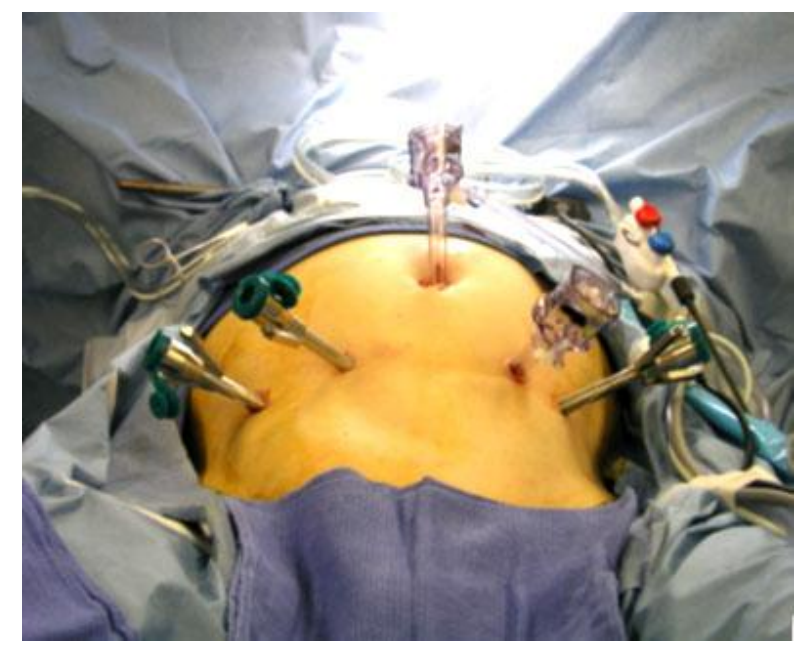

Figure 2. Minimally invasive surgery (MIS)

(Courtesy of http://www.danshope.com/news/showarticle.php?article_id=102) 


\subsubsection{Laparoendoscopic Single-Site Surgery (LESS)}

MIS is usually done by making four or more small incisions in the patient's abdominal wall to allow for the advancement of laparoscopic instruments. Laparoendoscopic single-site surgery (LESS) branches out from MIS by introducing only a single access port. Commercially available laparoscopic tools are used and are inserted through the single port for surgery. Although it is believed to further improve surgery recovery, manipulation of surgical tools is generally difficult in LESS. Dissection through a single port is more difficult than conventional multiport laparoscopy because the instrument shafts are crossed at the point of entry, making the external right-hand instrument the left instrument internally, and vice versa [3]. Figure 3 shows a typical LESS procedure.

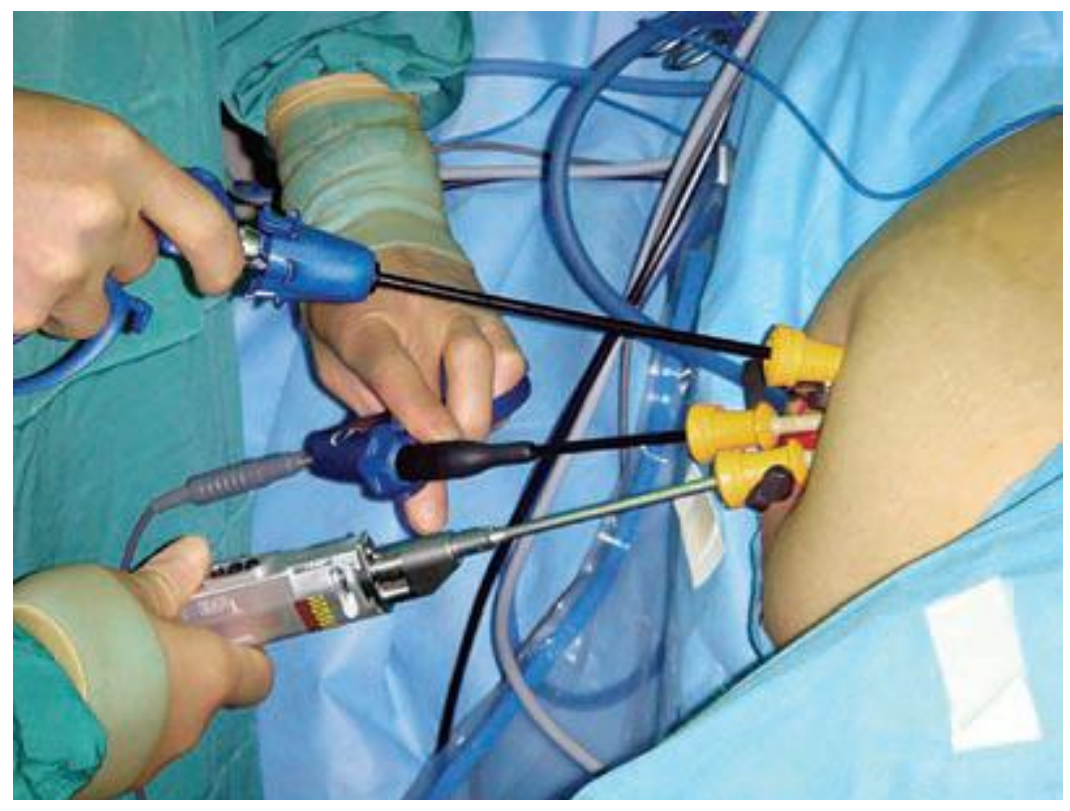

Figure 3. Laparoendoscopic single-site surgery (LESS) [3] 


\subsubsection{Natural Orifice Translumenal Endoscopic Surgery (NOTES)}

Natural orifice translumenal endoscopic surgery takes MIS even further by eliminating external incisions on the patient. This procedure is performed by guiding endoscopic surgical tools along natural orifices to the peritoneal cavity where surgeries are performed. Complications like infections and pain are eliminated and cosmetics are drastically improved with NOTES [4], along with the aforementioned benefits of MIS. Also, NOTES is advantageous compared to other methods because most organs have better access via the translumenal route [1]. The feasibility of NOTES has been proven in animal surgeries by Kalloo et al. [5], with successful survival studies that include transgastric liver biopsy, tubal ligation, lymphadenectomy, gastrojejunostomy, cholecystectomy and partial hysterectomy [6-9]. Rao et al. [10] succesfully performed the first human surgery via NOTES, and Swanstrom et al. [11] performed the first transgastric cholecystectomy in the United States in 2007.

\subsection{Instruments for MIS and LESS}

Due to the size constraints of the incisions for MIS and LESS procedures, the surgical instruments used are laparoscopic tools that are long and slender. Endoscopes are also inserted through one of the incisions to provide visual feedback. These tools are limited by the geometry constraints and it is generally difficult for the surgeons to estimate spatial positions. Small incisions also limit the degrees of freedom (DOF) of the surgical instruments and lead to small workspace area. To overcome such issues, instruments that are much more efficient and effective must be developed. 


\subsection{Surgical Robots}

\subsubsection{Robots in Surgery}

For the past decade, the usage of robots in surgery has become increasingly abundant. The first robot to be approved by the FDA was the Automated Endoscopic System for Optimal Positioning (AESOP). AESOP was used to control the camera in laparoscopic surgeries, but was largely an assistive device $[12,13,14]$. The more advanced da Vinci surgical system (Intuitive Surgery) and Zeus (Computer Motion) were produced and introduced in the late 1990s. Both systems have remote manipulators and are controlled from a separate surgical workstation [15]. However, the da Vinci system gives the impression that the patient is in front of the surgeon with the display of a stereoscopic image just above the surgeon's hands [15]. The Zeus system gives no illusion of telepresence, but rather a sense of a remote operation with enhanced capabilities [15]. These robotic surgical systems have proven to be highly successful and useful in MIS, with enhanced capabilities such as wristed motions, tremor reduction, and stereoscopic visual feedback $[13,16,17]$. However, they cannot be applied to NOTES because the surgical tool tips designed for these robots lack the necessary dexterity and flexibility needed for NOTES procedures. A different set of surgical robots with enhanced maneuverability are needed to perform NOTES, as discussed in the next section.

\subsubsection{Dexterous Robots for Surgery}

Faraz et al. [18] studied and formulated the workspace of three different types of dexterous designs because of the need for flexibility in orienting surgical tools during a laparoscopic surgery. Some notable research has been done on dexterous snake-like 
robots for surgery. Simaan et al. [19] designed a multi-backbone snake-like robotic slave for MIS telesurgery of the upper airway. In their design, the robot consists of a central tube which is the primary backbone, with three secondary backbones that are used for actuating the snake-like device. The Distal Dexterity Units (DDU) which make up this device allow at least $70^{\circ}$ bending.

Reynaerts et al. [20] incorporated shape memory alloys in their inchworm-type mobile robot. They claim that the superelastic property of SMA gives extremely high power-to-volume ratios and is a simple direct drive actuator design. In their design, dexterity is achieved by stacking individual "vertebrae" to form a "spinal column." Each vertebra has a stroke of $15^{\circ}$ and is $15 \mathrm{~mm}$ in diameter. Other designs that utilize SMA include Haga et al. [21] and Peirs et al. [22]. The SMA microcoil actuators by Haga et al. use NiTi and have a maximum bending angle of $110^{\circ}$ with a diameter of $6 \mathrm{~mm}$ and length of $40 \mathrm{~mm}$. Peirs et al. used a micromachined superelastic tube that guides the inserted surgical instruments to the surgical site. Their design allows $90^{\circ}$ bending in both directions and is $22.5 \mathrm{~mm}$ long. Most of the snake-like robots that are actuated by SMA are small and only articulate for a short length.

Several robotic systems geared towards added degrees of freedom have become available commercially over the years. The "R" scope (Olympus) was designed specifically for NOTES procedures and is a modified dual channel therapeutic scope. It has separate channels for suction, irrigation, and for endoscopic surgical instruments to pass through. The "R" scope also has two separate curvature sections that allow the tip to move independently while the primary flexure is locked. It has been reported that the " $R$ " scope is quite complex to control and cannot generate adequate force to operate 
effectively [23]. Swanstrom et al. collaborated with USGI Medical and developed two surgical systems for NOTES, namely the Transport and the Cobra [24]. Although neither system is robotically controlled, they are nevertheless crucial to the development of NOTES robots. The Transport features four large access channels and a four-way flexion at the tip, whereas the Cobra attempts to solve the triangulation problem described by Mummadi et al. [25] with three independent arms. The cable-driven controls for the surgical tool tips on both systems are imprecise and the fixed instruments make it time consuming to change surgical tool tips [26].

Another NOTES robot that utilizes the working channel paradigm is the ViaCath System by Abbott et al. [27]. It consists of a master console with haptic interfaces, slave drive mechanism, and flexible instruments running along an endoscope [27]. The CardioARM by Ota et al. is an MIS robot that consists of a serially connected, rigid cylindrical link system housing working ports where flexible instruments can be advanced [28]. Though fully robotic, the surgical instruments are still cable actuated, which does not address the issue raised by Lirici et al. [29].

Dexterous robots add more degrees of freedom for instrument manipulation, but issues like lack of force generation and a stable platform for surgery make it problematic for a procedure to be successfully performed. Lehman et al. attempts to address this by developing a dexterous miniature in vivo robot for NOTES that has two independent working arms [30]. Micromotors situated directly inside the robot arms provide more force to the tool tips, and the whole robot is attached to the upper side of the abdominal cavity by a magnet located externally against the skin. 


\section{Chapter 3. NOTES Robot Motivation}

\subsection{Design Premise}

NOTES robots are designed to overcome the aforementioned difficulties encountered by current MIS instruments while maintaining the functionality of standard laparoscopic tools. The basis of the robot design is to replace the cable driven method by placing actuators in robot arms and eliminating working channels in the articulated drive mechanism. The articulated drive mechanism is steerable using joysticks to guide the robotic manipulator and navigate through the curves of a natural orifice. The drive mechanism is also able to lock in position to provide the robotic manipulator with a stable platform during surgery. The robotic manipulator is able to move forward and back due to the translation capabilities of the articulating drive mechanism, which allows for a greater workspace within the peritoneal cavity. In essence, the articulated drive mechanism would allow easy positioning of the robotic manipulator and surgery would be performed without the need of an external abdominal incision.

\subsection{Design Requirements}

Information and definition of the surgical working area within the human abdominal cavity must be acquired before the designing of the articulated drive mechanism for the natural orifice translumenal endoscopic surgical robot. For clinical testing purposes, a porcine peritoneal cavity model was created with measurements taken

during a pig surgery. Figure 4 shows the model of the porcine peritoneal cavity with a width of 10.63 inches, length of 14.53 inches, and a height of 3.95 inches [31]. 


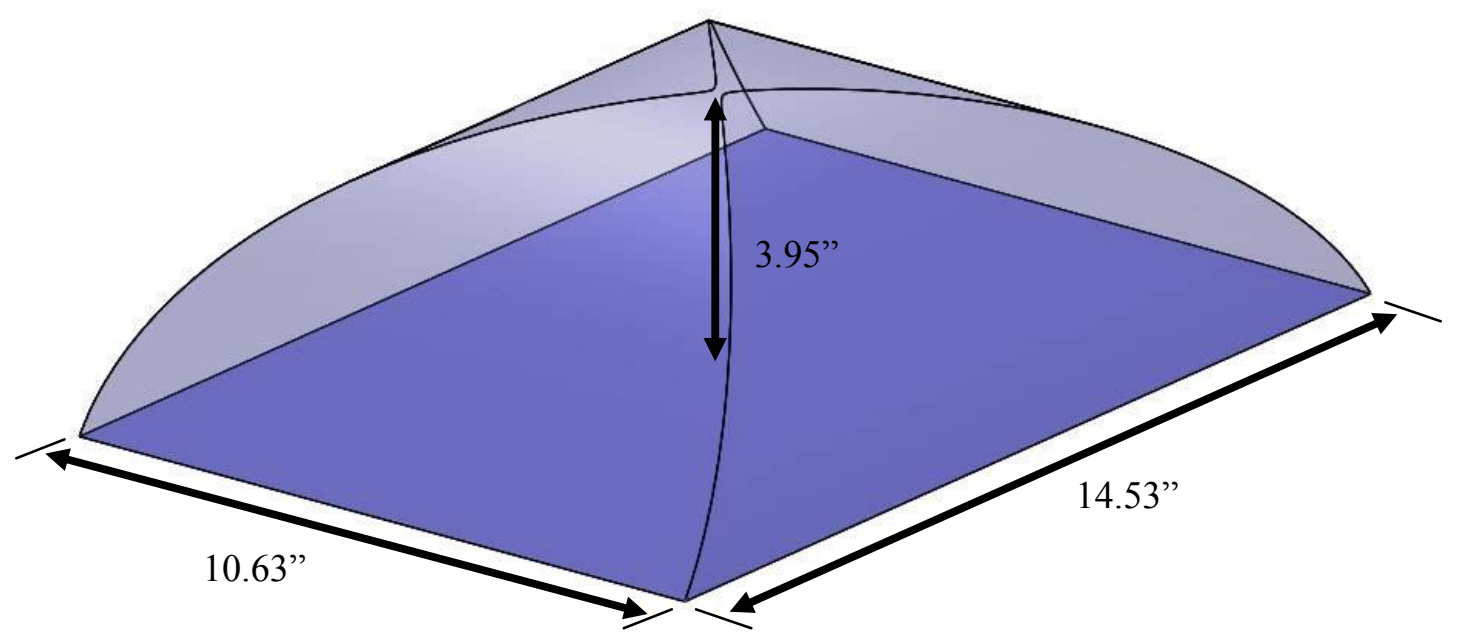

Figure 4. Model of porcine peritoneal cavity

A similar model was created for a human peritoneal cavity. Figure 5 shows the volume of a human peritoneal cavity, modeled with a width and height of 12.58 inches and a height of 4.04 inches.

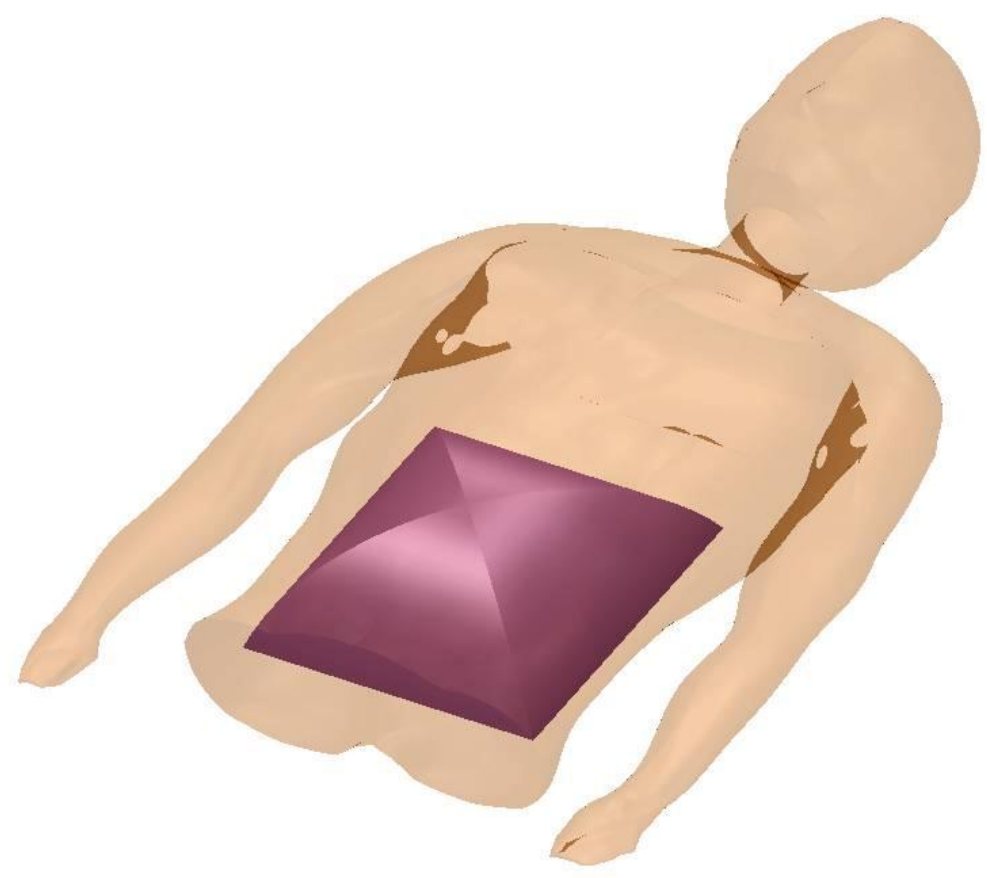

Figure 5. Model of human peritoneal cavity 
The mechanical properties of human natural orifices are also essential in the design process. In this case, the esophagus has been chosen as the preferred natural orifice because of ease of insertion. The tensile properties of the esophagus have been investigated and reported by Yamada et al. [32]. The average inner diameter of a human esophagus has been reported as 0.866 inches [33], and the percentage of elastic recovery just before rupture and immediately after removal of stress are $72 \%$ in the longitudinal and $48 \%$ in the transverse direction [32]. Table 1 summarizes the tensile properties of the human esophagus, as reported in [32].

Table 1. Tensile properties of the human esophagus

\begin{tabular}{|c|c|c|c|c|c|c|c|c|}
\hline \multirow{2}{*}{ Direction } & \multicolumn{7}{|c|}{ Age Group } & \multirow{2}{*}{$\begin{array}{l}\text { Adult } \\
\text { Average }\end{array}$} \\
\hline & $0-9 \mathrm{yr}$ & $10-19 \mathrm{yr}$ & $20-29 \mathrm{yr}$ & $30-39 \mathrm{yr}$ & $40-49 \mathrm{yr}$ & $50-59 \mathrm{yr}$ & $60-79 \mathrm{yr}$ & \\
\hline & \multicolumn{7}{|c|}{ Tensile Breaking Load per Unit Width $(\mathrm{g} / \mathrm{mm})$} & \\
\hline $\begin{array}{c}\text { Longitu- } \\
\text { dinal }\end{array}$ & $205 \pm 4.2$ & $\begin{array}{c}205 \pm \\
4.2\end{array}$ & $\begin{array}{c}191 \pm \\
4.8\end{array}$ & $\begin{array}{c}191 \pm \\
4.8\end{array}$ & $\begin{array}{c}184 \pm \\
3.7\end{array}$ & $\begin{array}{c}148 \pm \\
6.2\end{array}$ & $\begin{array}{c}129 \pm \\
4.0\end{array}$ & 162 \\
\hline \multirow[t]{2}{*}{ Transverse } & $83 \pm 3.9$ & $75 \pm 2.7$ & $70 \pm 2.7$ & $54 \pm 2.3$ & $51 \pm 1.8$ & $46 \pm 1.6$ & $41 \pm 2.0$ & 50 \\
\hline & \multicolumn{7}{|c|}{ Ultimate Tensile Strength $\left(\mathrm{g} / \mathrm{mm}^{2}\right)$} & \\
\hline $\begin{array}{l}\text { Longitu- } \\
\text { dinal }\end{array}$ & $79 \pm 1.3$ & $73 \pm 1.0$ & $70 \pm 1.0$ & $67 \pm 1.2$ & $65 \pm 1.0$ & $55 \pm 1.2$ & $51 \pm 1.1$ & 60 \\
\hline Transverse & $33 \pm 1.0$ & $26 \pm 0.6$ & $26 \pm 0.6$ & $18 \pm 0.6$ & $18 \pm 0.6$ & $16 \pm 0.6$ & $16 \pm 0.6$ & 18 \\
\hline
\end{tabular}

The bending angle of the articulated drive mechanism must be sufficient to successfully navigate down the esophagus. Based on laryngoscopes by Olympus [34] which have at least $240^{\circ}$ flexion, is it necessary for the NOTES robot to have similar capabilities. Figure 6 shows the bending angle achieved by an Olympus laryngoscope. 


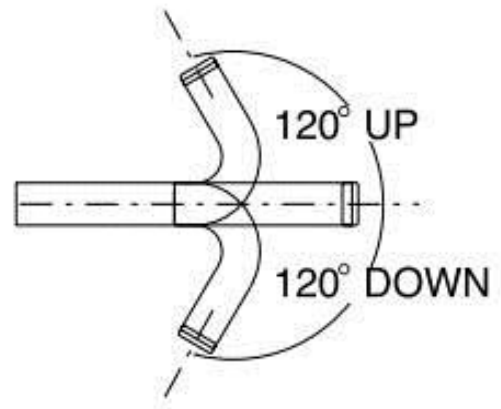

\section{Figure 6. Bending angle of Olympus LF-DP laryngoscope}

(Courtesy of http://www.olympusamerica.com/msg_section/download_brochures/ DPTPGP_SalesLiterature.pdf)

The dexterous workspace for three different types of designs, namely a four-bar linkage design, a lead screw multi-revolute joint design, and a tendon actuated multispherical joint design, was studied by Faraz et al. [35] to identify the most dexterous design of all. It was found that the four-bar linkage design allows a simple joint mechanism with 1 DOF but has difficulty achieving a wide range of rotation. The disadvantage of the lead screw design is the relatively high number of moving parts. The multi-spherical joint design allows 2 DOF but it is difficult to model friction and also hard to control the tension for moving and locking. However, based on the dexterity measurements as described in [35], the multi-spherical design is the most dexterous compared to the other two. Figures 7-9 depict the three types of designs. 


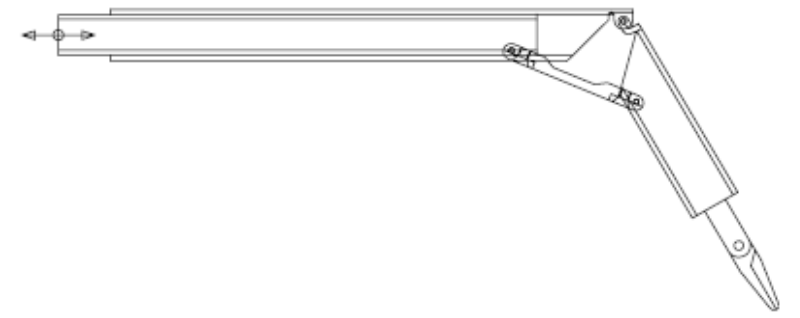

Figure 7. Four bar linkage design [35]

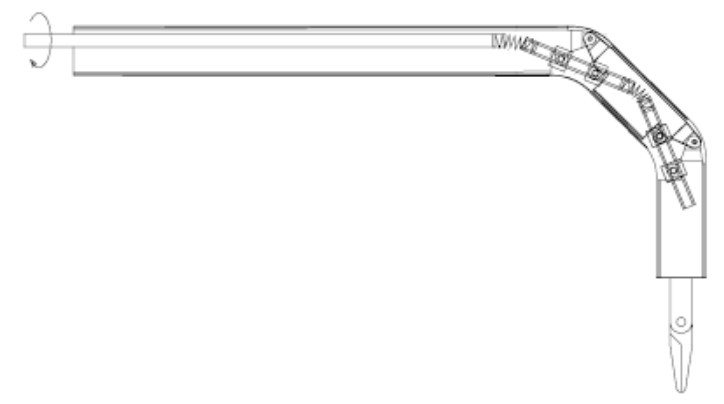

Figure 8. Lead scew multi-revolute joints design [35]

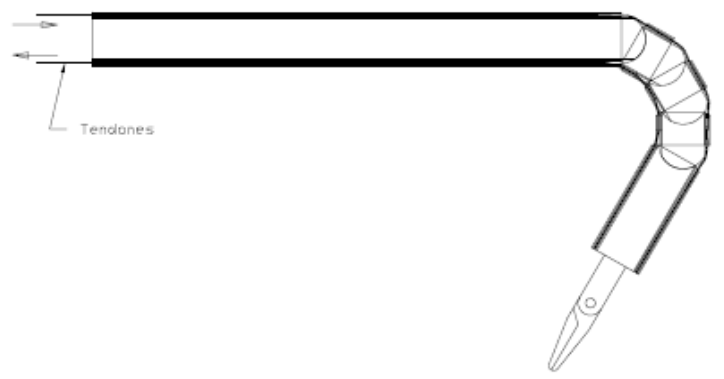

Figure 9. Tendon actuated multi-spherical joints design [35] 


\section{Chapter 4. Articulating Drive Mechanism}

\subsection{Functional Requirements}

The functional requirements for the articulated drive mechanism for the NOTES robot are listed below.

\section{Be articulated and steerable}

Since natural orifices are not straight and have some degree of curvature in them, it is essential that the drive mechanism be flexible enough to be passed through. However, having the drive mechanism behave as a passive tube is not ideal because the robotic manipulator would be attached at the distal end and would be difficult to insert just by manual pushing alone. Therefore it is important for the drive mechanism to be motor controlled and steerable by a surgeon.

\section{2. $\quad$ Be shape lockable}

Besides guiding the robotic manipulator to the surgical site, the articulated drive mechanism also functions as a platform for the robotic manipulator to perform surgical procedures. It is required to be flexible for navigation, but stiff and stable during surgery. The articulated drive mechanism should also have the capability to partially support an organ if the need arises.

\section{Be able to access the whole peritoneal cavity}

The articulated drive mechanism must be able to transport the robotic manipulator to remote sites in the peritoneal cavity. This must be achieved without having to move the whole motor housing from the outside, which would be difficult and time consuming. A simple translational motion in the articulated drive mechanism would allow the robotic 
manipulator to extend forward to reach a surgical site that would otherwise be inaccessible.

\subsection{Linkage Piece}

\subsubsection{Functionality and Design}

The articulated drive mechanism is composed of linkage pieces that are connected to each other by wire cables that run along the length of the entire mechanism. With the wire cables attached at the distal end of the drive mechanism, articulation can be achieved when tension is provided to the wires at the proximal end. The profile of the linkage pieces must be designed so that each piece can rotate relative to one another by a desired angular displacement. A ball and socket connection is the most obvious way to achieve said function. Each linkage piece should also have 5 through holes to allow wire cables to pass through. Initial conceptual designs for the linkage piece that were eventually found to be unsuitable are shown in Figures 10(a) and (b).

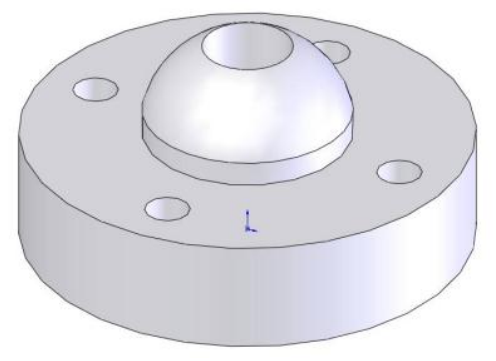

(a)

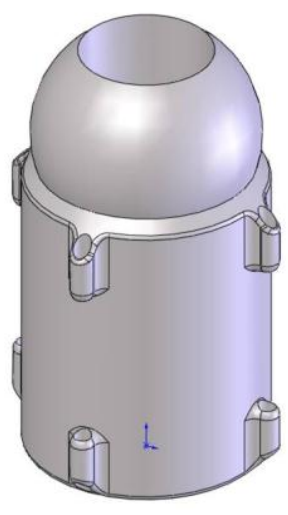

(b)

Figure 10. Early conceptual designs for linkage piece 
The preliminary designs were found to be flawed. The design in Figure 10(a) allows limited angular displacement, and would require a high number of linkage pieces to achieve a desired angle. The protruding wire cable rings in Figure 10(b) are undesirable because it is essential that the outer surface of the linkage piece is smooth to avoid friction issues (tissue damage) during insertion.

\subsubsection{Linkage Piece First Generation}

The conceptual designs eventually led to the first generation of the linkage piece. The design is similar to the design in Figure 10(b) in terms of shape. Instead of a flat cylindrical plate with a dome-shaped top, the linkage piece is a cylinder with a through hole along the central axis of symmetry. This center through hole would allow the central cable to pass through. The top of the linkage piece is shaped like a partial sphere to facilitate 3 degrees of freedom in rotation, although only 2 are used because the directional cables constrain the third "self-rotation" DOF, as shown in Figure 11. The bottom of the linkage piece is concave to connect with the spherical top of an adjacent piece. This type of connection allows an angular displacement of $30^{\circ}$ between two linkage pieces. Therefore, only 3 linkage pieces are required to achieve a $90^{\circ}$ displacement, which is sufficient for a majority of surgical procedures since it is unlikely to take an approach that would make it necessary to operate at a location behind the robotic manipulator. Figure 12 shows the angles between adjacent pieces. 


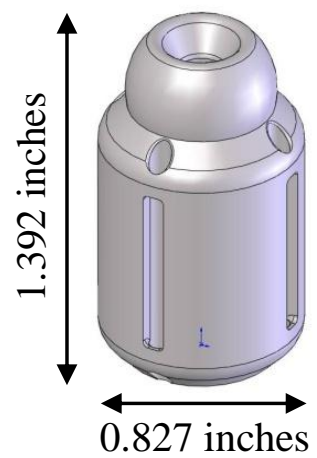

Figure 11. CAD model of first generation linkage piece

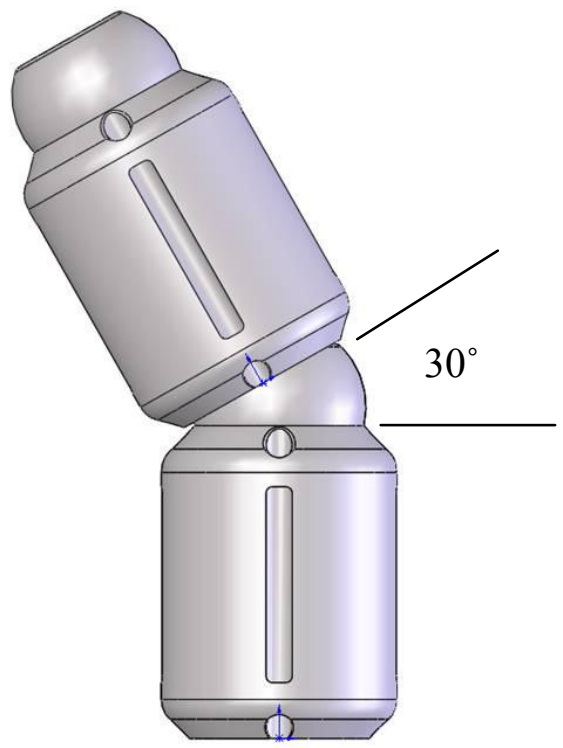

Figure 12. Angular displacement between two linkage pieces

The directional wire cables are allowed to pass through the linkage piece via four through holes that are longitudinally drilled just slightly below the surface. Four slots are cut on the wall of the linkage piece to allow for wire slack and to reduce friction on the wires when they are actuated. This design would allow the wire cables to run along the surface of the linkage piece for steering control without being subjected to excessive surface friction. The cross sections of the linkage piece in Figure 13(a) and (b) show the location and orientation of the wire cables. 


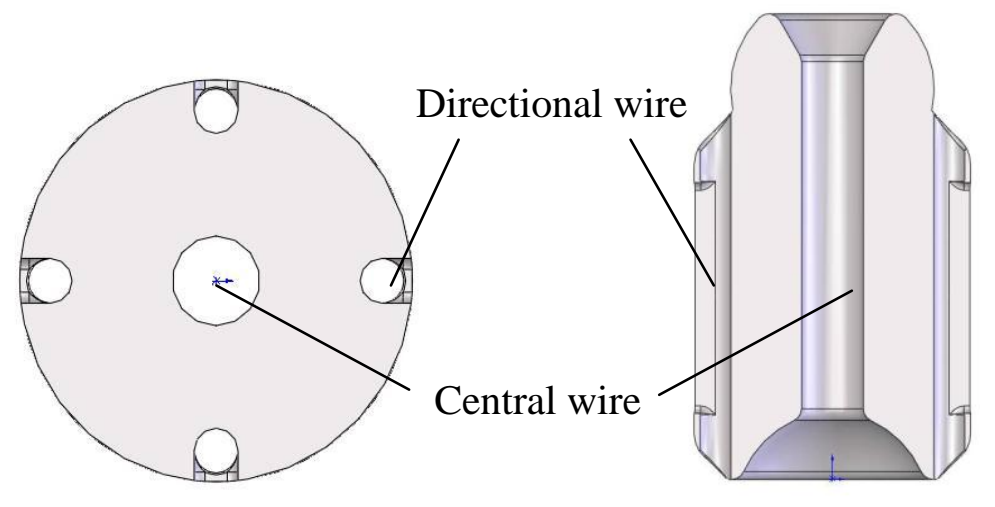

(a)

(b)

Figure 13. Cross sections of linkage piece with wire cable locations

According to [33], the average inner diameter of a human esophagus is 0.866 inches. In accordance with that, the outer diameter of the linkage piece must be smaller than that value for the articulated drive mechanism to safely pass through the esophagus. The first generation design is 0.827 inches in diameter and 1.392 inches in height.

The wires used for directional control are type 302/304 stainless steel nylon coated wire ropes from McMaster-Carr. The construction of the wire rope is $3 \times 7$ hollow core (3 strands of 7 wires wrapped together without a core) for flexibility and the outside diameter when coated is 0.0625 inches. The same wire was used for the central locking wire because thicker wire ropes lack the flexibility required for articulation. The nylon coating on the wire ropes reduces friction on the surface of the linkage pieces when the wires are actuated. The directional wires work antagonistically to provide articulation: two wires provide motion in the pitch axis, and two wires provide motion in the yaw axis. When tension is applied to a wire, the opposing wire is slacked to allow movement in the direction tension is applied. Figure 14 depicts the process. 


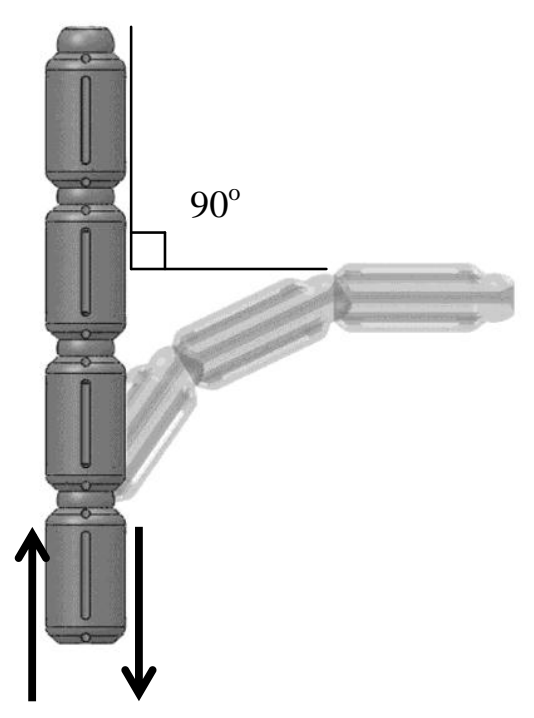

Figure 14. Wire actuation for drive mechanism articulation

\subsubsection{Linkage Piece Second Generation}

The first iteration of the linkage piece design received positive surgeon feedback, but several changes were recommended. The most obvious change that needed to be addressed was the overall dimensions (Figure 15). Although the outer diameter of the first generation design was smaller than that of an average human esophagus, it was still considered to be large enough to cause maneuverability issues and risk to patient safety. The wire cable used also has a smaller radius of curvature and is too thick, causing difficulties in articulation.

The principal design of the linkage piece is retained for the second iteration because preliminary bench-top results show successful functionality. The outer diameter is reduced from 0.827 inches to 0.551 inches for the second generation, and the height is also reduced to 1.279 inches. However, the reduction in overall size also means that the

through holes for the wires no longer fit, so a thinner wire cable is utilized in order to 
keep the functionality of the drive mechanism. The wire cables are Type 302/304 stainless steel nylon coated wire ropes with a 0.037 inch outer diameter when coated. The central locking wire cable remains the original 0.0625 inch size because the friction locking asserts significant force in this wire cable.

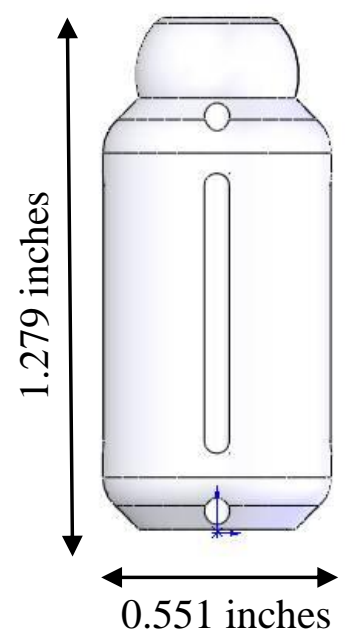

Figure 15. Second generation linkage piece

The much reduced diameter of the linkage piece will allow the drive mechanism to better access a natural orifice with more space for maneuverability. The risk of abrasion on the esophageal wall is also reduced with a slimmer drive mechanism. Since the drive mechanism will be passed down to the peritoneal cavity through an overtube, a smaller diameter means that the overtube can be of a smaller size and be easy to insert into the esophagus.

Both generations of the prototype were fabricated from aluminum by Computer Numerical Control (CNC) process. Although the ideal material for medical devices is stainless steel for biocompatibility and ease of sterilization, for prototyping and testing purposes aluminum was used instead. This is due to the fact that aluminum is an easier 
material to work with and costs less. Figure 16 shows the fabricated prototype linkage pieces and a comparison between the two generations.

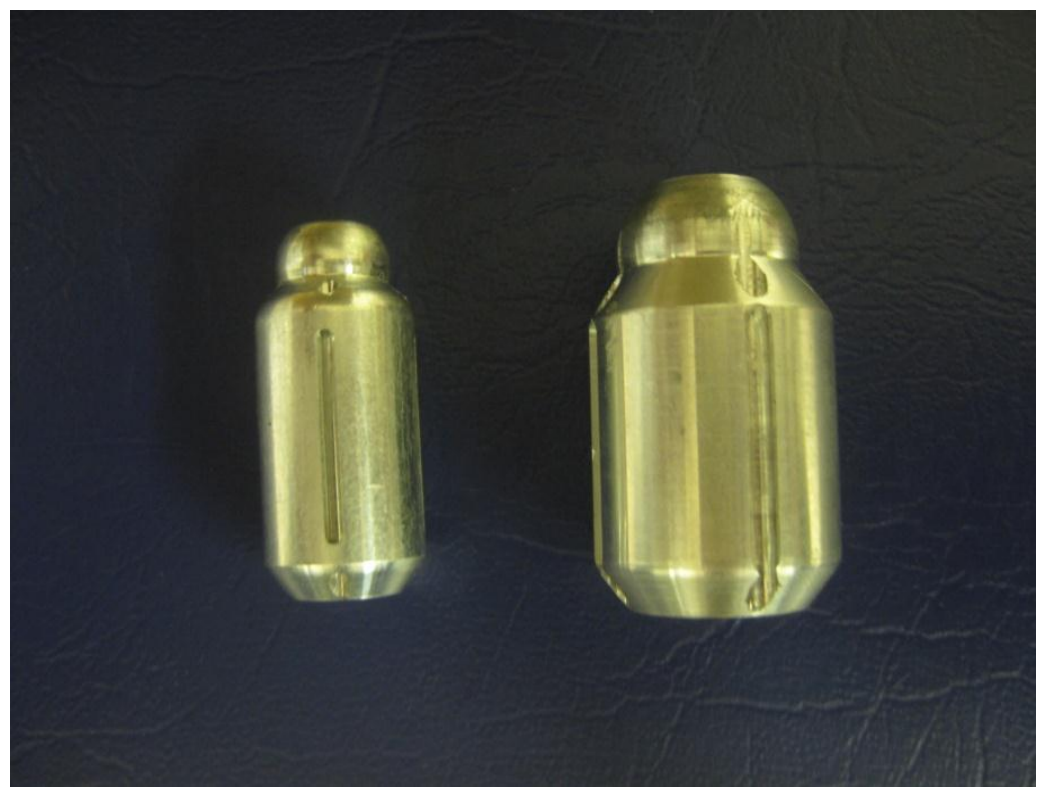

Figure 16. Comparison between first and second generations of linkage piece

\subsection{Motor Housing}

\subsubsection{Functionality and Design}

The wire cables are secured at the distal end of the drive mechanism and run along the length of the drive mechanism and out from the patient's body. The proximal ends of the wire cables are attached to motor shafts, with each motor actuating an opposing pair. The motors are aligned and placed in a housing that is located outside the patient's body; therefore there is no strict restriction in size. 


\subsubsection{Motor Housing First Generation}

The design for the first generation motor housing is a simple box with motor mounts and linear solenoids for achieving cable pretension. The box is 8 inches wide, 6 inches in length, and 6.25 inches tall. The main priority of this iteration is just to prove the functionality of the drive mechanism without concern for aesthetics. The components in this motor housing include three Faulhaber 2232A012SRIE2-512 DC motors with integrated encoders, four linear solenoids, and idler pulleys. The linear solenoids function to provide some tension to the wire cables to eliminate slack and to ensure proper wire movements. The idler pulleys are strategically placed to change the directions of the wires.

Due to the arrangement of the wire cables in the drive mechanism, the directions of the wires need to be changed for them to reach the motor shafts without getting tangled up. The downside of having to change the directions of the wire cables is that the tension may not fully transfer across the length of the wires due to friction between the idler pulleys and wires. A change of direction also means that there is extra length of wire between the exit point in the linkage piece and the motor shaft, which is a waste of material and space. Figure 17 shows the wire arrangements of the first generation motor housing. 

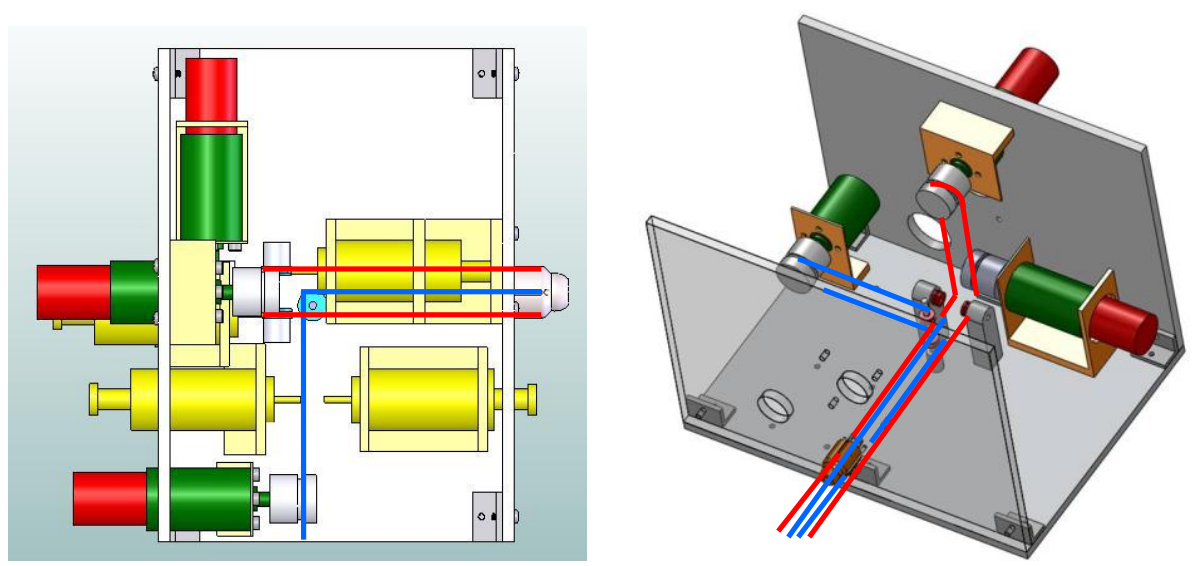

Figure 17. Change of directions in wire arrangement

Each direction is controlled by a wire that is looped around a pulley on the motor shaft, so when tension is applied on one end, the opposing wire will slacken in the opposite direction. The pulley on the motor shaft for the first generation is made out of nylon with a groove cut around it for wire placement. This arrangement failed during preliminary bench-top testing because the friction between the nylon pulley and wire was too low and the wire slipped around the pulley. The linear solenoids also did not work well because the wires slipped off from the custom-made pulleys that were attached to the solenoid tips. However, the idler pulleys worked well at changing direction and did not affect the performance of the wire cables when they were manually actuated.

Since the linear solenoids are no longer employed in the system, the vacated space in the motor housing can be taken away to make the design more compact. However, the priority is to get the steering capabilities to function well. Only when functionality can be proven will aesthetics come into play for the motor housing design. 


\subsubsection{Motor Housing Second Generation}

The exterior of the motor housing is retained for the second generation. The mechanism to actuate the steering is changed, however, by replacing the nylon pulleys with a chain and sprocket design. In the first generation, the nylon pulleys did not have enough friction on the surface to grip the wires, which is a major flaw in the design. Miniature plastic sprockets replace the nylon pulleys on the motor shafts in the second iteration. Also, the proximal ends of a pair of wire cables are attached to a chain by mechanical clamping. Figure 18 shows the chain and sprocket arrangements in the motor housing.

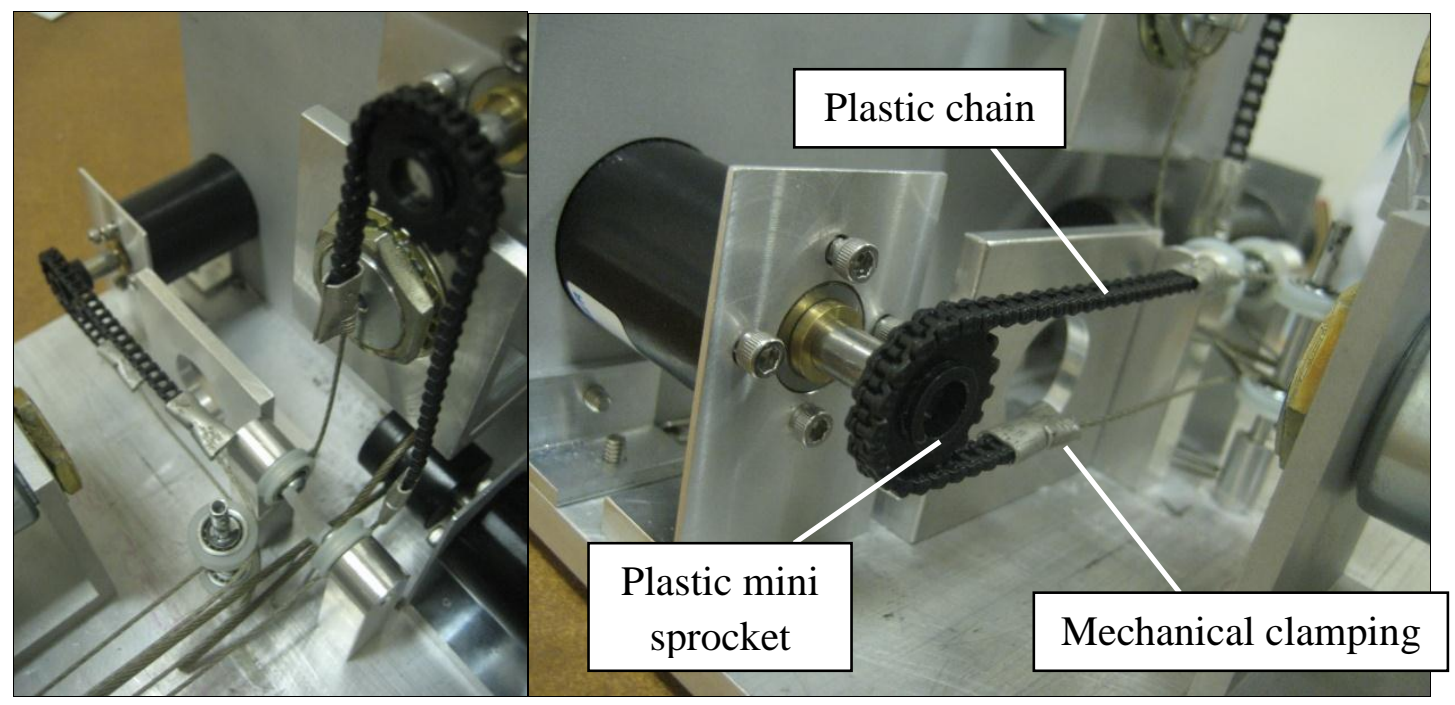

Figure 18. Chain and sprocket design for second generation motor housing

The chain and sprockets worked admirably in applying tension to the directional wires. The angular displacement when the directional wire was pulled was the best from all preliminary bench-top tests performed. However, the chain wasn't rigid enough and buckled in the opposite direction instead of releasing the hold. This caused the wires to slack too much and in turn affected the articulation of the drive mechanism. Although 
tension can be applied very well, the same cannot be said for the force "release" in the opposite direction.

The same chain and sprocket approach is utilized for the locking function. One difference is instead of having the chain wrap around the sprocket, the chain is only partially wrapped and the free end is glued to the sprocket. The same outcome occurred during bench-top testing, where the sprocket successfully provided tension to the central wire cable but failed to release properly when the motor was rotated in the opposite direction. The connection between the wire cable and chain would crumple and not release the hold on the drive mechanism.

The first and second generation motor housings have significant flaws in their design; therefore a third and improved version is designed to rectify them. Although the first generation failed to perform well in bench-top tests, it provided a platform for subsequent generations of the motor housing. The second iteration also did not live up to its standards during testing, but the chain and sprocket design provided somewhat positive results in applying tension. Bench-top testing results for the second generation were generally positive if not for the inefficient release in force in the wires.

\subsubsection{Motor Housing Third Generation}

A completely redesigned motor housing is fabricated for the third iteration. Whereas the first and second generations share the same housing, the third is significantly different than the previous generations. The most obvious change to the design is the dimensions, which have been drastically reduced to 4.75 inches tall, 3.1534 inches wide, and 3.2533 inches in length. The overall size is less than half the original dimensions and 
is much more compact and space efficient. Although there is no restriction on the motor housing size since it is located outside the patient, it is important to make the design compact to lessen the amount of free wire that would cause a loss of force transmission due to wire slack; this small size also can improve patient access by operating room personnel.

In terms of the steering mechanism inside the motor housing, some inspiration was drawn from the second generation in retaining some aspects of the chain and sprocket design, although not directly in applying tension. Instead, the concept is utilized in a passive pulley that is connected via the chain to a motor for the left and right directional control. In the third generation, the pulleys are custom machined from stainless steel. Each stainless steel has a thin spiraled groove cut in it to facilitate wire wrapping. This method of securing the wires around the pulley is inspired by the design found in a da Vinci surgical robot tool [36]. Hubless gears are attached to two of the pulleys for the aforementioned left/right control. Figure 19 shows the custom made pulleys.

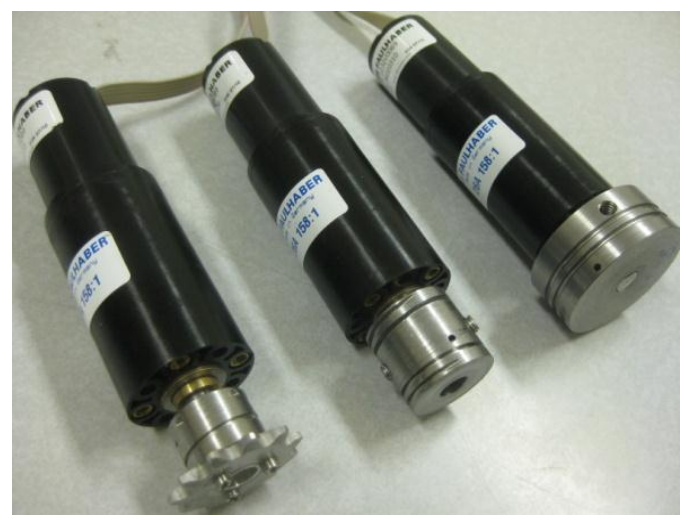

Figure 19. Custom machined stainless steel pulleys 
An idler pulley is also incorporated here for a slight change of wire direction, similar to the previous generations. The space management techniques used in this iteration include a change in motor orientation from horizontal to vertical, pulleys of different sizes, idler pulley for change in wire direction, and the chain and sprocket concept. The wires for the left and right directional control are connected to different pulleys here whereas previously they wrap around the same pulley. One of the wires is attached to the pulley that is fixed on the motor shaft, and the opposing wire is wrapped around a passive pulley that rotates about a rod that is fixed to the housing base using bearings. This is better illustrated in Figure 20.

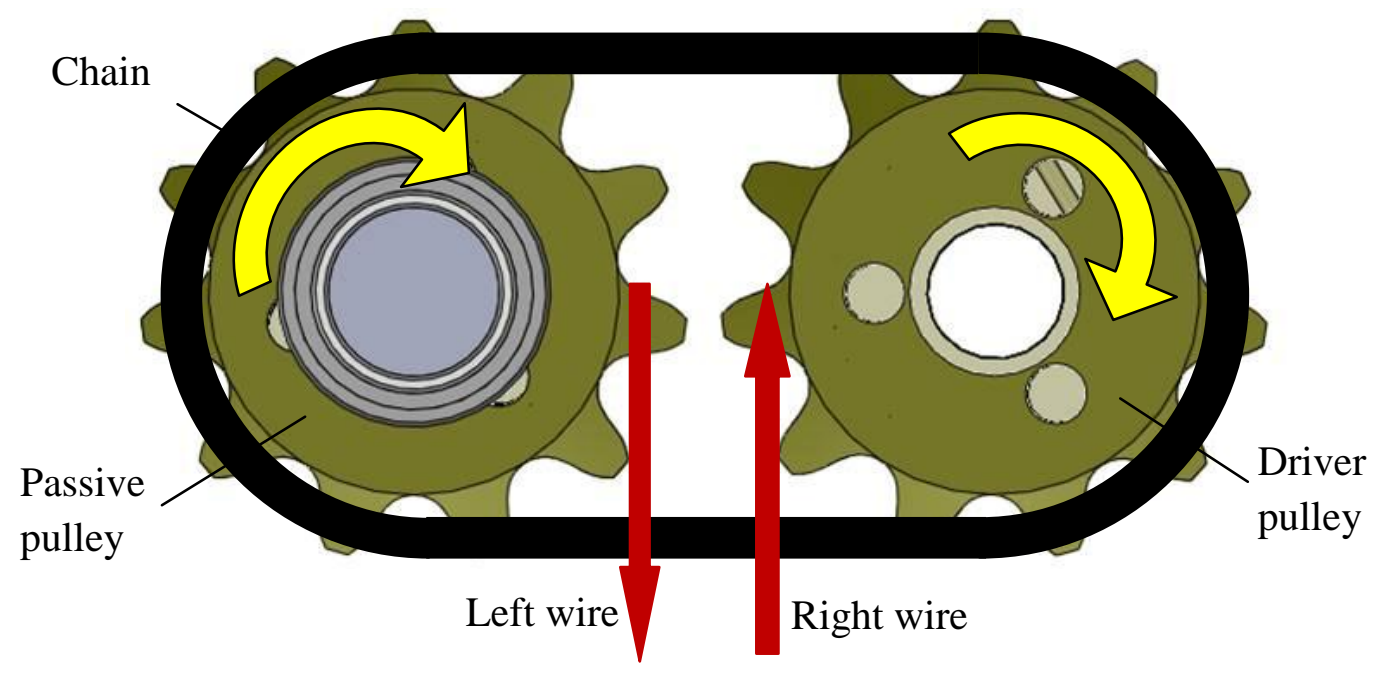

Figure 20. Chain and sprocket for wire manipulation

This arrangement allows one wire to be pulled when the motor rotates the driver pulley and through the chain rotates the passive pulley as well, releasing the opposing wire in the process. Another reason this arrangement is designed is to allow the up/down directional wires and the central locking wire cable to pass through to their respective motor shafts with minimum change in wire direction, and hence less friction loss. 
The overall arrangement of the motors is illustrated in Figure 21 with their respective pulleys. The arrangement in this iteration has made the motor housing much more compact and portable.

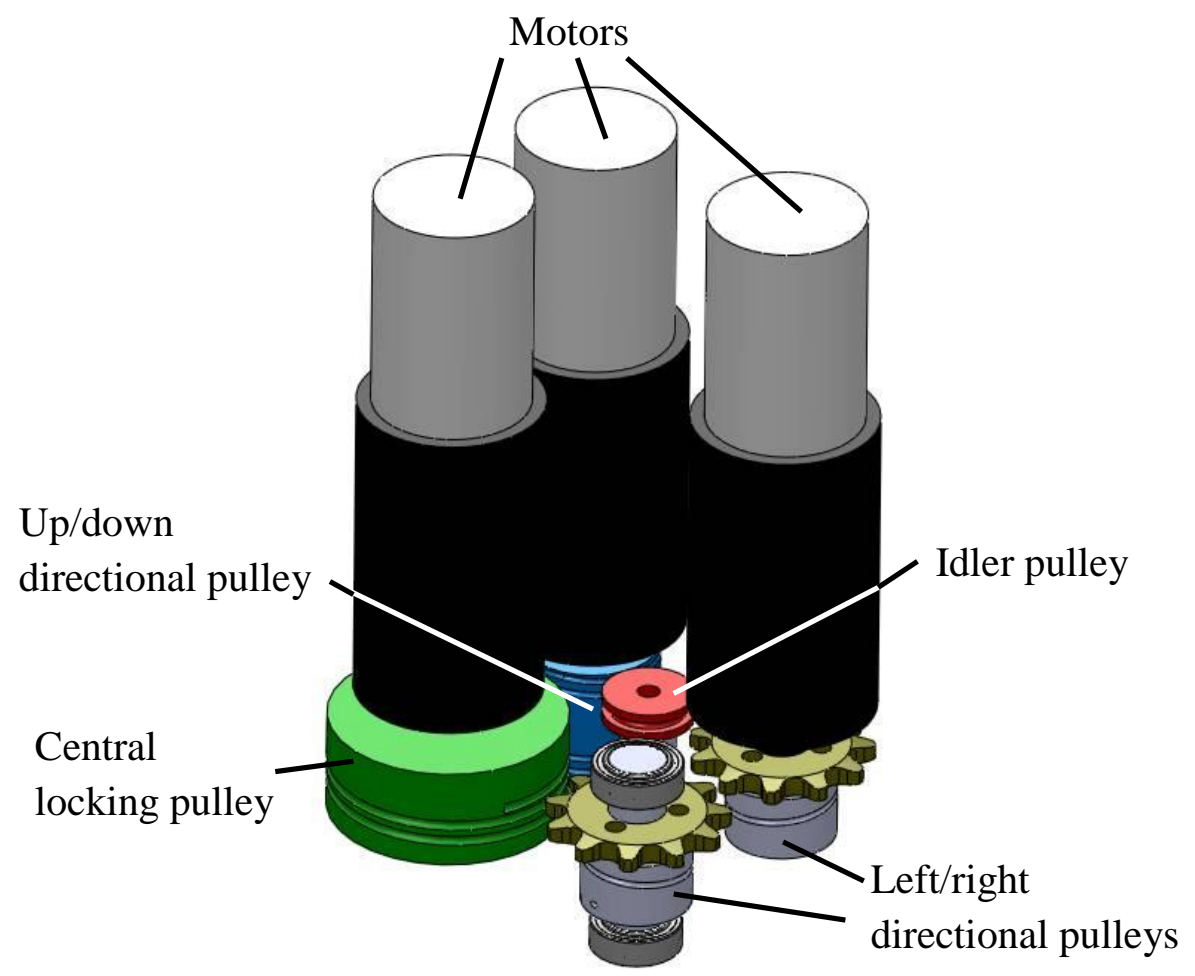

Figure 21. Overall arrangement of motors in housing

The walls of the motor housing are cut from a sheet of ABS plastic with a thickness of 0.25 inches. The cover for the motor housing has slots cut out for the motor connectors to pass through. Wire management is made easier with this slot since the motor connectors protrude from the same slot and also in the same direction. In general, the third generation motor housing is more aesthetically pleasing than the previous generations. To support the three motors in the housing, a holder is rapid prototyped to fit the shape of the housing and the arrangement of the motors. Figure 22 shows the 
complete motor housing modeled in SolidWorks, and Figure 23 shows the fabricated prototype.

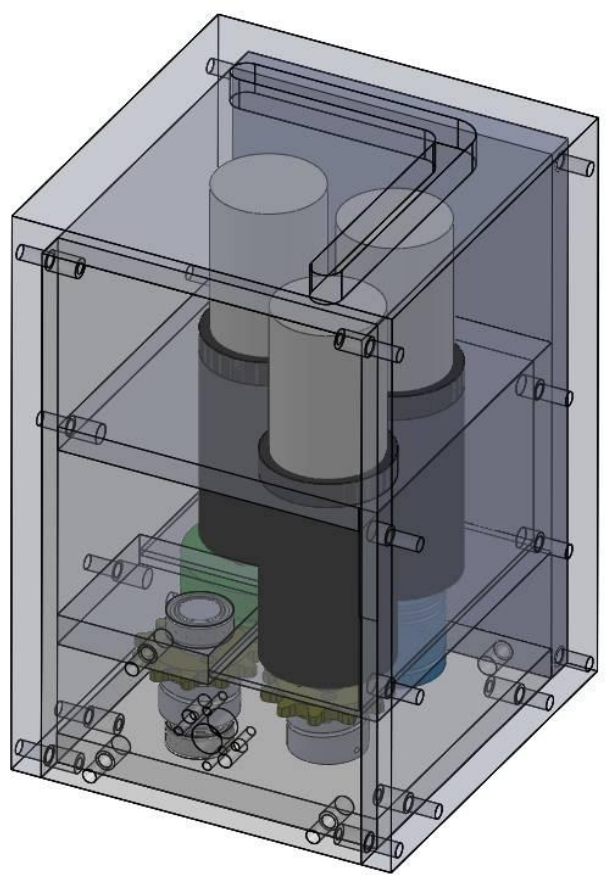

Figure 22. Third generation motor housing

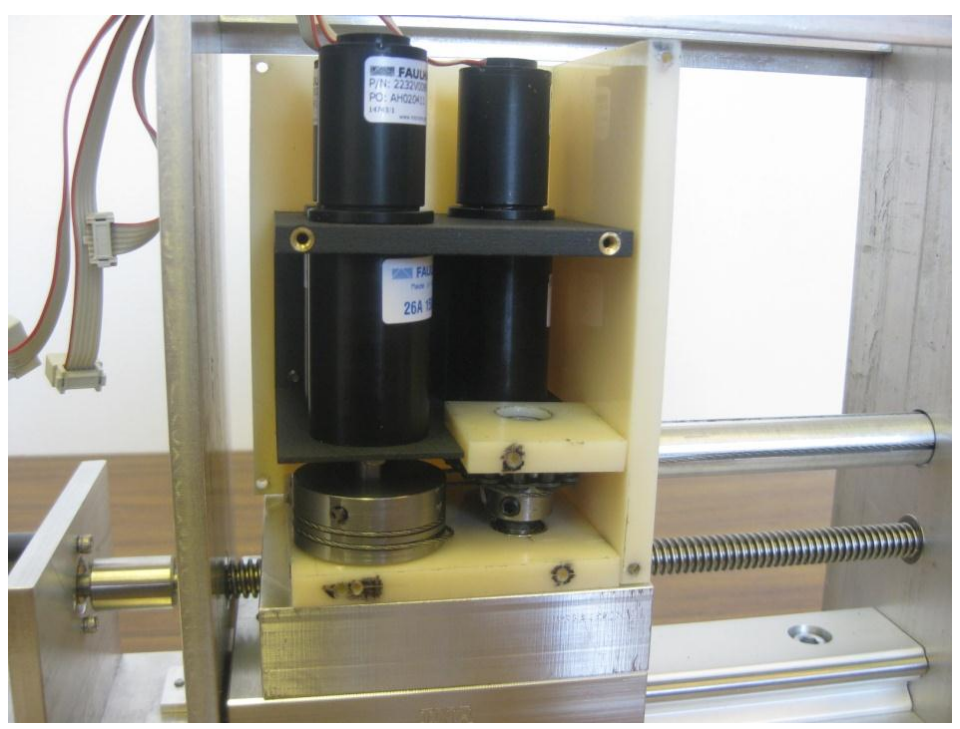

Figure 23. Prototype of third generation motor housing 


\subsubsection{Translational Motion}

The articulated drive mechanism has pitch and yaw degrees of freedom which allow the manipulation and placement of the multifunctional robotic manipulator in the peritoneal cavity. However, the robotic system lacks the ability to extend or reach forward in the surgical site without moving the whole motor housing outside the patient's body. Having to relocate the entire motor housing is undesirable because it increases the risk of injuring the patient and personnel in the operating room, not to mention being time

consuming. Therefore, based on surgeon recommendation, a translational degree of freedom is added to the motor housing. This addition allows the motor housing to translate and move the drive mechanism forward for a short distance, effectively extending the workspace for the manipulator inside the peritoneal cavity.

The translational motion is achieved by mounting the third generation motor housing on a linear slide carriage, which travels on a rail. The slider carriage and guideway are products of INA by Schaeffler Technologies. The guideway measures 7 inches in length and is a single track rail. The linear slide carriage is a rectangular slab measuring 3.5 inches in length, 3.15 inches in width, and has a thickness of 0.6 inches. The carriage and guideway assembly is shown in Figure 24. 


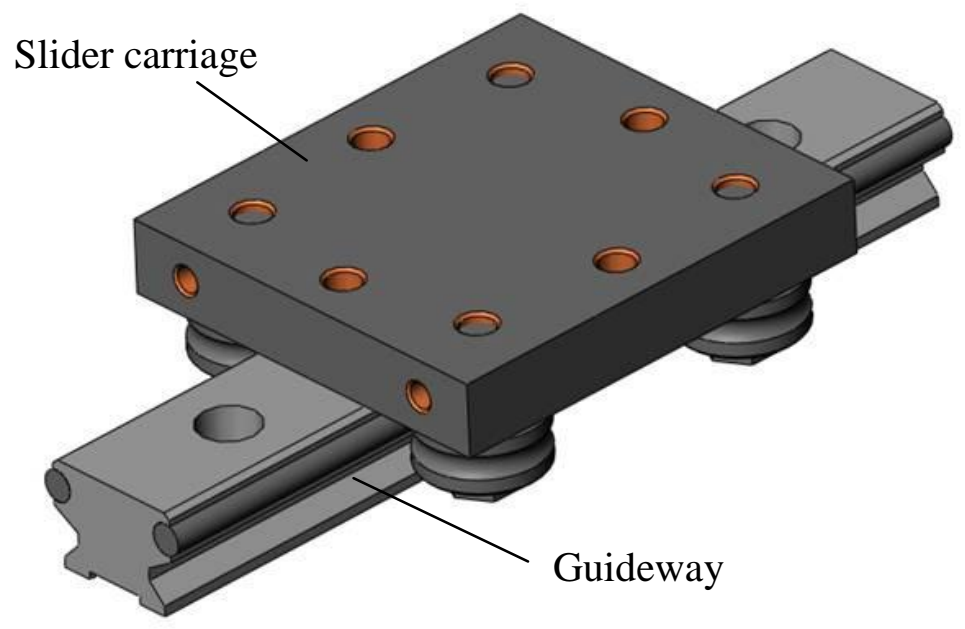

Figure 24. Track roller guidance system for translational motion

An extra slab of aluminum is mounted on top of the slider carriage to allow a threaded shaft to pass through and move the carriage along the guideway. A clearance hole is drilled through the aluminum piece and a slot is cut to accept a hex nut that is used to drive the slider carriage. Figure 25 illustrates this more clearly.

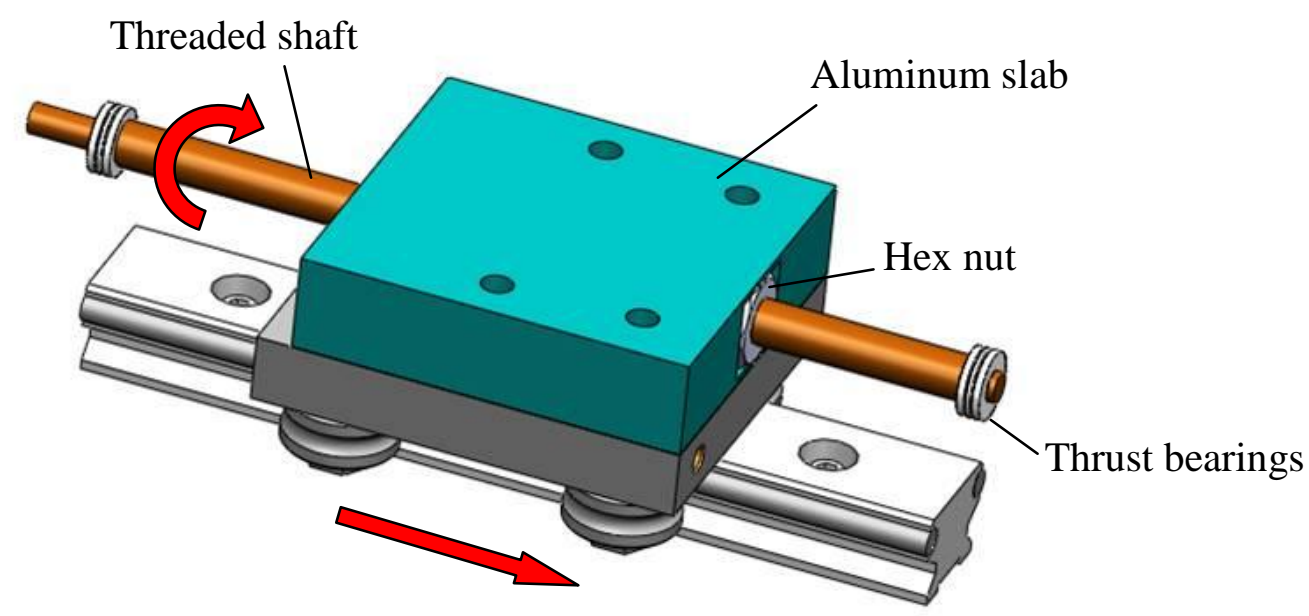

Figure 25. Threaded shaft and hex nut to drive translation 
The threaded shaft is coupled to a motor that rotates the threaded shaft that in turn moves the slider carriage via the hex nut. Both ends of the threaded shaft are turned down to fit into thrust bearings that facilitate the rotation, making sure there is minimum friction between the shaft and housing wall. The total distance traveled by the carriage on the guideway is 3.55 inches, which is not a great distance but sufficient for the robotic manipulator to work in the peritoneal cavity.

The track roller guidance system and the motor housing are placed in a simple box frame that is made up of a front and back wall and thin aluminum bars at the top for support. There is also a motor mount located behind the main box frame. The overall system is compact and easily transported around the operating theatre if needed. To support the linkage pieces, the last linkage piece that is fixed to the motor housing is redesigned with an extended length to provide stability to the rest of the linkage pieces when the translation is in motion. The hole in the front panel of the box frame is designed to have a big enough clearance for the linkage piece to slide in and out without obstruction. Figure 26 shows the CAD model of the overall translational system.

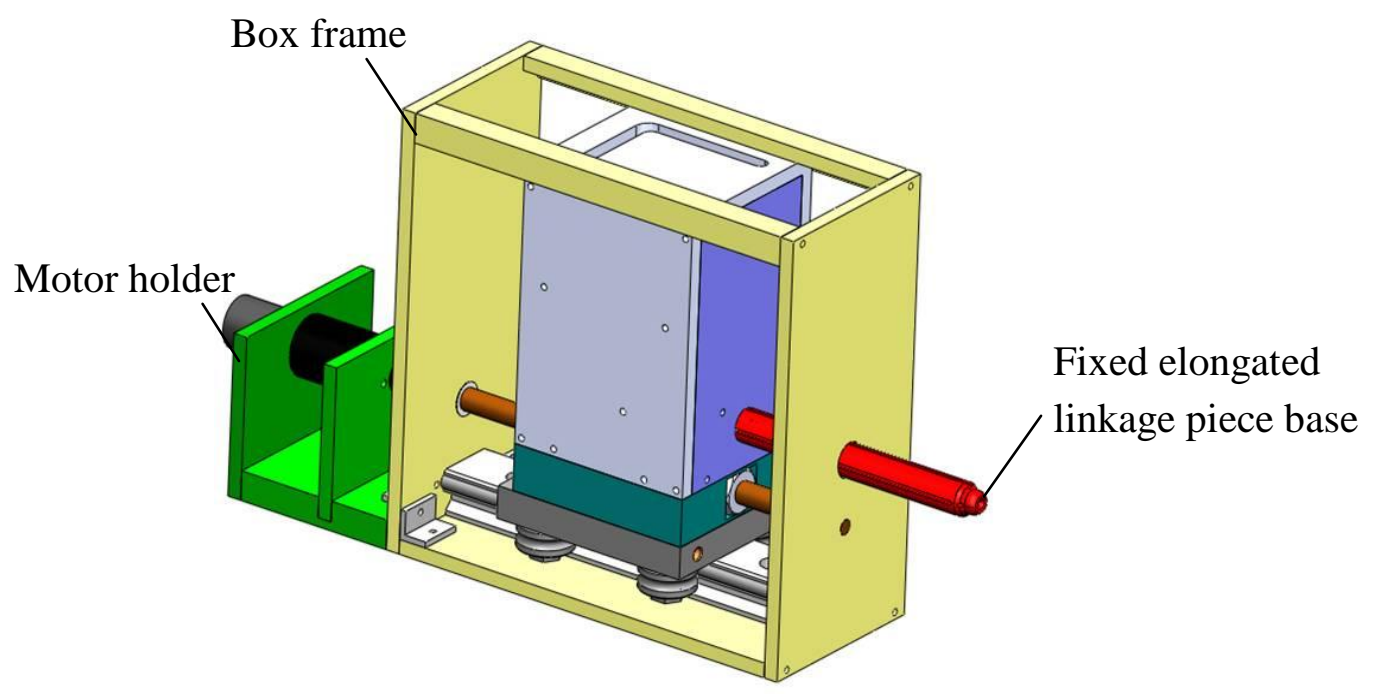

Figure 26. Overall translational system with motor housing 
The system is mounted on a commercially available computer monitor mount. Two tapped holes are drilled on the bottom of the box frame base to allow attachment to the monitor mount disk. The monitor mount is a two-armed stand with a swivel disk mount by Bracket Technology. The swivel disk allows $360^{\circ}$ of rotation for easy positioning of the system, and the two-armed design allows more flexibility in the placement of the system. The monitor stand is attached to the surgery table by clamping on two pieces of aluminum that are custom machined to fit on the surgery table rails. The system is positioned above the patient at an angle that allows easy access to the esophagus and the stand allows the motor housing to be positioned at an optimum position without having the need to move the patient. The compact size of the third generation motor housing has made the translational motion feasible. Figure 27 depicts the motor housing with translation attached on the surgery table.

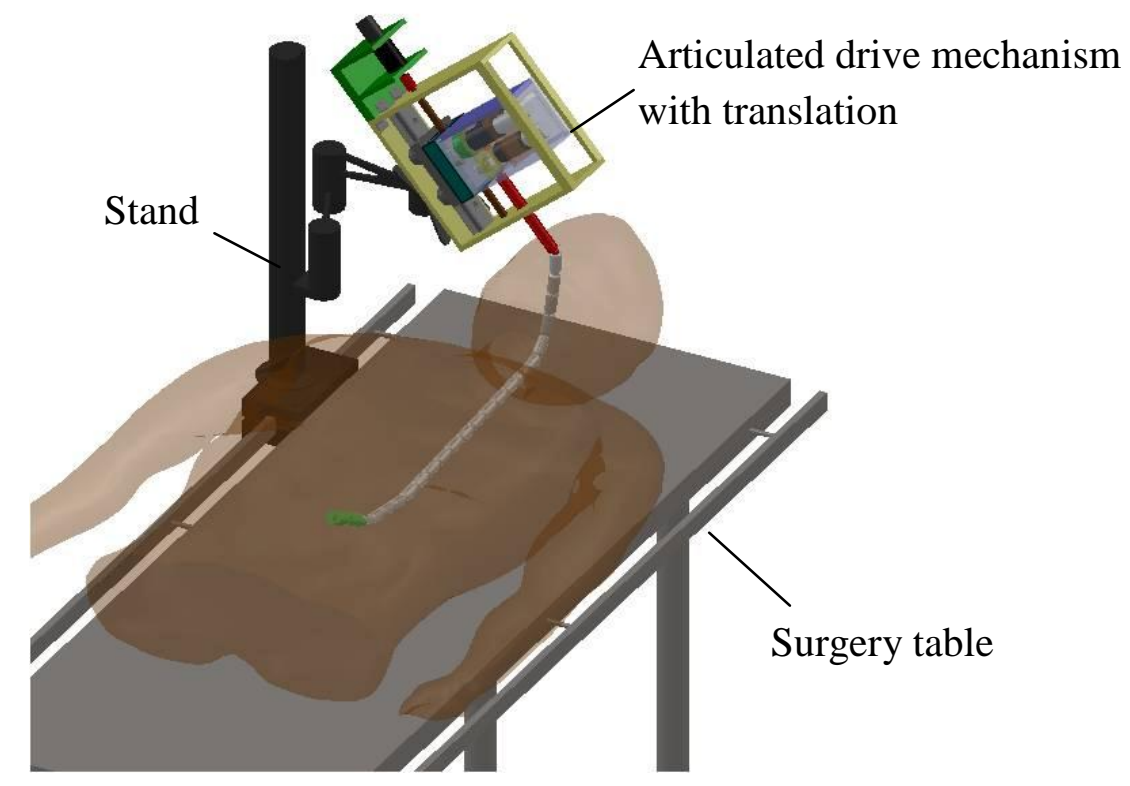

Figure 27. Articulated drive system in a surgery setting 


\section{Chapter 5. Kinematic Analysis}

\subsection{Workspace Analysis}

The purpose of the articulated drive mechanism is to bring the robotic end effector down the esophagus and into the peritoneal cavity. Once there, the drive mechanism has the ability to guide the manipulator around the surgical space. Therefore it is important to explore the workspace area of the articulated drive mechanism. Since the linkage pieces can rotate relative to one another, the general workspace area is expected to be shaped like a spheroidal shell.

Since the drive mechanism rotates equally on all axes, the workspace is generated by doing the kinematics in $2 \mathrm{D}$. The profile of the workspace is then revolved $360^{\circ}$ and represented visually using Matlab®. Using the Denavit-Hartenberg (DH) notation and based on the kinematic structure of the serial linkage, the angle $\alpha_{\mathrm{i}-1}$ is zero and $\mathrm{d}_{\mathrm{i}}$ is also zero. The DH parameters and frame of reference [37] describing the kinematics of the drive mechanism are shown in Figure 28 and Table 2.

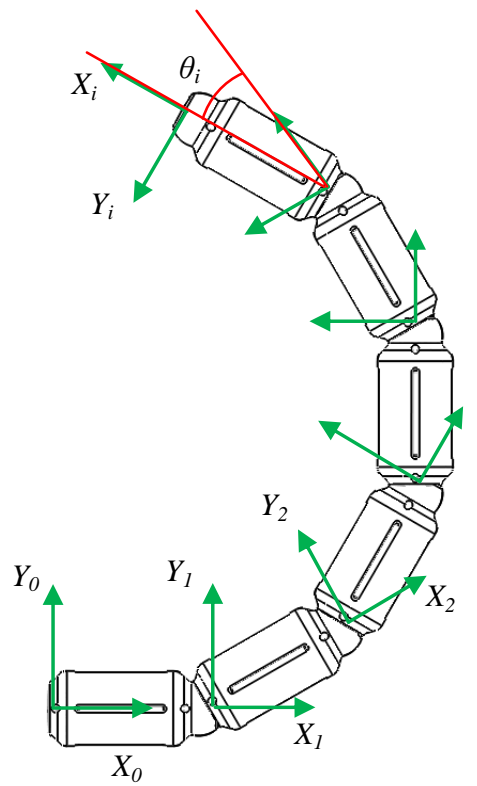

Figure 28. Reference frame for DH method 
Table 2. Denavit-Hartenberg parameters

\begin{tabular}{ccccc}
\hline $\boldsymbol{i}$ & $\mathbf{a}_{\mathbf{i}-\mathbf{1}}$ & $\boldsymbol{\alpha}_{\mathbf{i}-\mathbf{1}}$ & $\mathbf{d}_{\mathbf{i}}$ & $\boldsymbol{\theta}_{\mathbf{i}}$ \\
\hline 1 & $\mathrm{a}_{0}$ & 0 & 0 & $\theta_{0}$ \\
2 & $\mathrm{a}_{1}$ & 0 & 0 & $\theta_{1}$ \\
3 & $\mathrm{a}_{2}$ & 0 & 0 & $\theta_{2}$ \\
4 & $\mathrm{a}_{3}$ & 0 & 0 & $\theta_{3}$ \\
5 & $\mathrm{a}_{4}$ & 0 & 0 & $\theta_{4}$ \\
\hline
\end{tabular}

The length of the linkage pieces is constant for every piece; therefore the values of $\mathrm{a}_{0}$ through $\mathrm{a}_{4}$ are the same. Similarly, the range of rotation between neighboring pieces is also equal; assuming even distribution of displacement among all the underactuated links, the joint variable $\theta_{\mathrm{i}}$ is known for a given cable displacement. Table 3 summarizes the values for the parameters.

Table 3. Link parameter value and joint variables working range

\begin{tabular}{ccc}
\hline $\begin{array}{c}\text { Link } \\
\text { Parameter }\end{array}$ & Value & Units \\
\hline $\mathrm{a}_{\mathrm{i}-1}$ & 1.2806 & {$[\mathrm{in}]$} \\
\hline $\begin{array}{c}\text { Joint } \\
\text { Variable }\end{array}$ & $\begin{array}{c}\text { Working } \\
\text { Range }\end{array}$ & Units \\
\hline$\theta_{\mathrm{i}}$ & $-30^{\circ}$ to $30^{\circ}$ & {$\left[{ }^{\circ}\right]$} \\
\hline
\end{tabular}

The general transformation matrix is shown in (1) [37].

$$
{ }_{1}^{i-1} T=\left[\begin{array}{cccc}
\cos \theta_{i} & -\sin \theta_{i} & 0 & a_{i-1} \\
\sin \theta_{i} \cos \alpha_{i-1} & \cos \theta_{i} \cos \alpha_{i-1} & -\sin \alpha_{i-1} & -\sin \alpha_{i-1} d_{i} \\
\sin \theta_{i} \sin \alpha_{i-1} & \cos \theta_{i} \sin \alpha_{i-1} & \cos \alpha_{i-1} & \cos \alpha_{i-1} d_{i} \\
0 & 0 & 0 & 1
\end{array}\right]
$$

Since the length of the linkage piece is constant, the position matrix is the same for every joint, and is shown in (2). 


$$
{ }^{i-1} P=\left[\begin{array}{c}
1.2806 \\
0 \\
0
\end{array}\right]
$$

The rotation matrix for the drive mechanism in an extreme position is given as (3). It is the same for every joint because the kinematics is performed in two dimensions and the links only rotate about the $\mathrm{z}$-axis from $-30^{\circ}$ to $30^{\circ}$.

$$
{ }_{i}^{i-1} R=\left[\begin{array}{ccc}
\cos 30^{\circ} & -\sin 30^{\circ} & 0 \\
\sin 30^{\circ} & \cos 30^{\circ} & 0 \\
0 & 0 & 1
\end{array}\right]
$$

With the position and rotation matrices, the homogenous transform for the most extreme in-plane motion becomes (4).

$$
{ }_{i}^{i-1} T=\left[\begin{array}{cccc}
0.866 & -0.5 & 0 & 1.2806 \\
0.5 & 0.866 & 0 & 0 \\
0 & 0 & 1 & 0 \\
0 & 0 & 0 & 1
\end{array}\right]
$$

A graphical interpretation of the workspace area (by revolving the planar workspace) is shown in Figure 29. It shows the workspace with three linkage pieces protruding into the peritoneal cavity, and it is clearly observed that the workspace is a portion of a spherical shell. Three linkage pieces would allow a range of rotation from $90^{\circ}$ to $90^{\circ}$. 


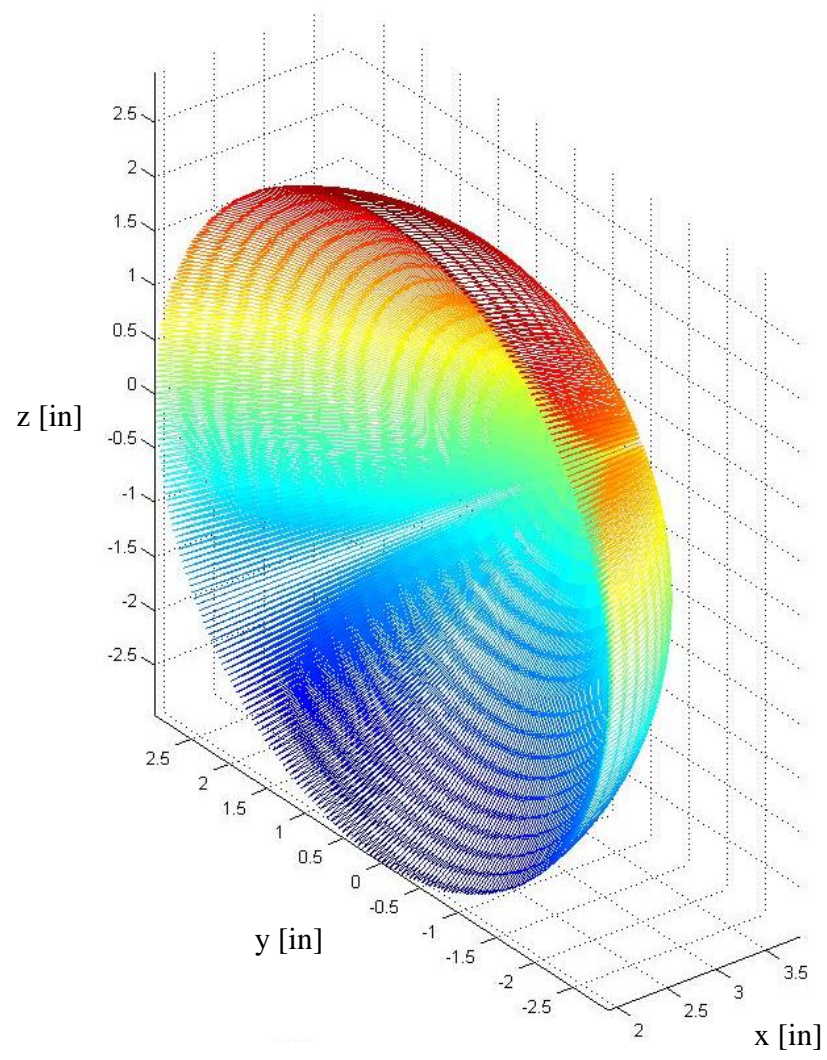

\section{Figure 29. Graphical interpretation of drive mechanism workspace}

To better illustrate the drive mechanism in the peritoneal cavity, the workspace was transposed onto a model of a human peritoneal cavity shown in Figure 30 . The workspace allows the robotic end effector to reach the sides and half of the cavity space. With the translational motion, the drive mechanism can be inserted deeper into the peritoneal cavity by 2.5 inches, which is equal to inserting an additional two linkage pieces. With more linkage pieces, the workspace area becomes closer to a sphere, and allows the robotic manipulator to reach around behind the access point, though this scenario is unlikely to happen. More importantly, it allows the robotic manipulator to operate at sites that would otherwise be out of reach. 


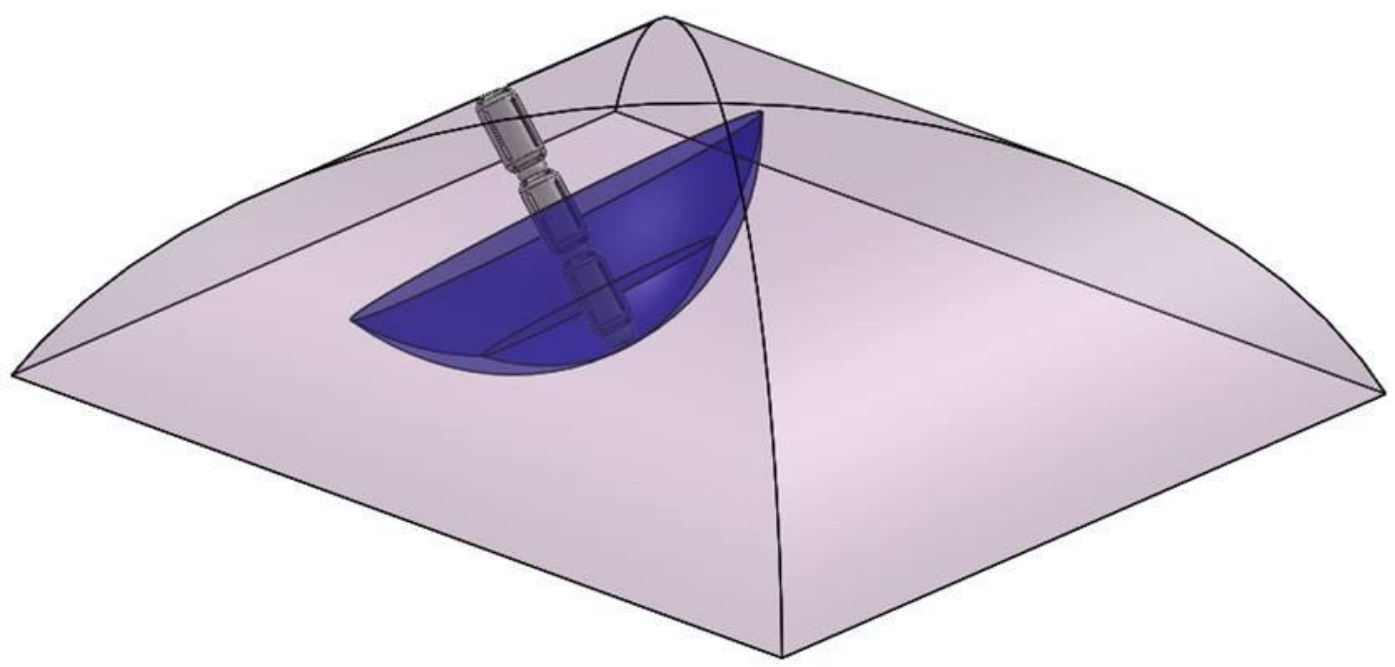

Figure 30. Workspace of drive mechanism without translational motion in peritoneal cavity

Figure 31 shows the graphical representation of the workspace area when four linkage pieces are inserted, and Figure 32 illustrates the workspace area when five linkage pieces protrude into the cavity.

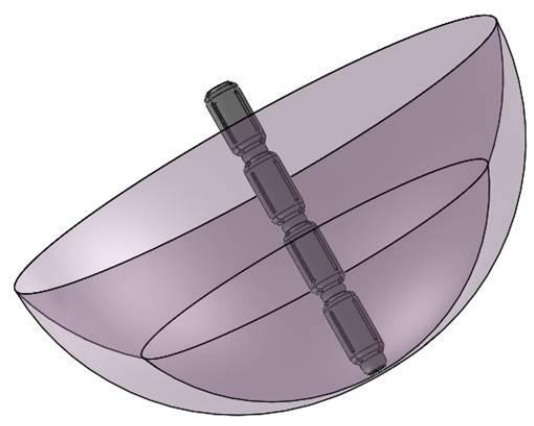

Figure 31. Workspace area with four linkage pieces 


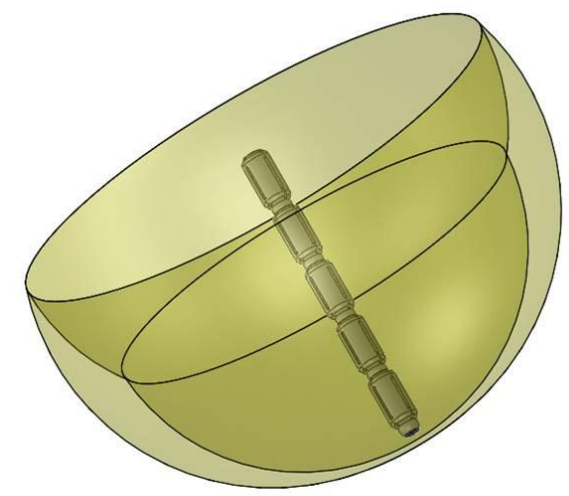

\section{Figure 32. Workspace area with five linkage pieces}

With the addition of the translational degree of freedom, the workspace area of the drive mechanism becomes much larger and easily allows the robotic manipulator to reach the bottom of the peritoneal cavity where most surgeries are performed. The robotic manipulator has its own workspace area, and the combination of both increases the overall workspace quite significantly, as shown in Figure 33.

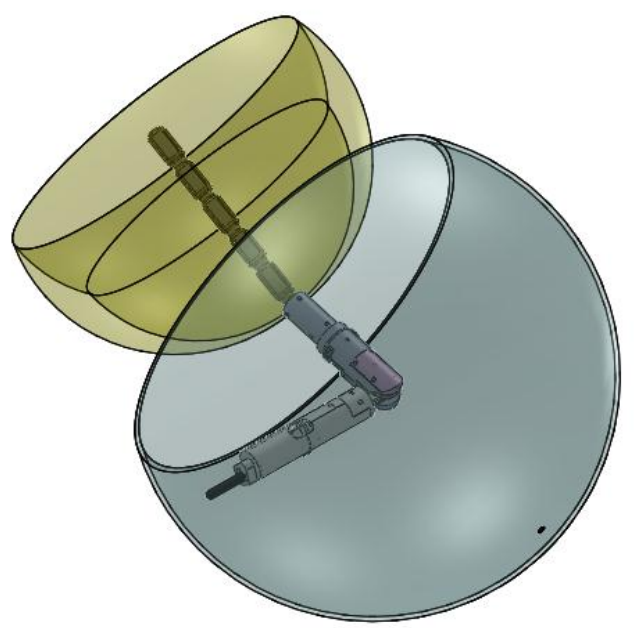

Figure 33. Drive mechanism workspace with robotic manipulator workspace 


\subsection{Force Analysis}

The articulated drive mechanism is designed to lock in shape to provide stability and support to the robotic end effector during surgery. Therefore it is essential to know the tension that is applied on the central wire cable so that the locking function can be achieved without breaking the wire cable. To calculate the required tension, several assumptions are made. First, it is assumed that when the drive mechanism is placed straight horizontally, it behaves like a cantilever beam with a uniformly distributed force. It is also assumed that the concave bottom of the linkage piece comes in perfect contact with the domed-shape top of the neighboring piece. Most importantly the calculation is done with a very conservative approach because the drive mechanism will not be in a cantilevered position during a surgery. In fact, the drive mechanism is partially supported by the esophagus and surrounding organs.

Figure 34 shows the free-body diagram for the force analysis on the cantilever model of the drive mechanism. Since the last linkage piece is fixed to the wall of the motor housing, it is considered as the base for the free body diagram.

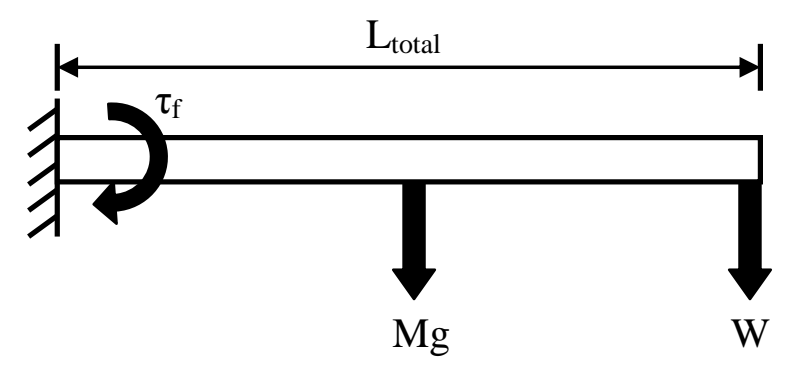

Figure 34. Cantilever model for tension analysis 


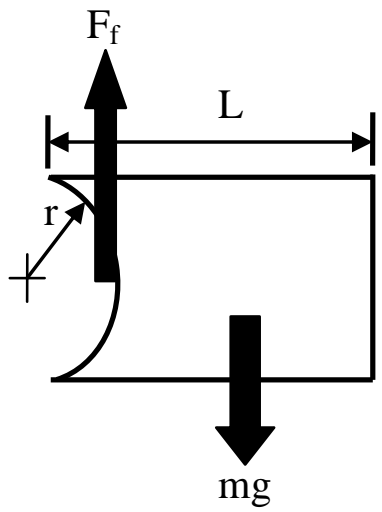

Figure 35. Forces acting on a single linkage piece

Figures 34 and 35 show the forces acting on the cantilever model of the drive mechanism and also on a single unit of the linkage piece. The parameters for the analysis are summarized in Table 4.

Table 4. Parameters for tension analysis

\begin{tabular}{cccc}
\hline Symbols & Description & Values & Units \\
\hline $\mathrm{L}$ & $\begin{array}{c}\text { Length of one } \\
\text { linkage piece }\end{array}$ & 0.0325 & {$[\mathrm{~m}]$} \\
$\mathrm{L}_{\text {total }}$ & $\begin{array}{c}\text { Total length of drive } \\
\text { mechanism }\end{array}$ & 0.6496 & {$[\mathrm{~m}]$} \\
$\mathrm{m}$ & Mass & 0.0107 & {$[\mathrm{~kg}]$} \\
$\mathrm{M}$ & Total mass & 0.2138 & {$[\mathrm{~kg}]$} \\
$\mathrm{W}$ & Arbitrary weight & 5 & {$[\mathrm{~N}]$} \\
$\mathrm{g}$ & Gravitational force & 9.81 & {$\left[\mathrm{~m} / \mathrm{s}^{2}\right]$} \\
\hline
\end{tabular}

From the parameters and values in Table 5, the friction torque acting on the last linkage on the proximal end is calculated. The value is obtained by the method of summing moments, as shown in (5). 


$$
5 N\left(L_{\text {total }}\right)+2.097\left(\frac{L_{\text {total }}}{2}\right)=\tau_{f}
$$

From (5), the friction torque is calculated to be $3.929 \mathrm{Nm}$. Since the radius of the spherical top of the linkage piece is known, the friction force can be calculated from the friction torque. The pressure that is exerted on the surface of the spherical top is shown in Figure 36. The value of the pressure can be calculated by relating the friction force with a known coefficient of friction. Table 5 lists the radius and coefficient of friction values.

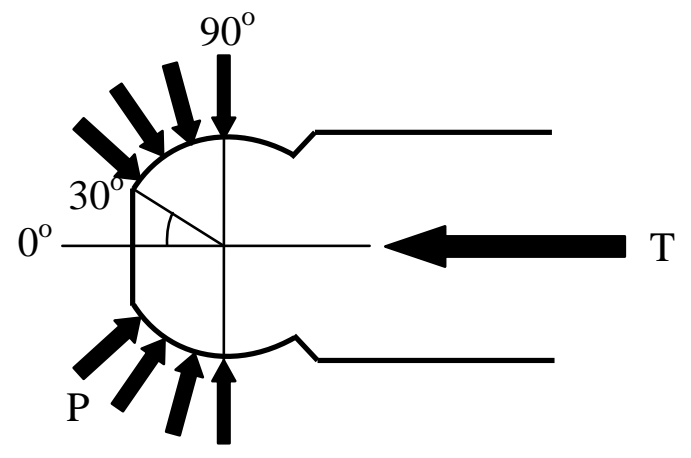

Figure 36. Pressure acting on surface of spherical top of linkage piece

Table 5. Additional parameters for tension analysis

\begin{tabular}{cccc}
\hline Symbols & Description & Values & Units \\
\hline $\mathrm{r}$ & $\begin{array}{c}\text { Radius of spherical } \\
\text { top }\end{array}$ & 5.08 & {$[\mathrm{~mm}]$} \\
$\mu$ & $\begin{array}{c}\text { Coefficient of } \\
\text { friction }\end{array}$ & 0.78 & - \\
\hline
\end{tabular}

The coefficient of friction used here is for steel on steel and is approximated to be 0.78 [38]. Figure 36 shows that the pressure exerted on the spherical top by the concave bottom of a preceding linkage piece only range from $30^{\circ}$ to $90^{\circ}$, and not the entire surface area. Therefore, to get an accurate value of the pressure, the surface area should be integrated over that range. Equations (6-9) are used to obtain the tension in the wire, T. 


$$
\begin{gathered}
\tau_{f}=F_{f} r \\
F_{f}=\mu N=\mu P A \\
\tau_{f}=\mu r P \int_{30^{\circ}}^{90^{\circ}} 2 \pi r^{2} \sin \theta d \theta \\
T=P \int_{30^{\circ}}^{90^{\circ}} 2 \pi r \sin \theta \cos \theta r d \theta
\end{gathered}
$$

The pressure, $P$, is calculated to be $7061525.45 \mathrm{~N} / \mathrm{m}^{2}$. It is assumed that the pressure exerted on the surface is uniform. (This assumption is clearly imperfect since pressure would be expected to have a maximum value at $\theta=0$ and steadily decrease with increasing $\theta$. However, the error may not affect the end result greatly and thus the assumption is retained.) From this, the tension in the central cable, T, can be obtained through (9). The final tension value is calculated to be $429 \mathrm{~N}$, which is very large but not unexpected. First of all, the cantilever beam model is an extremely conservative model and the drive mechanism will never be supported that way in an actual setting. Furthermore, for a long beam-like structure being supported by frictional contact on a surface with a small effective moment arm, a large pressure (and the tension to produce it) is expected. 


\section{Chapter 6. Bench-Top Testing}

\subsection{Directional Motions}

\subsubsection{First Generation}

After all the designing and fabrication were completed, a series of bench-top tests were performed to validate the functionality of the design. For early bench-top tests, the articulated drive mechanism was connected to a National Instruments MID-7654/7652 4/2 axis servo motor drive. The PID parameters for the controls were set in the National Instruments Measurement and Automation Explorer (MAX) program. The directions of the motors were controlled by changing the velocity values in the program. No joysticks were utilized for the initial bench-top testing.

For the first generation motor housing, no articulation was achieved because the wires failed to catch onto the nylon pulleys. The grooves cut into the nylon pulleys were too large and did not fit the wires, and the surface friction between the nylon pulleys and nylon coated wires was too low. The design was flawed and bench-top testing failed.

\subsubsection{Second Generation}

For the second generation motor housing, the same bench-top test procedure was performed. With the chain and sprocket mechanism, the wires were successfully pulled and articulation was achieved. When tension was applied to the wire, the drive mechanism managed to turn and rotate in the intended direction by more than $90^{\circ}$. The ability to achieve such rotations was deemed a success.

However, changing from one direction to the opposite direction proved to be much less successful. This was due to the fact that the wires did not properly slacken in 
the opposite direction. It was observed that the wires buckled at the connection between the wire and chain because the miniature plastic chains used were not stiff enough. Therefore the force was not properly transferred, causing the drive mechanism to behave less predictably.

This bench-top result showed that although the chain and sprocket mechanism had success in providing articulation to the drive mechanism, it was not the best solution in the long term.

\subsubsection{Third Generation}

With the partial success in the second generation bench-top tests, some modifications to the mechanism were made to increase the functionality. The replacement of sprockets with custom made pulleys with grooves allows the wire cables to be tightly wound and anchored around the motor shaft. Theoretically this should ensure successful wire manipulation for articulation purposes. When the third generation motor housing was first assembled, the chains used were metal roller chains with a 0.25 inch pitch. However, it was found after trial runs that the roller chains constantly rubbed against the wire cables and stripped the nylon coating off of them. This was due to the thickness of the metal roller chains. The wire cables wore out quickly after a few rounds of testing.

To solve this problem, the hubless sprockets that were originally attached to the custom made pulleys were replaced with mini acetal sprockets with a 0.1227 inch pitch. The roller chains were also replaced with miniature plastic roller chains with less thickness. The miniature chains proved to be much less intrusive during testing, and allowed more space for wire manipulation. The downside of employing the miniature 
roller chains is the potential compromise in strength. Although no significant effects have been discovered during testing, the working load is lower than that of the metal roller chains.

Another change in this version was the wire attachments at the distal end of the drive mechanism. The wire cables were originally clamped at the distal tip with the opposite ends looped around the pulleys in the motor housing. This arrangement was found to be flawed because although articulation was achieved, the wires frequently loosened and slipped away from the pulleys and interfered with subsequent trials, making repeatability low. Instead of individually clamping four wire ends, two wires were looped back into the motor housing and attached to opposing pulleys.

This arrangement resulted in smooth and almost faultless articulation of the drive mechanism. Repeatability was also much higher than in previous trials. It is noted that at this point the bench-top tests were run without the attachment of the robotic manipulator at the distal end of the drive mechanism. Articulation was successful in all four directions when tested using the National Instruments MID-7654/7652 4/2 axis servo motor drive with MAX. Figure 37 (a)-(c) shows the yaw articulation angles achieved by the drive mechanism from a horizontal starting position. 


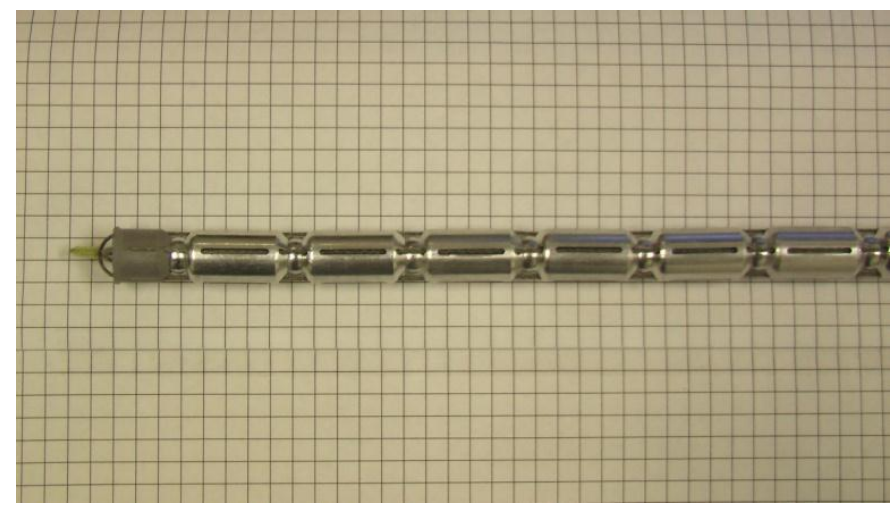

(a)

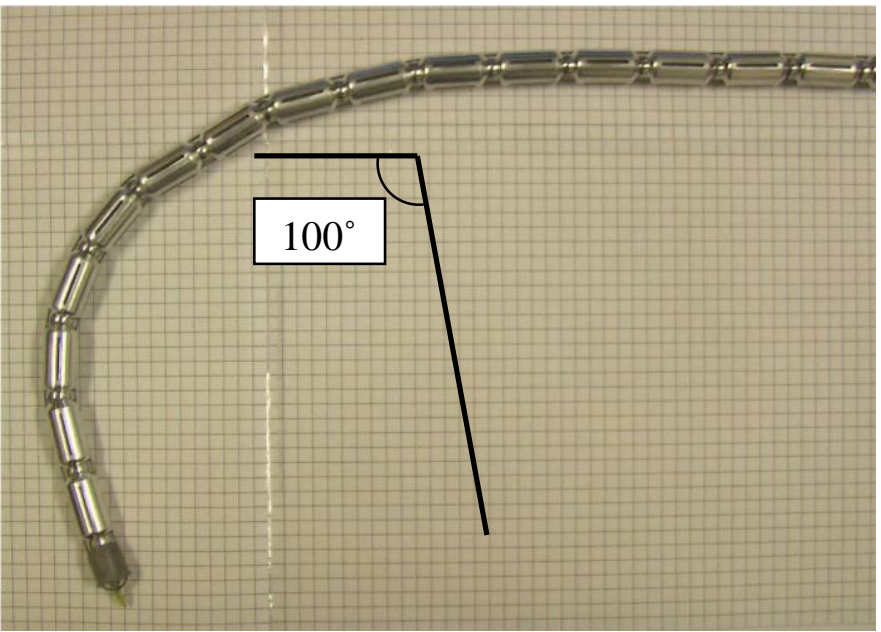

(b)

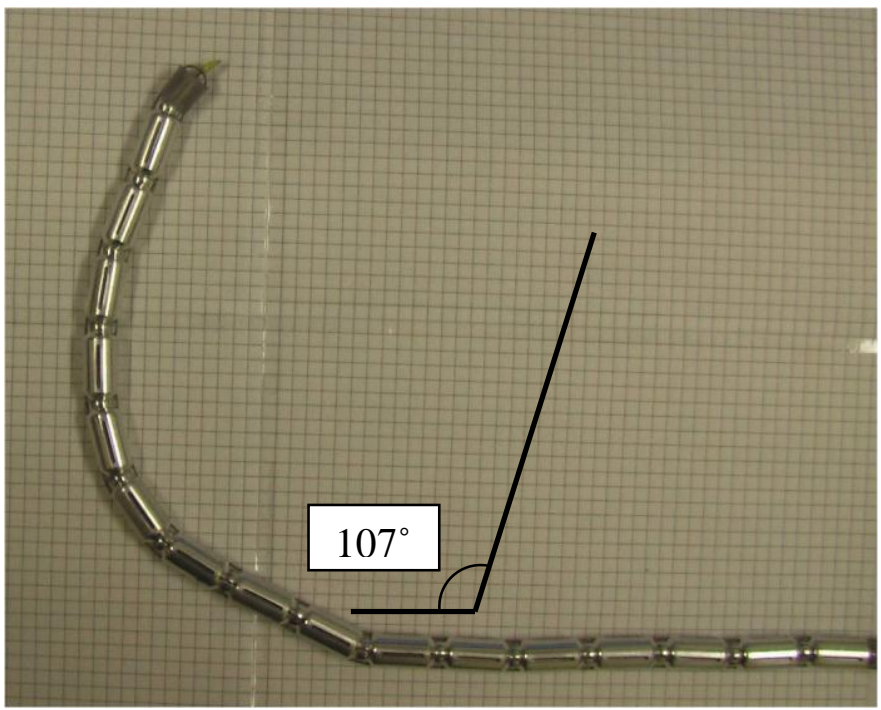

(c)

Figure 37. (a) Drive mechanism at horizontal starting position (b) Drive mechanism articulated to the left (c) Drive mechanism articulated to the right 
It was observed from the bench-top testing that the drive mechanism is perfectly capable of articulation in the yaw axis, as shown in Figures 37 (b) and (c). The drive mechanism achieved an angle of at least $100^{\circ}$ when actuated to the left. The curvature of the drive mechanism when actuated to the left from a horizontal starting position was smooth and continuous. When the drive mechanism was actuated to the right, the angle achieved was at least $107^{\circ}$. For both actuation directions, the drive mechanism could achieve more than $100^{\circ}$, surpassing the $90^{\circ}$ maximum articulation assumed as the requirement for surgery. The curvature of the drive mechanism when actuated to the right was not as smooth, as the linkage pieces did not sequentially rotate. As observed from Figure 37 (c), a short portion of the linkage pieces remained in a straight line. This could be caused by higher friction on the surfaces of the three non-rotated linkage pieces.

\section{Articulation Behavior with Non-Lubricated Linkage Pieces}

Another set of bench-top tests were performed to observe the difference in the behavior of articulation when the drive mechanism is moved from a starting position that is at the extreme left to the end position which is the extreme right. Figures 38 (a)-(f) show the snapshots of the articulation sequence for the bench-top test. 


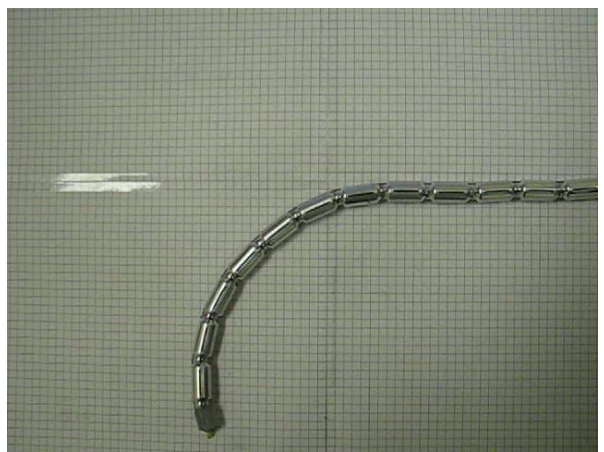

(a)

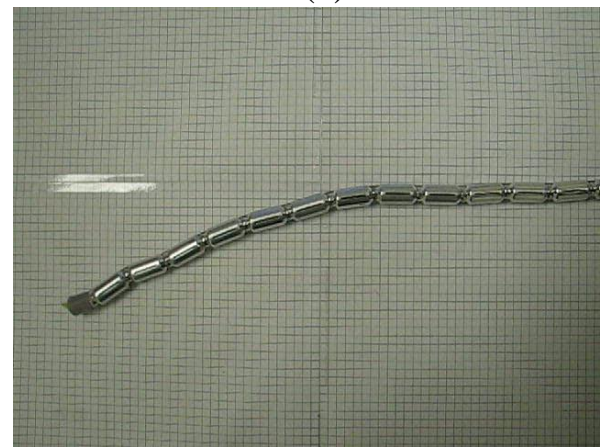

(c)

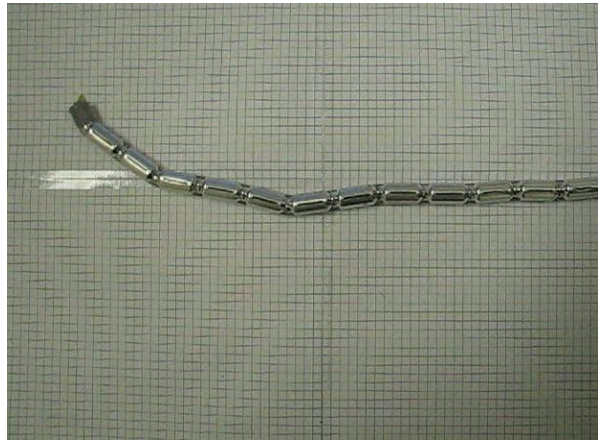

(e)

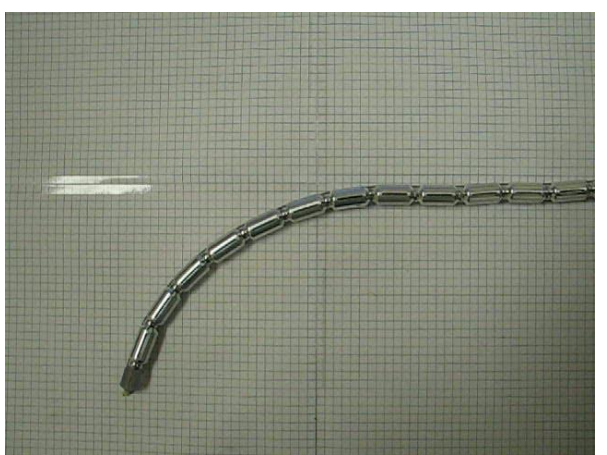

(b)

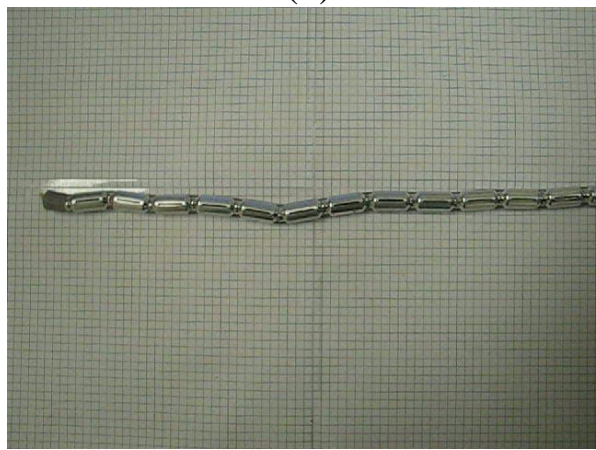

(d)

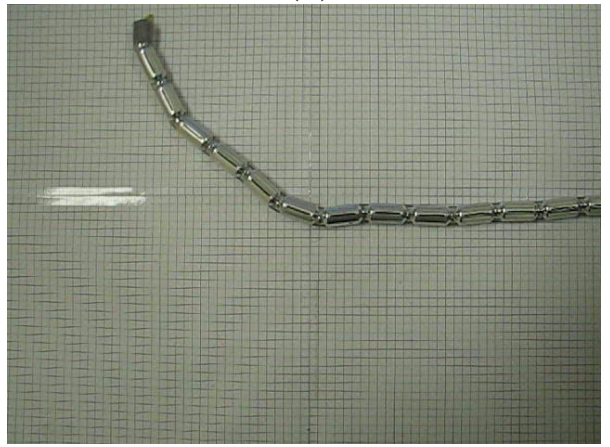

(f)

\section{Figure 38. Drive mechanism articulation sequence from extreme left to extreme right position}

The drive mechanism was first articulated to the left as shown in Figure 38 (a). Using that as the starting position, the drive mechanism was moved towards the right. As the drive mechanism approached horizontal, it was observed that one or two linkage pieces did not rotate properly. This got worse as the articulation continued. When the final position was reached as seen in Figure 38 (f), the linkage pieces were crooked and 
not nicely rotated as expected. Also, the final position was less than that achieved when the drive mechanism was articulated from a horizontal starting position. One reason that could explain this phenomenon is the different surface qualities within the spherical joints of the linkage pieces, leading to different friction forces and causing binding in some joints. The total time for the whole articulation sequence was approximately 7 seconds.

The same bench-top test was performed on the pitch axis articulation. The drive mechanism was laid out straight on a flat surface as the starting position. Figures 39 (a) and (b) show the results from the pitch axis bench-top tests.

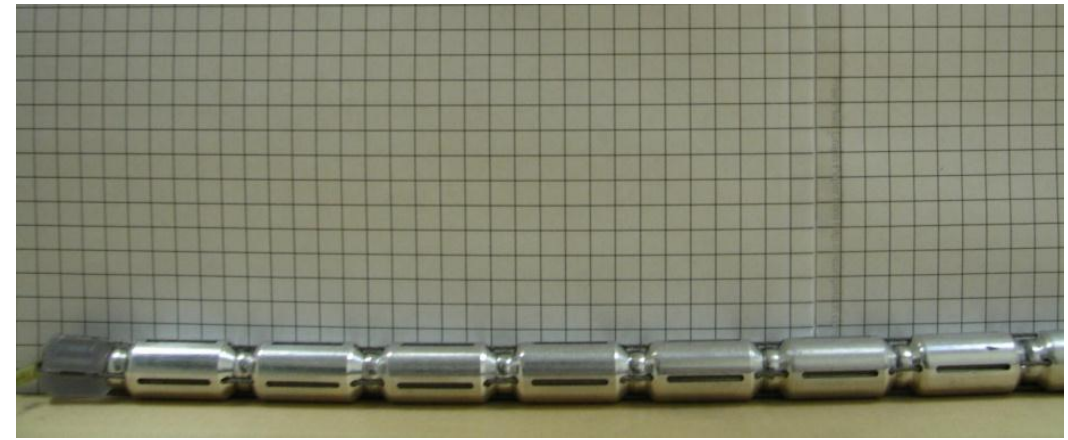

(a)

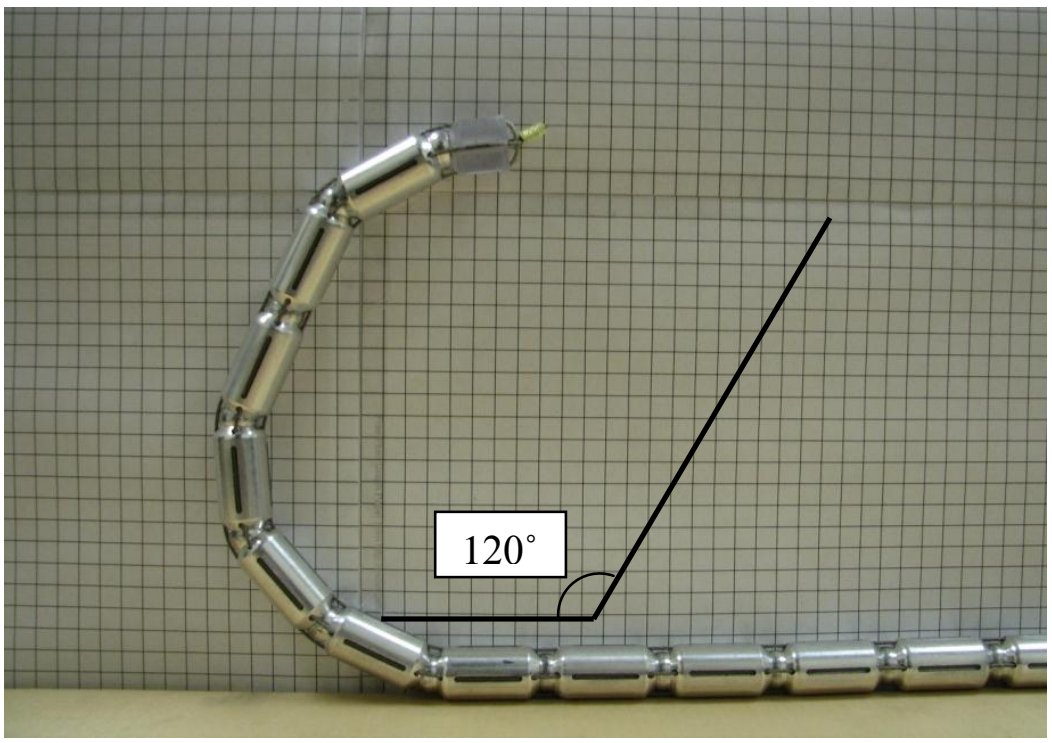

(b)

Figure 39. (a) Starting position for drive mechanism (b) Drive mechanism lifted up 
It was also observed from the bench-top trials that the linkage pieces did not properly rotate in sequence. However, the drive mechanism managed to lift itself up at least $120^{\circ}$. Again, the drive mechanism showed its capability to lift up much more than $120^{\circ}$, but since it exceeds the maximum requirement, the exact maximum angle achieved was not recorded. Still images captured from the video shown in Figure 40 were used to investigate the link-by-link movement.

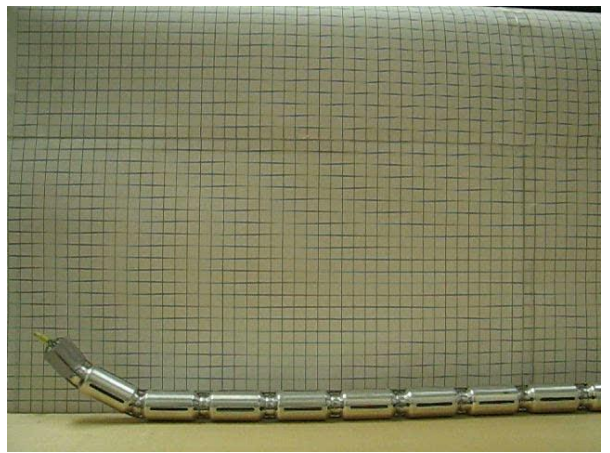

(a)

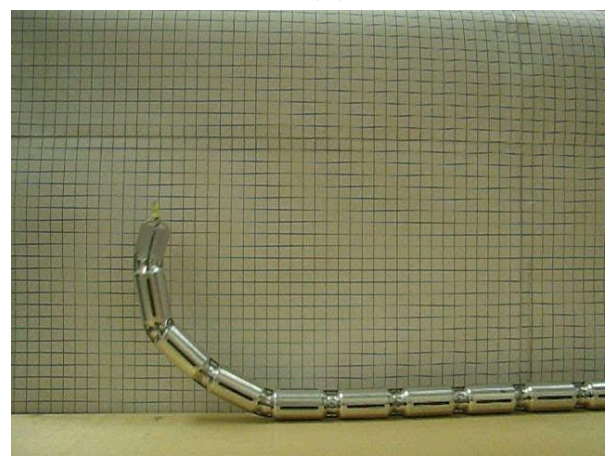

(c)

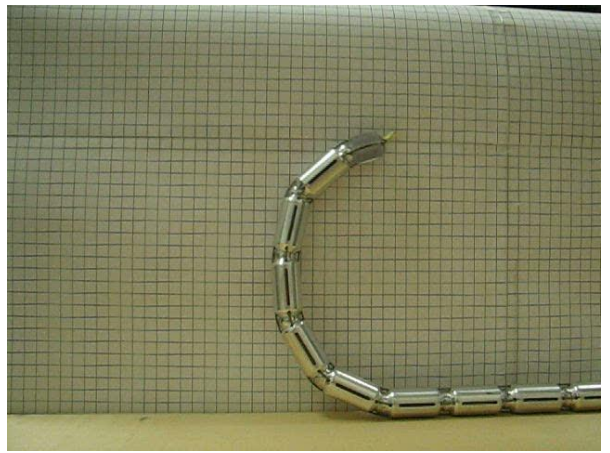

(e)

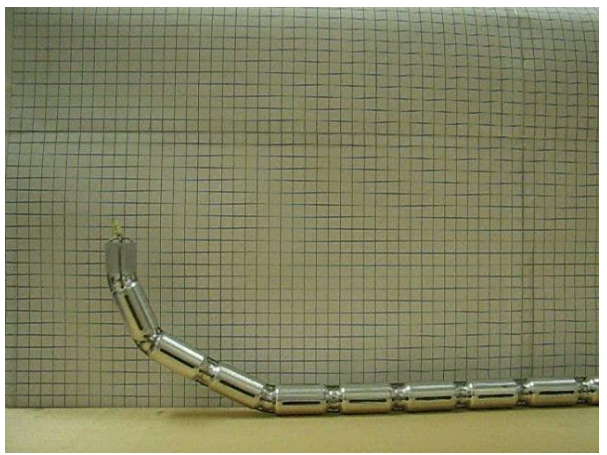

(b)

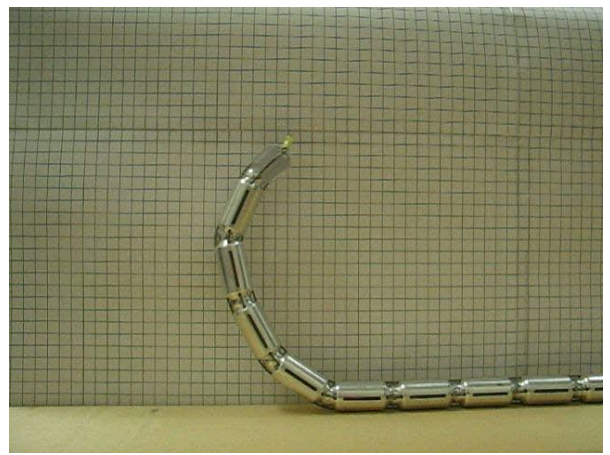

(d)

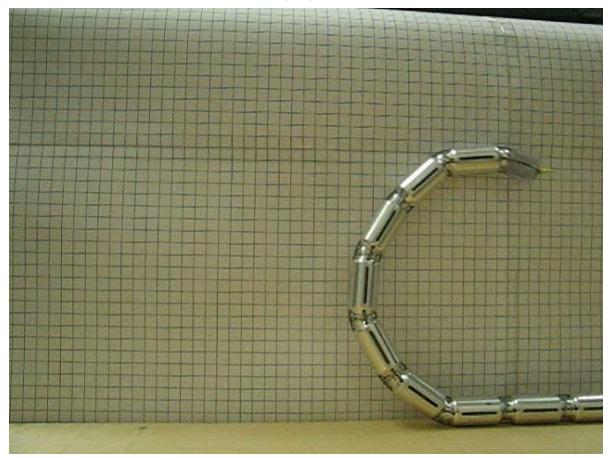

(f)

Figure 40. Drive mechanism pitch articulation sequence 
Similar to the observation made in Figure 39(b), the articulation sequence in Figure 40 was slightly off. At the start of the articulation sequence, the first linkage piece was actuated, but it was not followed by the subsequent piece. Instead, the third piece moved first, followed by the second. The rest of the pieces actuated sequentially. However, the articulation sequence did not seem to be consistent over a number of trial runs. The total time for the drive mechanism to move from the horizontal starting position to its final position was approximately 7 seconds.

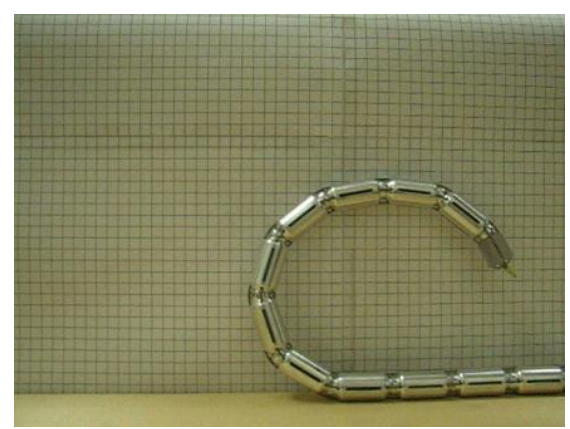

(a)

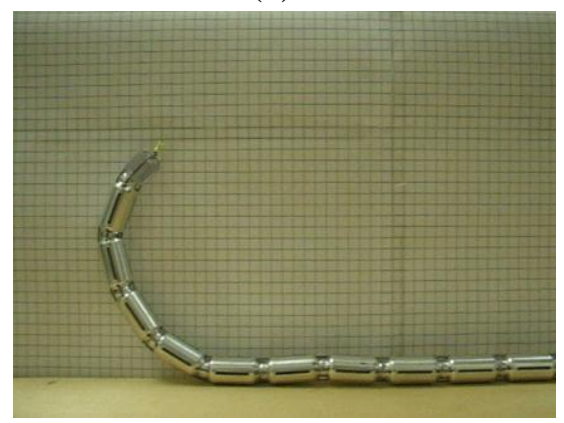

(c)

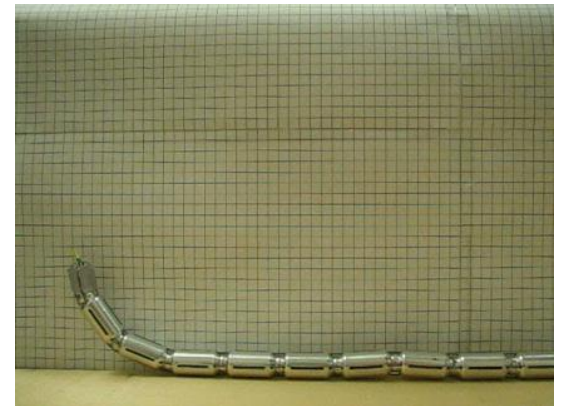

(e)

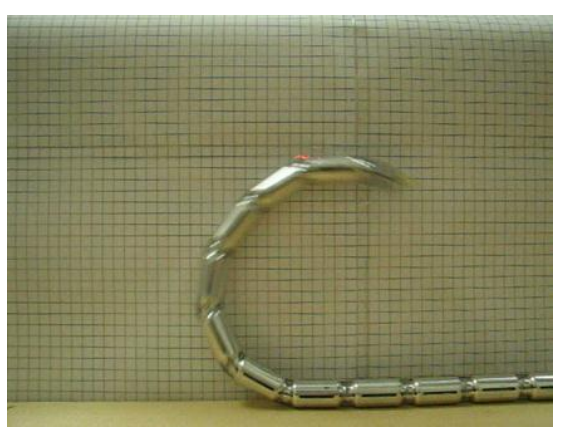

(b)

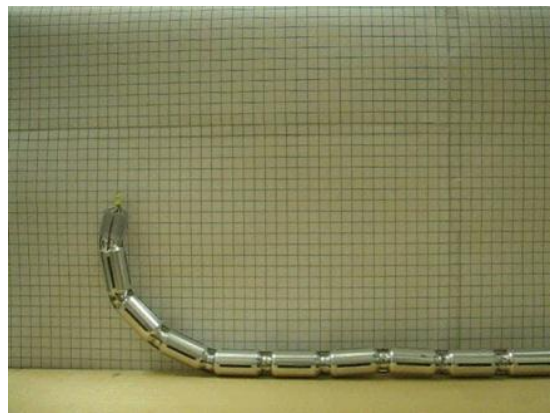

(d)

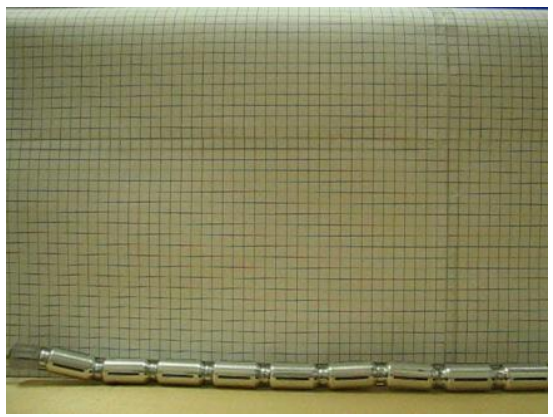

(f)

Figure 41. Drive mechanism reverse pitch sequence 
When the pitch sequence was run in reverse, it was observed that gravity caused the drive mechanism to accelerate, as seen in the blurred movement in Figure 41(b). However, the overall time for the reverse sequence was also 7 seconds because although it accelerated initially, the drive mechanism slowed down towards the horizontal position.

With the bench top observations and results, the workspace of the drive mechanism was reconstructed and compared to the theoretical workspace area that was presented in Chapter 5. Using the snapshot in Figure 39(b), the joint angles were measured and input into Matlab to generate the actual workspace. Figure 42 shows the comparison of the cross-sectional theoretical workspace (red) and the actual workspace (blue).

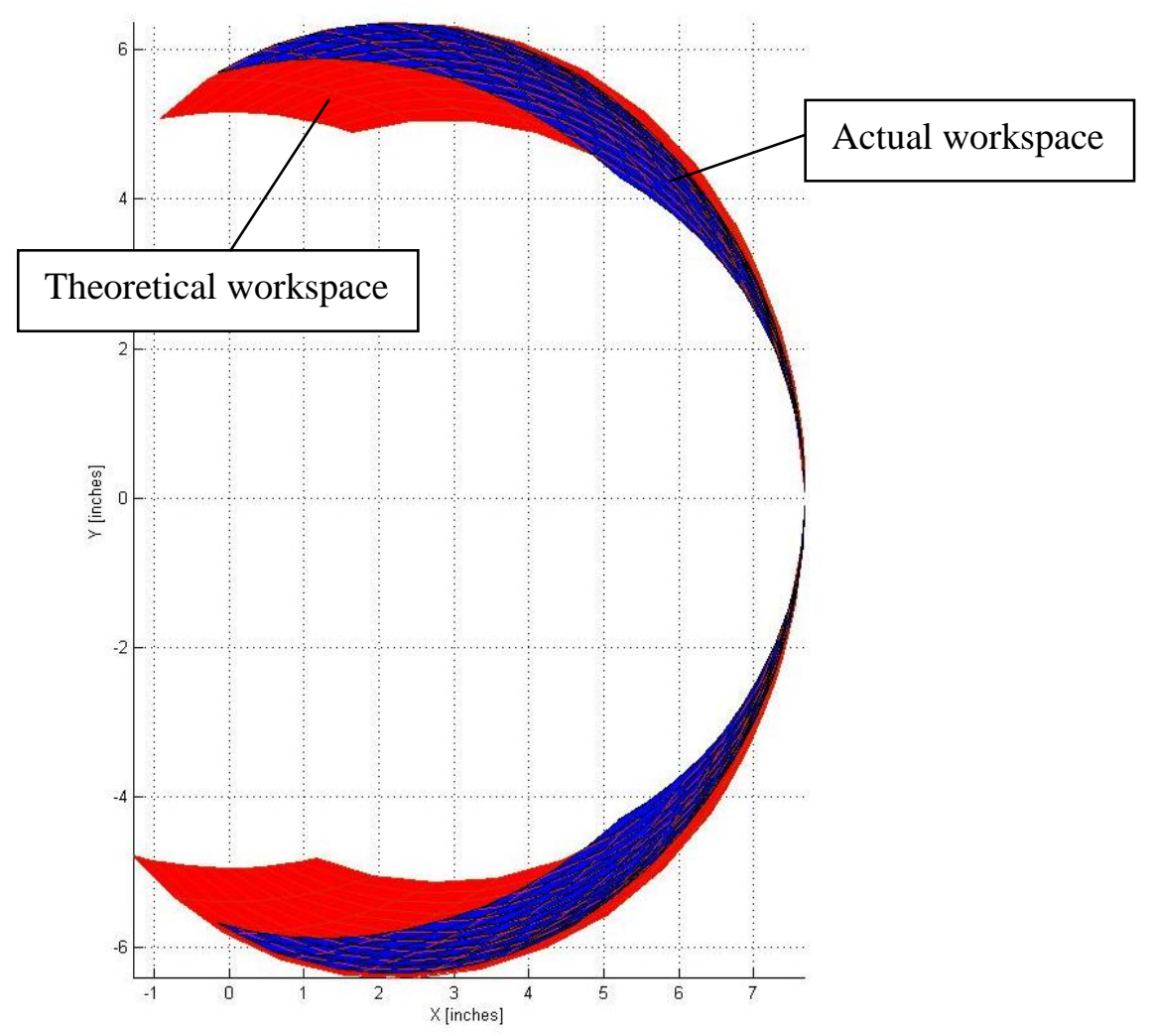

Figure 42. Comparison between actual and theoretical workspace of drive mechanism 
Assuming the drive mechanism achieves the same angles when articulated in all the other directions, a 3D representation of the workspace was generated and compared to that of the theoretical as well. Figure 43 shows the comparison.

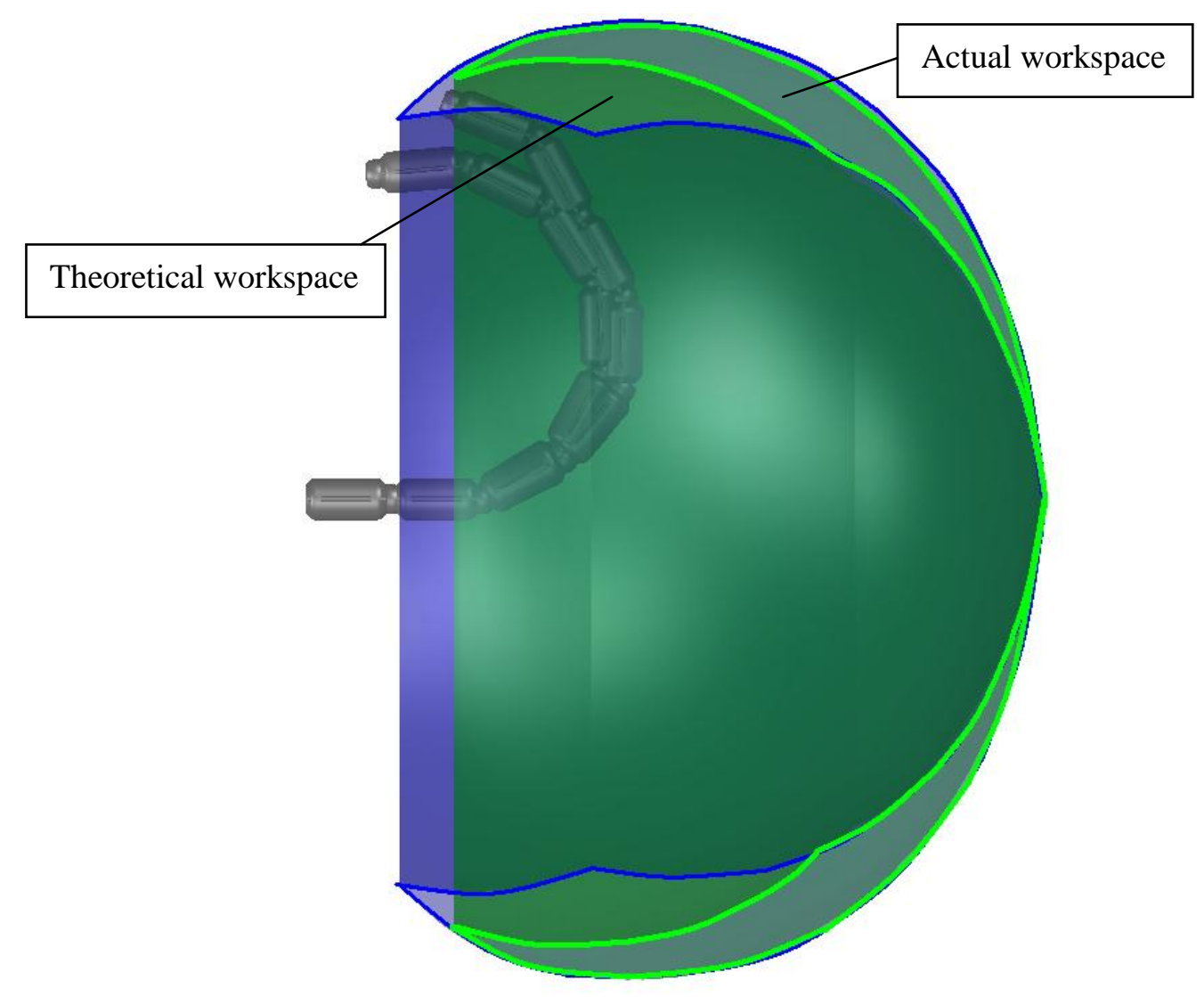

Figure 43. Comparison between actual 3D workspace with theoretical workspace

The workspace in red depicts the theoretical workspace, and the blue workspace is the actual functional workspace. From the simulated drive mechanisms, it can be observed that the mechanism did not reach as far back as the theoretical model, hence making the actual workspace a lot smaller. However, although the actual workspace does not fit the theoretical workspace well, the achieved workspace is still large enough and more than sufficient for a surgical procedure. 


\section{Articulation Behavior with Lubricated Linkage Pieces}

A series of bench-top trials was run with lubricated linkage pieces. The purpose of this bench-top testing is to observe and compare the effects of lubrication on the curvature of the drive mechanism. In the previous bench-top trials, it was observed that the spherical joints of the drive mechanism exhibit a certain degree of binding when actuated which cause inconsistency in the performance of the drive mechanism as a whole.

Initially the linkage pieces were lubricated with a gel based lubricant, but it was quickly discovered that this method of lubrication is not ideal because the gel dried quickly and turned sticky, making the linkage pieces bind more. Other methods considered include dry lubrication, such as talcum powder or graphite powder. However, due to convenience and easy applicability, a commercial spray-on lubricant (WD-40) was used solely for experimental purposes. When used in vivo, the method of lubrication must be changed to ensure biocompatibility.

Like the previous non-lubricated trials, the drive mechanism was actuated from an extreme left position to the extreme right position with no pauses in between. A series of snapshots was taken of the articulation sequence and the curvature is compared with the previous results. Figures 44 (a)-(f) show the video stills of the articulation motion. 


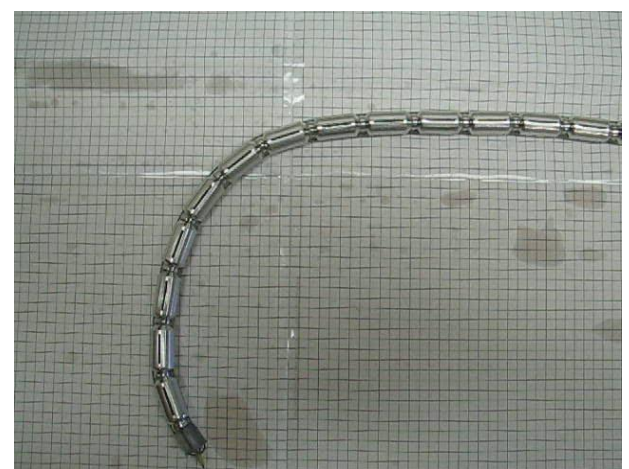

(a)

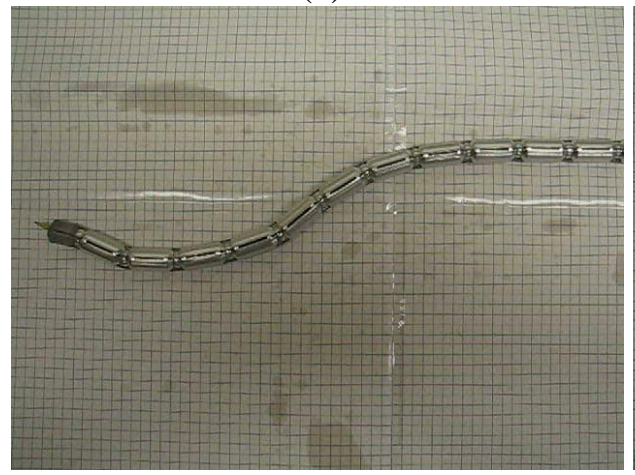

(c)

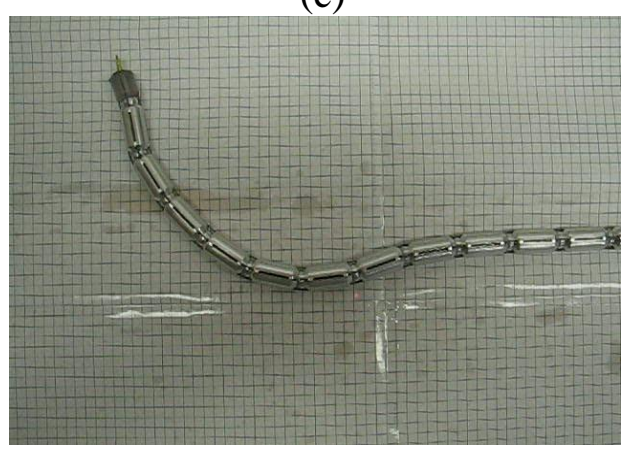

(e)

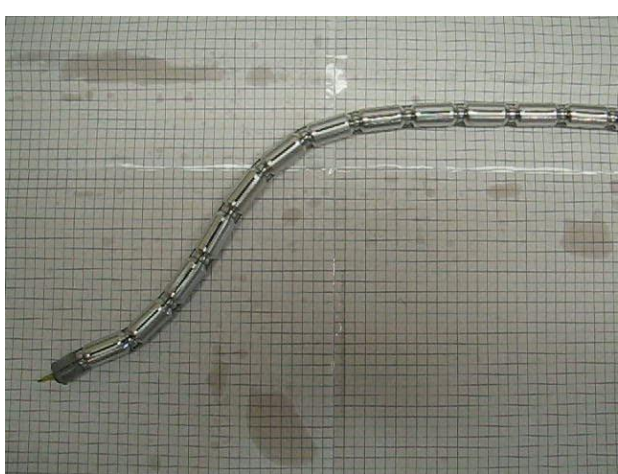

(b)

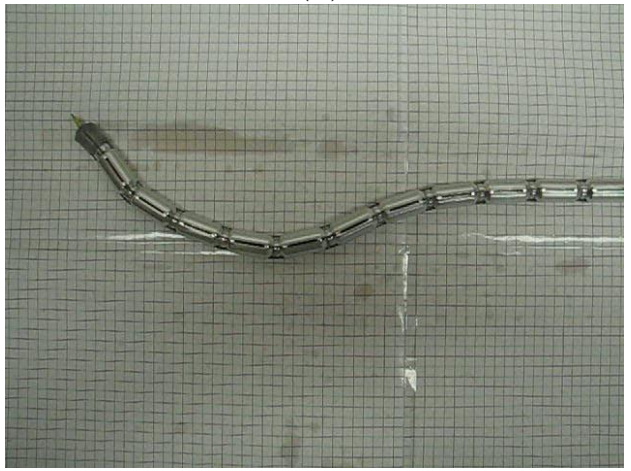

(d)

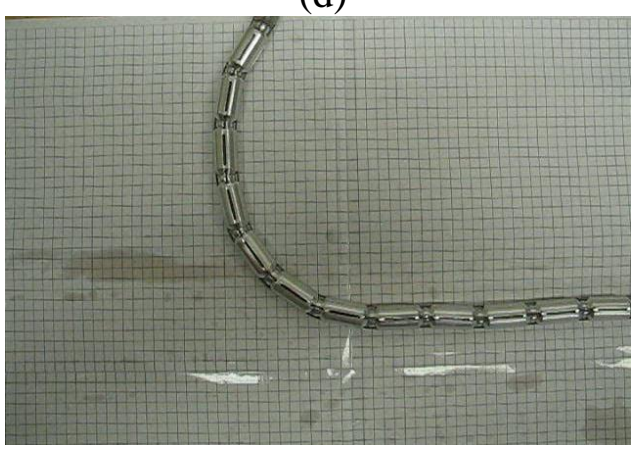

(f)

Figure 44. Articulation sequence with lubricated linkage pieces

The curvature of the drive mechanism when the spherical joints of the linkage pieces are lubricated is much smoother, as expected. During the bench-top trials, the linkage pieces did not bind and the sequence of articulation was very satisfactory. As observed in Figure 44, the curvature of the drive mechanism is a smooth inflected curve. This is because the distal linkage piece was actuated first and the rest of the linkage pieces followed suit. Although the drive mechanism never reached a perfect horizontal in 
the middle, the lubricated linkage pieces allowed the drive mechanism to articulate from one extreme position to another nicely without any kinks.

The conclusion that is made from this observation is that the surface quality of the linkage pieces plays a very important role in ensuring consistency in the behavior of the drive mechanism. It is essential to keep the linkage pieces lubricated when used during a surgery, although during in vivo usage the method and type of lubrication must be changed due to biocompatibility issues.

\section{Articulation with Different Drive Mechanism Lengths}

Besides testing the functionality of the drive mechanism and exploring the effects

of lubrication on the articulation behavior, it is of interest to also explore and observe the curvature of the drive mechanism when the total length of the drive mechanism is changed. The purpose of this experiment is to hopefully get a best fit function for the curvature and also from the outcome of observation, relate the locations of the bends to the esophagus and stomach so that an optimum length can be obtained.

To change the total length of the drive mechanism, the number of linkage pieces that make up the drive mechanism is altered. For the purpose of this experiment, three lengths were chosen, as summarized in Table 6 . The three lengths correspond to 18,14 , and 10 of the linkage pieces. Snapshots of the curvature for all three lengths were taken for comparison, as are shown in Figures 45(a)-(c). 
Table 6. Number of linkage pieces and corresponding length of drive mechanism

\begin{tabular}{cc}
\hline Number of Linkage Pieces & Total Length [in] \\
\hline 18 & 27.65 \\
14 & 22.53 \\
10 & 17.40 \\
\hline
\end{tabular}
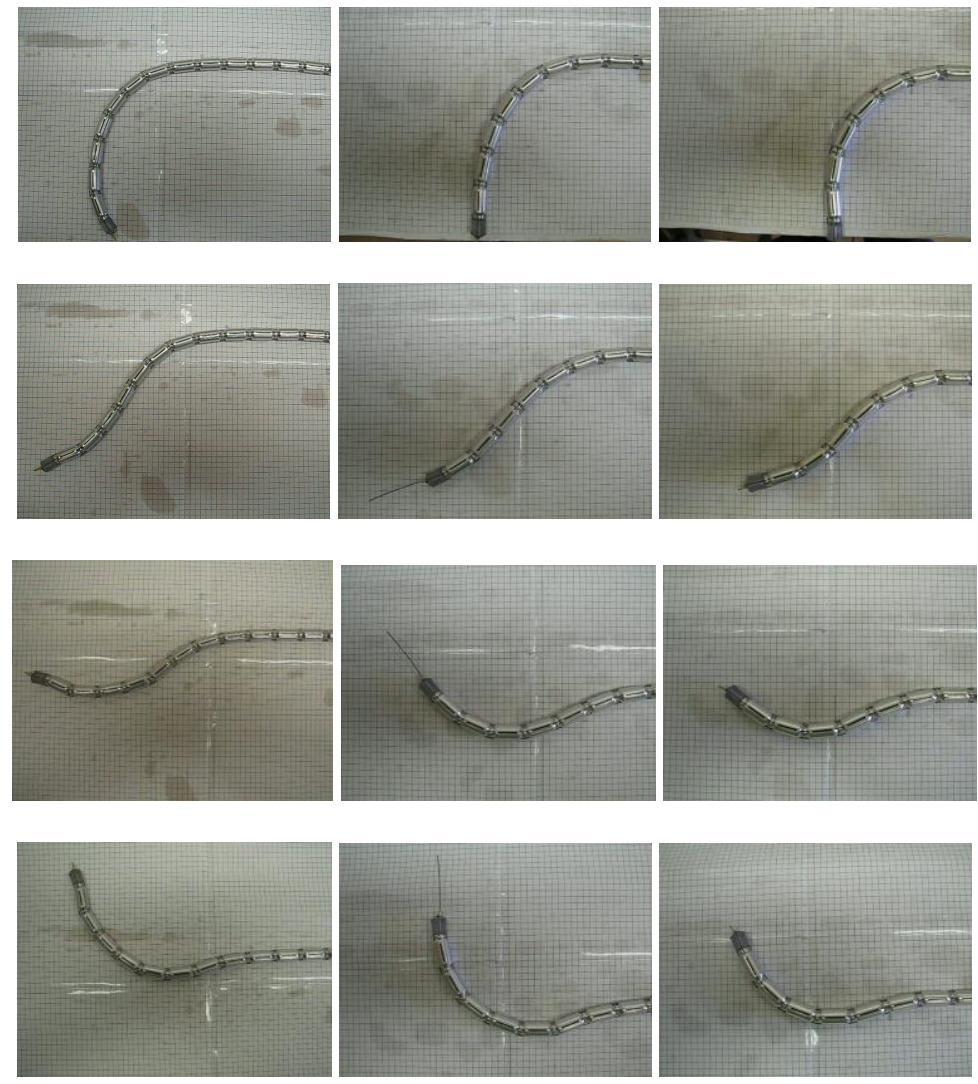

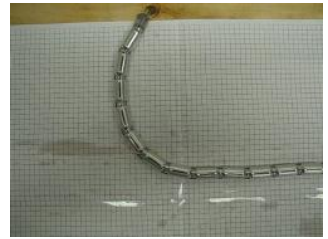

(a)

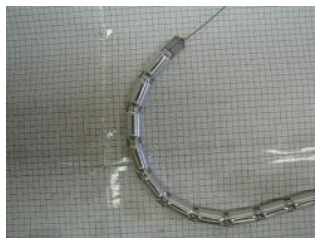

(b)

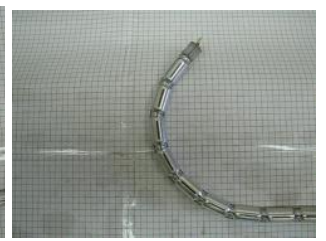

(c)

Figure 45. (a) Curvature for 18 pieces (b) Curvature for 14 pieces (c) Curvature for 10 pieces 
From Figures 45(a)-(c), it is observed that the curvature of the drive mechanism maintained a consistent pattern for all three varied lengths. Moreover, the primary bending location for all of them is the same; that is, bending primarily occurs in the final 7 pieces of the drive mechanism irrespective of the total length. The rest of the linkage pieces after that point of bending do not exhibit significant bending at all, which is a positive observation because this means that the articulation behavior of the drive mechanism is independent of the total length. This also means that the drive mechanism can be designed to better fit a patient. For instance, a shorter drive mechanism can be employed if the patient is a child, and a longer one for adult patients.

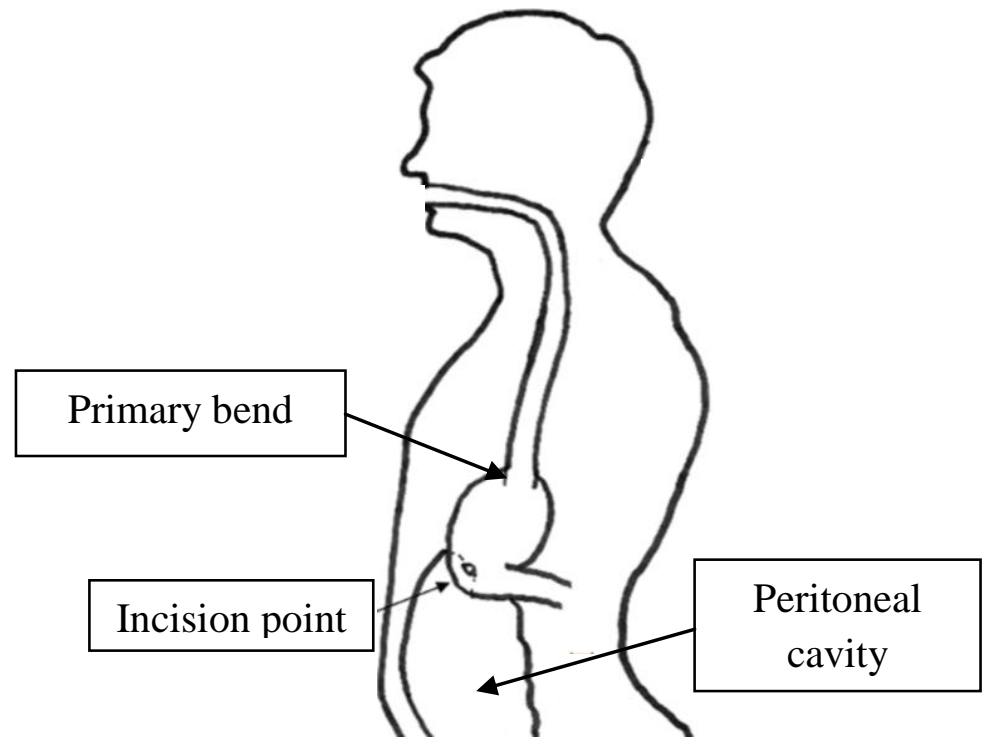

Figure 46. Location of bending of esophagus and incision point

The observation that only the distal portion of the drive mechanism exhibits bending is also ideal because this shows that the drive mechanism has superior steering capability. When related to an adult esophagus, such as the one shown in Figure 46, it is seen that majority of the esophagus is straight and the only primary curve is at the point 
where the esophagus meets the stomach. Since active articulation occurs only at the distal tip of the drive mechanism, the drive mechanism can protrude out into the peritoneal cavity through the incision point and be actuated without displacing surrounding organs or cause unnecessary harm to the esophagus. Based on the behavior of the drive mechanism during bench-top trials, the portion after the primary bending point remains largely straight and will conform to the shape of the esophagus.

\section{Articulation of Drive Mechanism with Varied Motor Velocity}

A small series of experiments were also performed to observe the behavior of the articulation when the motor velocity is varied. The times for the articulation from extreme left to right are recorded for each motor velocity in Table 7 . The motor velocities

that were used were $200 \mathrm{rpm}, 300 \mathrm{rpm}, 400 \mathrm{rpm}, 500 \mathrm{rpm}, 600 \mathrm{rpm}, 700 \mathrm{rpm}, 800 \mathrm{rpm}$, $900 \mathrm{rpm}$, and $1000 \mathrm{rpm}$.

Table 7. Motor velocities and articulation time

\begin{tabular}{ccc}
\hline Motor Velocity [rpm] & Motor Velocity [rad/s] & Total time [s] \\
\hline 200 & 20.94 & 22 \\
300 & 31.42 & 16 \\
400 & 41.89 & 13 \\
500 & 52.36 & 12 \\
600 & 62.83 & 9 \\
700 & 73.30 & 7 \\
800 & 83.76 & 6 \\
900 & 94.25 & 5 \\
1000 & 104.72 & 4 \\
\hline
\end{tabular}

The experiments showed that the drive mechanism exhibited the same behavior in curvature even when the motor velocity was increased. Therefore articulation behavior is independent of motor velocity. However, when run at $200 \mathrm{rpm}$, the articulation sequence 
took almost 22 seconds, whereas at $600 \mathrm{rpm}$, the time taken was 9 seconds. At $1000 \mathrm{rpm}$ the time of 4 seconds was recorded. Based on the observations, the best velocity to run the motor is at the range of $600 \mathrm{rpm}$ to $800 \mathrm{rpm}$ because the times recorded (6 to 9 seconds) are the best, especially when the factor of patient safety is considered. The articulation motions at $1000 \mathrm{rpm}$ seem to be too forceful at times. 


\section{Chapter 7. Curvature Function}

It is observed from the bench top tests that the curvature of the drive mechanism is independent of length and motor velocity. Therefore, it is of interest to obtain a mathematical function for the curvature, which could prove to be a useful tool for determining the behavior of other snake-like robotic mechanisms, especially those using sequential spherical joints.

The same series of still shots from the articulation motion in Figure 44 are used to obtain the functions. The $\mathrm{x}$ and $\mathrm{y}$ Cartesian coordinates are easily obtained and plotted using Microsoft Excel ${ }^{\circledR}$. The positions of the drive mechanism used for determining the curvature functions include the initial and final positions with four intermediate positions. The four intermediate positions are shown to be good $5^{\text {th }}$ order polynomial functions, but the initial and final positions do not have a good fit with any basis function. Figure 47 shows the Cartesian plot of six positions used for the curvature functions. 


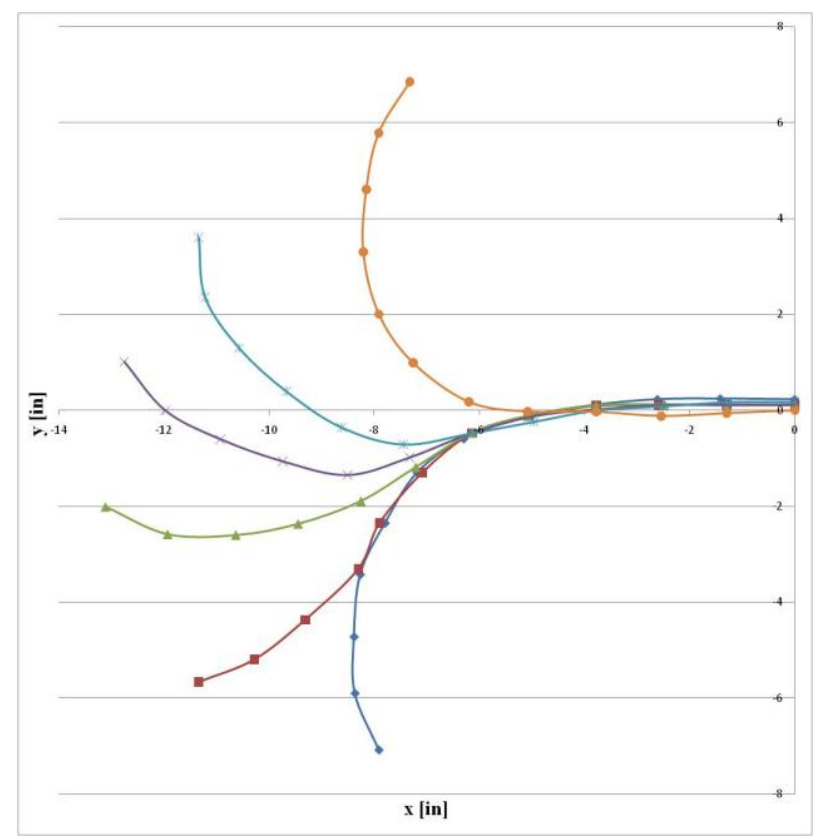

\section{Figure 47. Cartesian coordinates of six positions of drive mechanism}

The curvature of the drive mechanism can be obtained by another way which is the finite-difference method [39]. A forward difference is expressed in the form of (10) and the second order central difference is expressed as (11).

$$
\begin{gathered}
f^{\prime}(x) \approx \frac{f(x+h)-f(x)}{h} \\
f^{\prime \prime}(x) \approx \frac{f(x+h)-2 f(x)+f(x-1)}{h^{2}}
\end{gathered}
$$

The curve of the drive mechanism is discretized with constant intervals of value $h$, set at 0.295 inches based on the grid size. The coordinates of the points are obtained by manually measuring with the aid of a grid. In some cases, the frame of reference is rotated and moved to fit the curve of the drive mechanism to avoid singularities in the derivative values and ensure the $2^{\text {nd }}$ order finite difference formula produces reasonable 
results. Figure 48 shows the drive mechanism with a frame of reference, the portion highlighted in yellow is the curve used for the finite difference method.

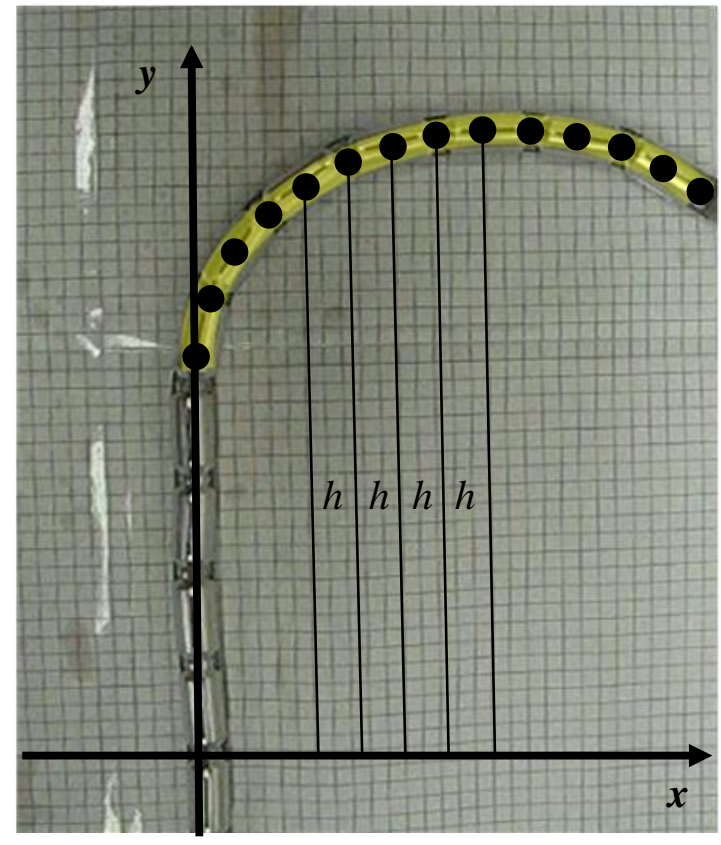

Figure 48. Discretized curve for finite-difference method with constant interval $h$.

For plane motion where the curve is described in $\underline{x y}$ coordinates by $\mathrm{y}=\mathrm{f}(\mathrm{x})$, the expression for curvature is shown as (12) [40], where $\rho$ is radius of curvature.

$$
\frac{1}{\rho}=\frac{\left|d^{2} y / d x^{2}\right|}{\left(1+(d y / d x)^{2}\right)^{3 / 2}}
$$

The coordinates of all the points are input into Matlab® and a polynomial curve fit is performed to get a smooth curvature. The first and second order finite-difference are then obtained. Plugging the values into (12), the radius of curvature in relation to the shape of the drive mechanism (x positions) and the curvature are plotted. Figures 49-53 show the relationship between the shape of the drive mechanism and the radius of 
curvature transitioning from its initial position (extreme left) to final position (extreme right).
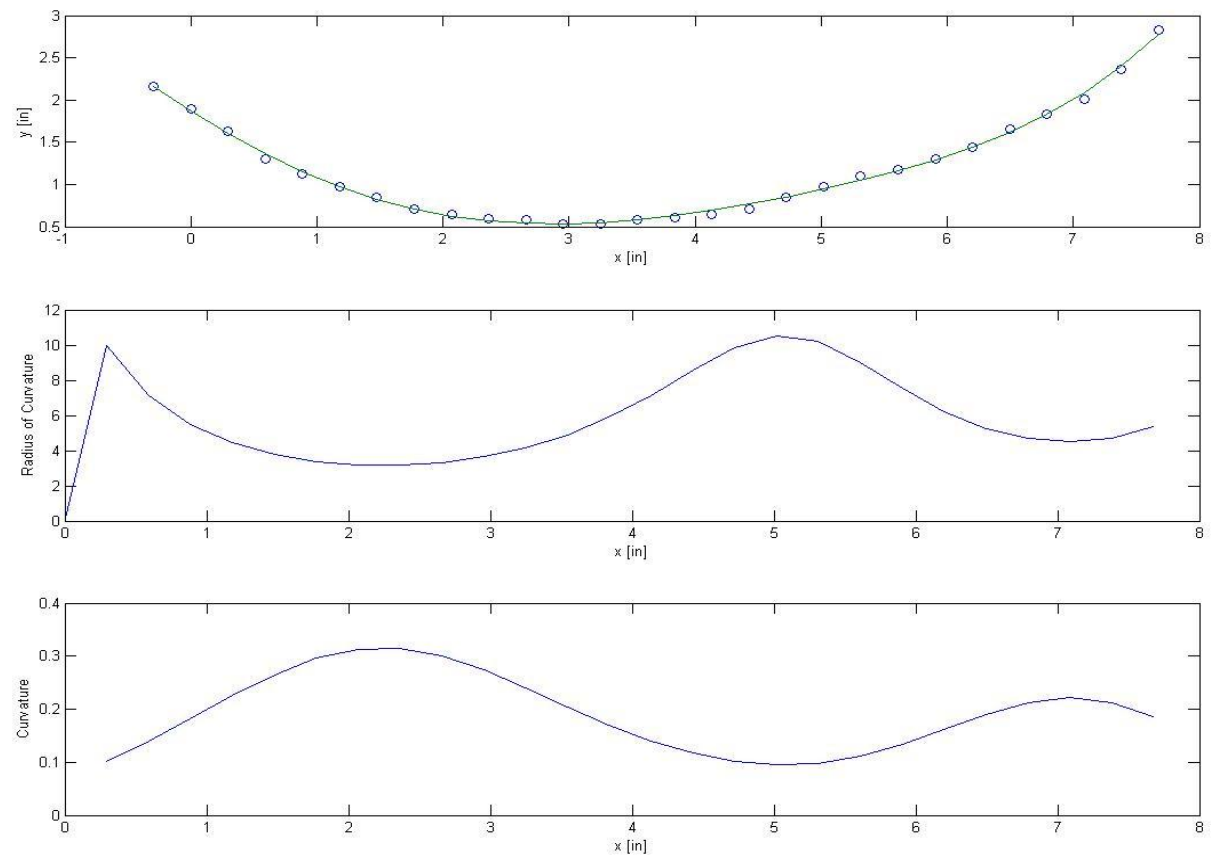

\section{Figure 49. Plots of xy coordinates, radius of curvature, and curvature for drive mechanism in initial position}

The plot at the top of Figure 49 is the shape of the drive mechanism, where the measured points are shown in blue circles and the polyfit points are shown in green. It is observed from the radius of curvature plot that the radius of curvature started off with a relatively large value before gradually becoming smaller. This means that there is not much articulation near the base of the drive mechanism. However, there is a bump in the radius of curvature after that which can be explained as a slightly flatter portion of the curve. The most important feature of the plot is that the tip of the drive mechanism has a low radius of curvature, which is desirable. 

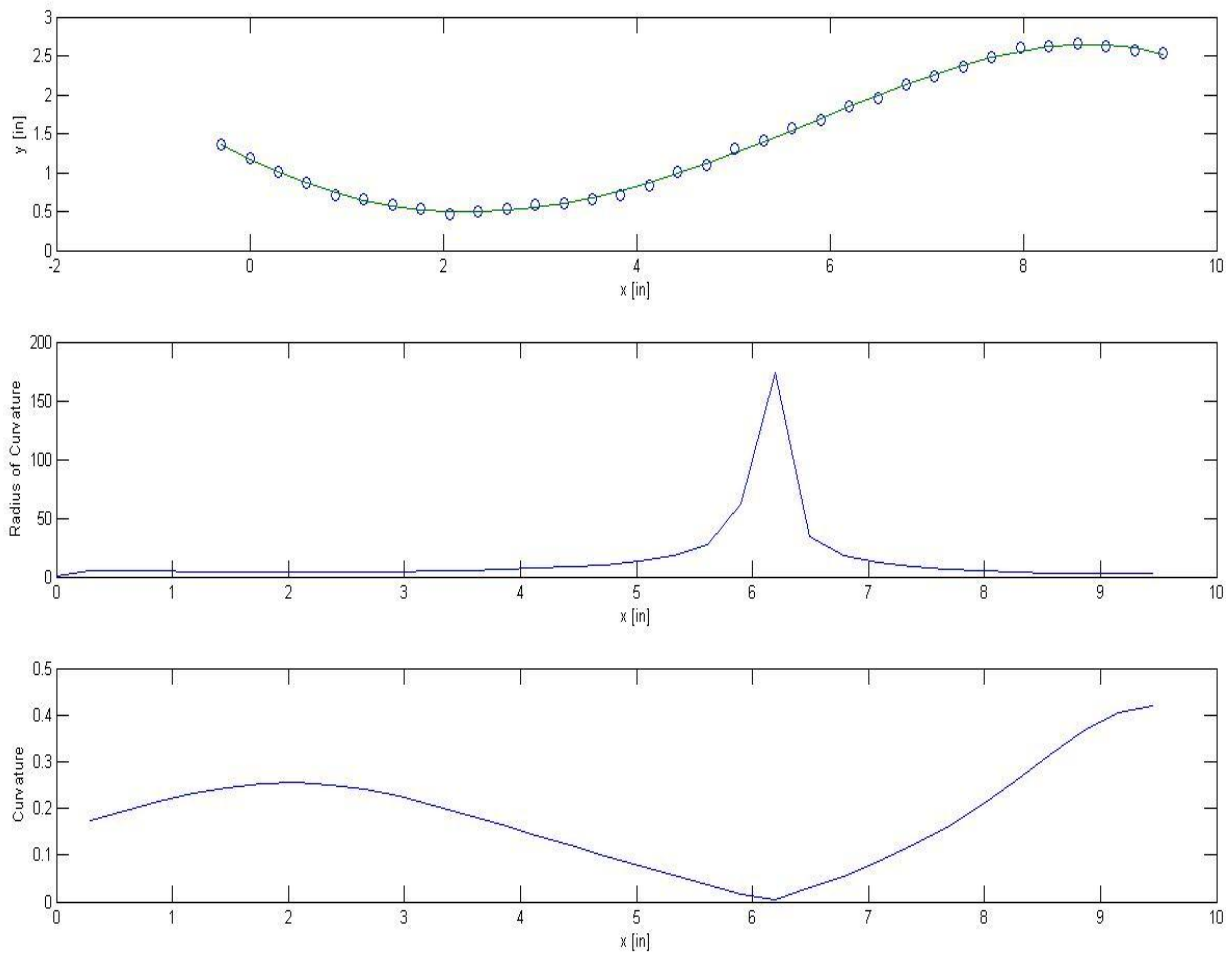

Figure 50. Plots of xy coordinates, radius of curvature, and curvature for drive mechanism in second position

Figure 50 shows the same series of plots for the drive mechanism in the second position. The radius of curvature is generally low in this position, until it reaches the inflection point in the curve of the drive mechanism where it peaks. It is important to note again that the radius of curvature is low towards the tip of the drive mechanism. 

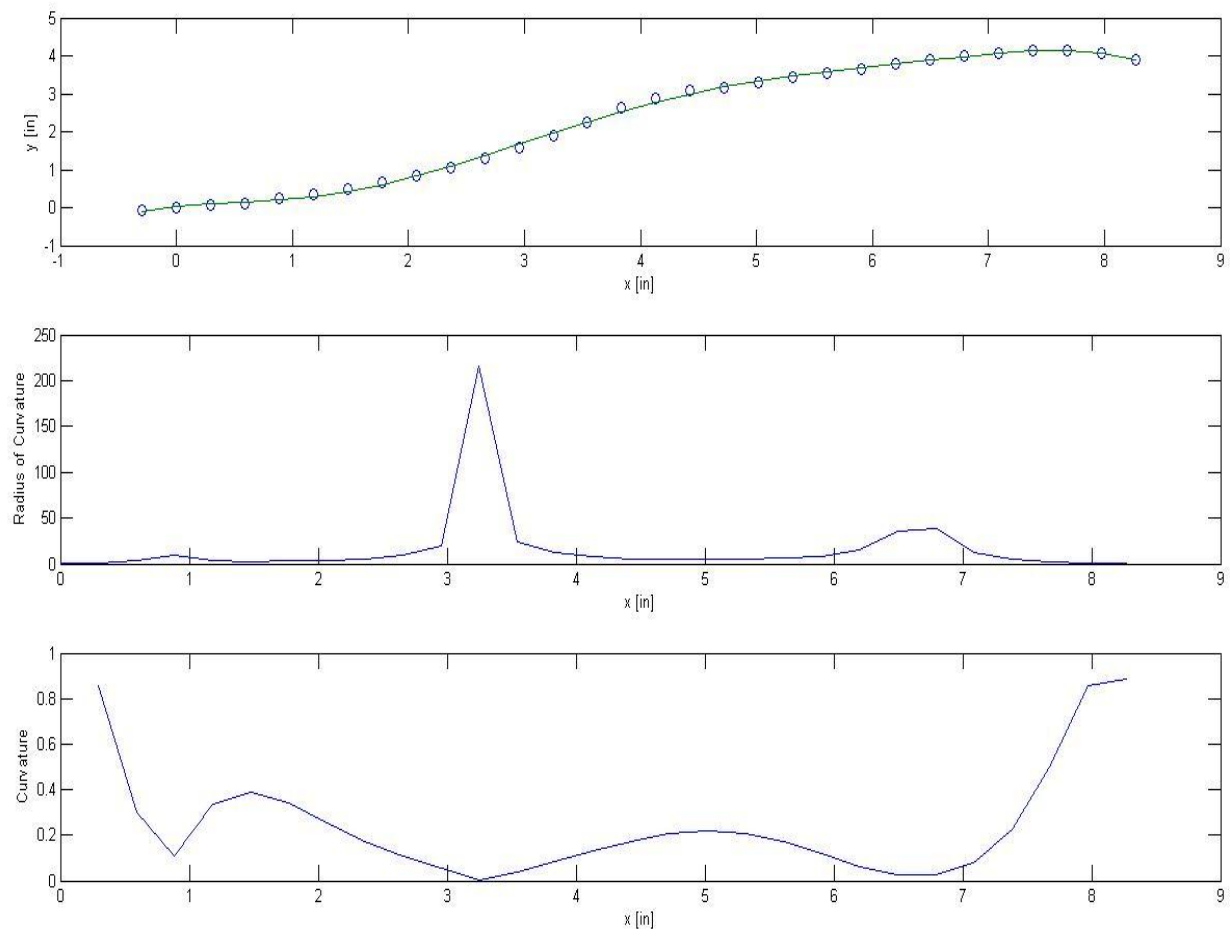

\section{Figure 51. Plots of $x y$ coordinates, radius of curvature, and curvature of drive mechanism in third position}

Figure 51 shows the drive mechanism in a position further transitioning towards the extreme right. Similarly, the peaks and bumps in the radius of curvature plot correspond to inflection points and flatter areas in the linkage curve. It is again observed that the drive mechanism has a tighter curve nearer to the tip, as shown by the low values of radius of curvature. 

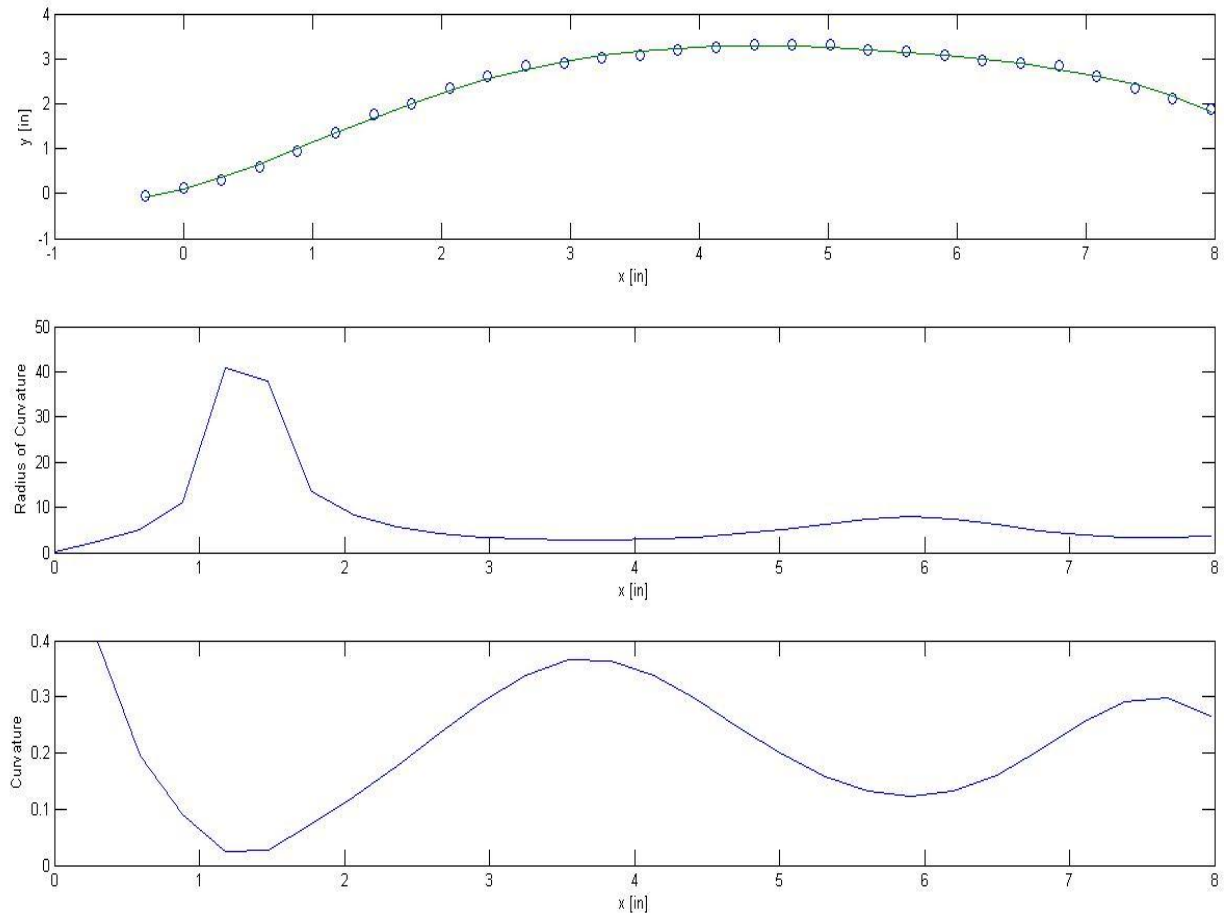

Figure 52. Plots of xy coordinates, radius of curvature, and curvature of drive mechanism in fourth position

Similarly, Figure 52 shows the drive mechanism approaching the final position that is at the extreme right. The radius of curvature plot shows a similar relationship as previous plots except that the peaks are lower because there are less obvious inflection points in the drive mechanism. Generally the radius of curvature is relatively low towards the distal end of the drive mechanism. 

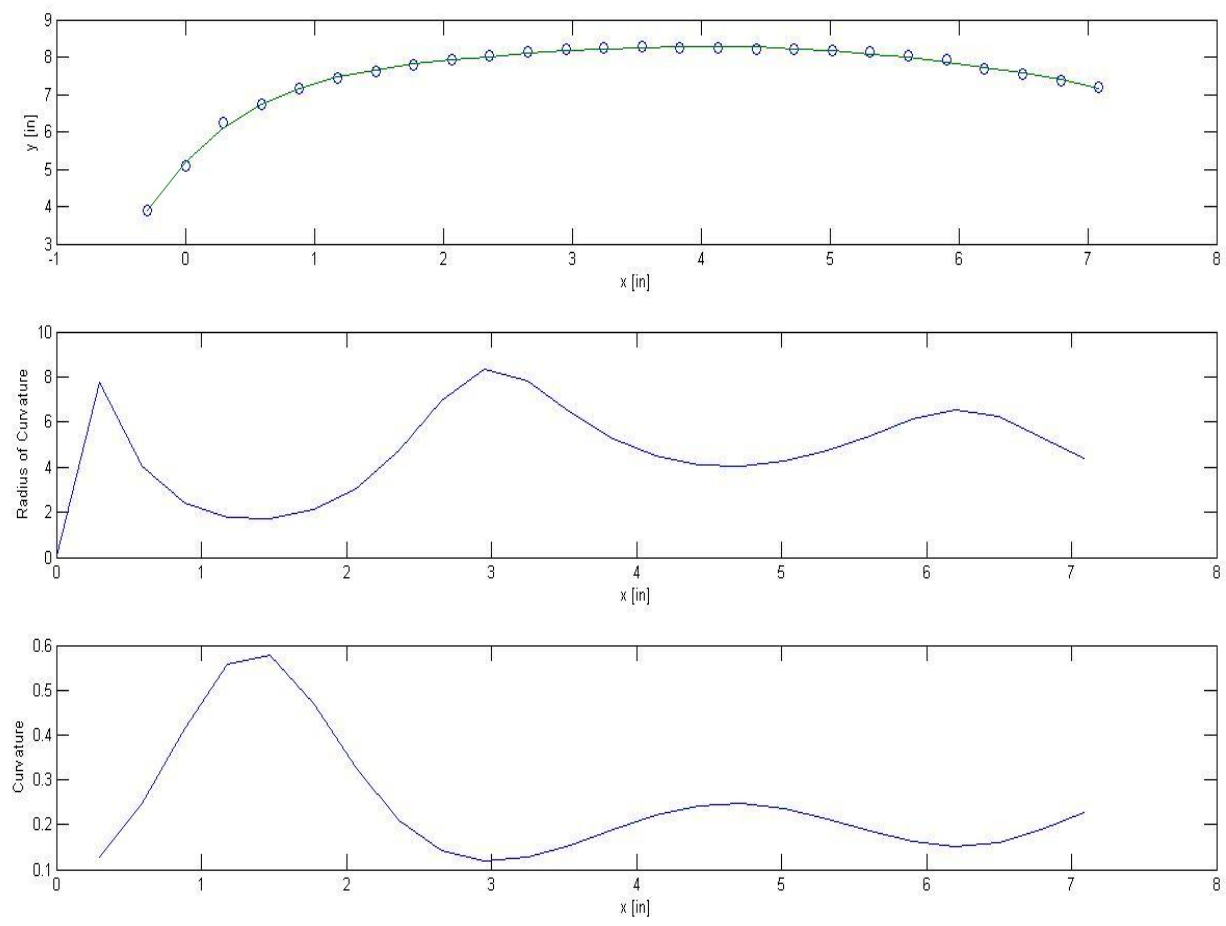

\section{Figure 53. Plots of $x y$ coordinates, radius of curvature, and curvature of drive mechanism in its final position}

Finally, Figure 53 shows the drive mechanism in its final position at extreme right. Since this position is basically the inverse of the initial position, the radius of curvature is expected to be similar in terms of behavior and magnitude. The plot in Figure 53 shows that this is indeed true.

The drive mechanism shows a tighter curve and hence a lower radius of curvature at the distal end in all of the positions explored. This consistency is important because it supports the bench top observations that active articulation only occurs near the distal end which gives the drive mechanism good control and positioning ability. The same analysis is done for the upward articulation as well. 
For the upward articulation, a snapshot of the drive mechanism at its most extreme position where it curves around itself is used to analyze the curvature. Since the curve of the drive mechanism during upward articulation is essentially the same throughout the motion, only the final position is used to obtain the radius of curvature because of its unusual shape.

The curvature of the drive mechanism has to be split into two portions and analyzed separately for the finite-difference method to work properly (again for avoidance of singularities in the derivative values). Similarly, the $\mathrm{x}$ and $\mathrm{y}$ Cartesian coordinates are obtained and a polyfit is done to get a smooth curve using Matlab® for each portion of the curve. Figure 54 shows the two separated portions.

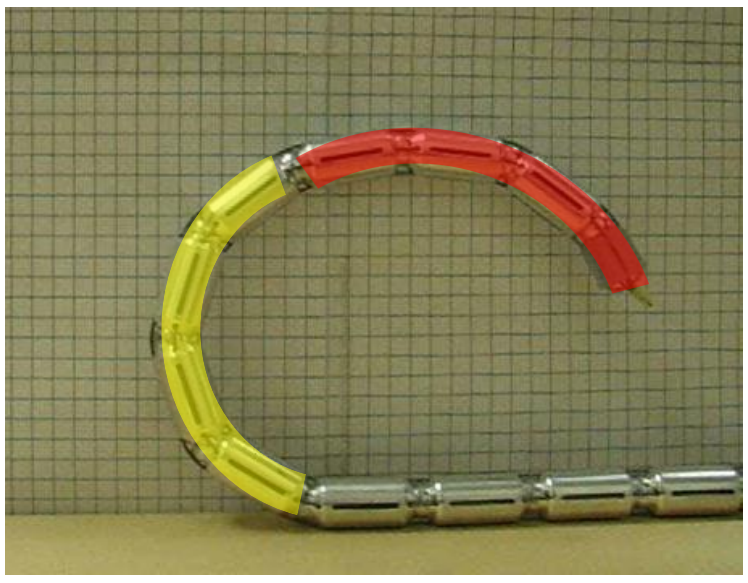

Figure 54. Curve of drive mechanism separated into two portions (yellow and red) for finite-difference method 

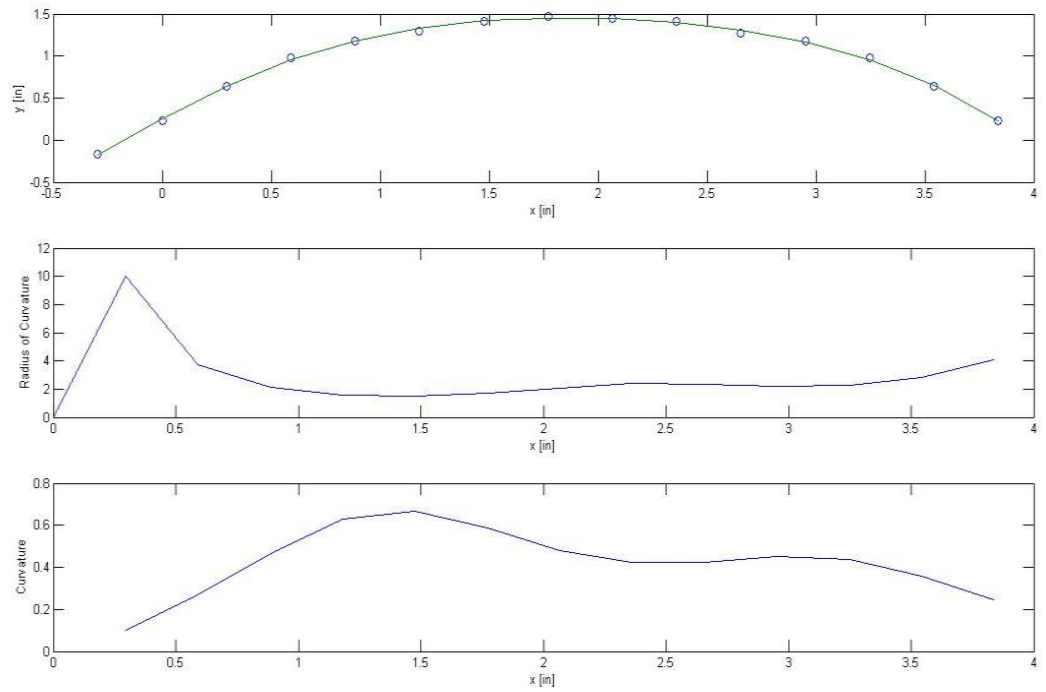

Figure 55. Plots of $x y$ coordinates, radius of curvature, and curvature for the first portion of upward articulation

Figure 55 shows the results for first portion of the drive mechanism, previously depicted in yellow in Figure 54. The radius of curvature remains quite consistent throughout the portion of the curve before slightly increasing towards the end.
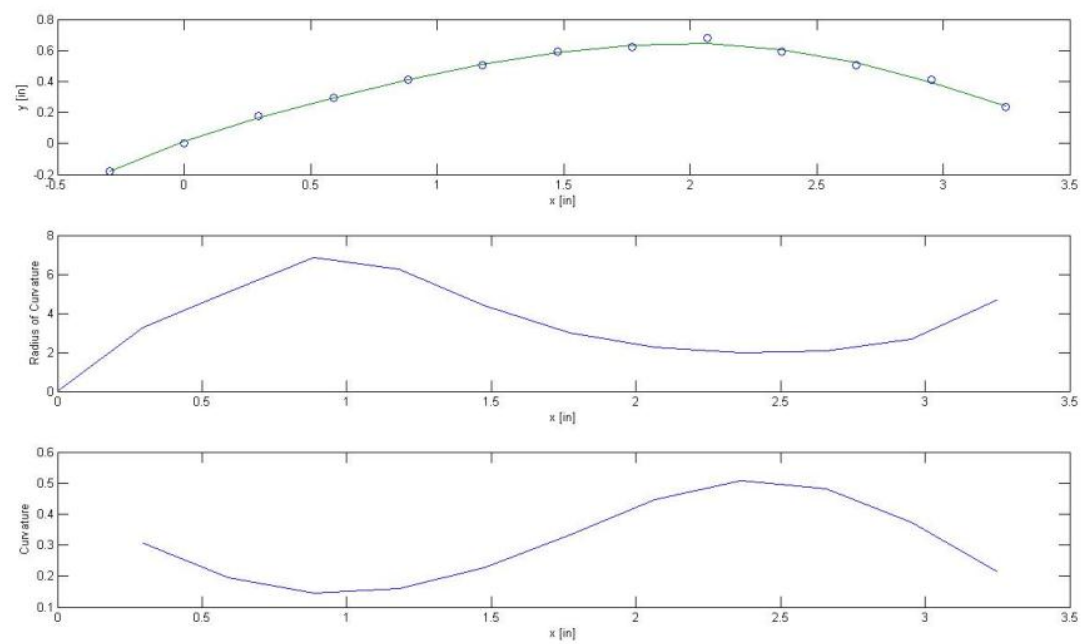

Figure 56. Plots of xy coordinates, radius of curvature, and curvature for the second portion of upward articulation 
Figure 56 shows the second portion, shown in red in Figure 54. The radius of curvature is slightly larger than the first portion, especially at the beginning which corresponds to the increase in radius in the previous portion, before getting lower towards the distal end. Overall, the curvature of the drive mechanism in this position can be summarized as having a tighter curve nearer to the proximal end, and then transitioning to a larger radius of curvature before returning to a smaller radius of curvature at the distal tip. This behavior is different compared to the left/right articulation whereby the curvature nearer to the proximal end is generally small (large radius of curvature) and it can be explained by the fact that when the drive mechanism curves back around itself, the curve of the first portion gets smaller and tighter due to the weight of the linkage pieces in the second portion.

An animation of the changes of curvature with respect to time has been made using Matlab® to better illustrate the behavior of the drive mechanism. 


\section{Chapter 8. Summary and Conclusion}

This thesis presents the design and analysis of an articulating drive mechanism for a natural orifice translumenal endoscopic surgery robot. Although the first generation of the linkage piece possesses limitations in size, the design has been proven to be successful in functionality and is used as a standard for the second iteration. The second generation of the linkage piece improves on the previous design by drastically reducing in dimensions without compromising functionality. Three generations of the motor housing are also presented. Each generation improves upon the previous with better space management, easier assembly process, and most importantly, superior maneuverability and repeatability. An added translational degree of freedom to the drive mechanism provides the robot with the ability to reach deeper into the peritoneal cavity for surgical purposes.

Kinematic and force analysis are presented also to verify the capabilities of the articulated drive mechanism. The theoretical workspace generated using Matlab® shows that the drive mechanism has great reachability, especially with the added translational degree of freedom. Bench-top trials are performed to verify the theoretical findings and the results observed are satisfactory although not entirely matching. Also, observations from bench-top trials show the importance of lubrication of the linkage pieces for consistent behavior and curvature of the drive mechanism. It is also observed from bench-top tests that the curvature is independent of both the total length of the drive mechanism and motor velocity. Finally a mathematical function of the curvature is 
obtained using Matlab®. This could prove to be useful for the design of similar snakelike robots.

Further work must be done to validate the NOTES robotic system, for instance by implementing it in non-survival porcine surgeries. More work has to be done on the surgeon control console so that surgeons can intuitively actuate the drive mechanism. Other concerns that require attention include making the drive mechanism more robust as to withstand repeated usage, simpler assembly methods, biocompatible lubrication, and utilizing a suitable overtube for insertion of the drive mechanism. In the analysis of the drive mechanism, since the linkage pieces have to be lubricated for them to articulate properly, a more accurate coefficient of friction is needed to obtain the true tension in the central cable. Also, further bench-top trials need to be run with the robotic manipulator attached at the distal end of the articulated drive mechanism.

Although a number of issues remain to be solved, the articulated drive mechanism could prove to be an essential component in all NOTES approaches, making NOTES a more feasible surgical method and replacing MIS and LESS as the surgical standard. 


\section{References}

[1] Giday, S.A., Kantsevoy, S.V., Kalloo, A.N. 2006. Principle and history of natural orifice translumenal endoscopic surgery (NOTES). Minimally Invasive Therapy, 15(6): 373-377.

[2] Kim, V.B., Chapman, W.H., Albrecht, R.J., Bailey, B.M., Young, J.A., et al. 2002. Early experience with telemanipulative robot-assisted laparoscopic cholecystectomy using da Vinci. Surgical Laparoscopy, Endoscopy \& Percutaneous Techniques, 12(1): 33-40.

[3] Tracy, C.R., Raman, J.D., Cadeddu, J.A., Rane, A. 2008. Laparoendoscopic singlesite surgery in urology: where have we been and where are we heading? Nature Clinical Practice Urology, 5(1): 561-568.

[4] ASGE and SAGES. 2006. ASGE/SAGES working group on natural orifice translumenal endoscopic surgery, white paper October 2005. Gastrointestinal Endoscopy, 63(2): 199-203.

[5] Kalloo, A.N., Sing, V.K., Jagannath, S.B., et al. 2004. Flexible transgastric peritoneoscopy: a novel approach to diagnostic and therapeutic interventions in the peritoneal cavity. Gastrointestinal Endoscopy, 60(1): 114-117.

[6] Jagannath, S.B., Kantsevoy, S.V., Vaughn, C.A., Chung, S.S., et al. 2005. Peroral transgastric endoscopic ligation of fallopian tubes with long-term survival in a porcine model. Gastrointestinal Endoscopy, 61(3): 449-453.

[7] Kantsevoy, S.V., Jagannath, S.B., Niiyama, H., Chung, S.S., et al. 2005. Endoscopic gastrojejunostomy with survival in a porcine model. Gastrointestinal Endoscopy, 62(2): 287-292.

[8] Park, P.O., Bergstrom, M., Ikeda, K., Fritscher-Ravens, A., et al. 2005. Experimental studies of transgastric gallbladder surgery: cholecystectomy and cholecystogastric anastomosis (videos). Gastrointestinal Endoscopy, 61(4): 601606.

[9] Merrifield, B.F., Wagh, M.S., Thompson, C.C. 2006. Peroral transgastric organ resection: a feasibility study in pigs. Gastrointestinal Endoscopy, 63(4): 693-697.

[10] Rao, G.V., Reddy, D.N., Banerjee, R. 2008. NOTES: human experience. Gastrointestinal Endoscopy Clinics of North America, 18(2): 361-370. 
[11] USGI Medical. 2007. USGI announces first NOTES transgastric cholecystectomy $\begin{array}{llll}\text { procedures. } & \text { Retrieved } & \text { 8/15/2010 }\end{array}$ http://www.usgimedical.com/news/releases/062507.htm.

[12] Jacobs, L.K., Shayani, V., Sackier, J.M. 1997. Determination of the learning curve of the AESOP robot. Surgical Endoscopy, 11(1): 54-55.

[13] Ballantyne, G.H. 2002. Robotic surgery, telerobotic surgery, telepresence, and telementoring. Review of early clinical results. Surgical Endoscopy, 16(10): 13891402 .

[14] Corcione, F., Esposito, C., Cuccurullo, D., Settembre, A., et al. 2005. Advantages and limits of robotassisted laparoscopic surgery: preliminary experience. Surgical Endoscopy, 19(1): 117-119.

[15] Satava, R.M. 2002. Surgical robotics: the early chronicles. A personal historical perspective. Surgical Laparoscopy, Endoscopy, and Percutaneous Techniques, 12(1): 6-16.

[16] Simaan, N., Xu, K., Wei, W., Kapoor, A., Kazanzides, P., Taylor, R., Flint, P. 2009. Design and integration of a telerobotic system for minimally invasive surgery of the throat. The International Journal of Robotics Research, 28(9): 1134-1153.

[17] Guthart, G., Salisbury, K. 2000. The Intuitive ${ }^{\mathrm{TM}}$ telesurgery system: overview and application. In Proceedings of IEEE International Conference on Robotics and Automation, San Francisco, CA, 618-621.

[18] Faraz, A., Payandeh, S., Nagy, A.G. 1995. Issues and design concepts in endoscopic extenders. In Proceedings of $6^{\text {th }}$ IFAC Man-Machine Systems, MIT, 109-114.

[19] Simaan, N., Taylor, R., Flint, P. 2004. High dexterity snake-like robotic slaves for minimally invasive telesurgery of the upper airway. In Proceedings of Medical Image Computing and Computer-Assisted Intervention (2), 17-24.

[20] Reynaerts, D., Peirs, J., Van Brussel, H. 1999. Shape memory micro-actuation for a gastro-intestinal intervention system. Sensors and Actuators, 77(2): 157-166.

[21] Haga, Y., Matsunaga, T., Makishi, W., Totsu, K., Mineta, T., Esashi, M. 2006. Minimally invasive diagnostics and treatment using micro/nano machining. Minimally Invasive Therapy,15(4): 218-225. 
[22] Peirs, J., Reynaerts, D., Van Brussel, H. 2000. Design of miniature parallel manipulators for integration in a self-propelling endoscope. Sensors and Actuators, 85(1-3): 409-417.

[23] Bardaro, S.J., Swanstrom, L. 2006. Development of advanced endoscopes for natural orifice translumenal endoscopic surgery (NOTES). Minimally Invasive Therapy, 15(6): 378-383.

[24] Swanstrom, L.L., Whiteford, M., Khajanchee, Y. 2008. Developing essential tools to enable transgastric surgery. Surgical Endoscopy, 22(3): 600-604.

[25] Mummadi, R.R., Pasricha, P.J. 2008. The eagle or the snake: platforms for NOTES and radical endoscopic therapy. Gastrointestinal Endoscopy Clinics of North America, 18(2): 279-289.

[26] Swanstrom, L.L., Khajanchee, Y., Abbas, M.A. 2008. Natural orifice translumenal endoscopic surgery: the future of gastrointestinal surgery. The Permanente Journal, 12(2): 42-47.

[27] Abbott, D.J., Becke, C., Rothstein, R.I., Peine, W.J. 2007. Design of an endoluminal NOTES robotic system. In Proceedings of 2007 IEEE/RSJ International Conference on Intelligent Robots and Systems, San Diego, CA, 410416.

[28] Ota, T., Degani, A., Schwartzman, D., Zubiate, B., McGarvey, J., Choset, H., Zenati, M.A. 2009. A highly articulated robotic surgical system for minimally invasive surgery. Annals of Thoracic Surgery, 87(4): 1253-1256.

[29] Lirici, M.M., Arezzo, A. 2006. Surgery without scars: the new frontier of minimally invasive surgery? Controversies, concerns, and expectations in advanced operative endoscopy. Minimally Invasive Therapy, 15(6): 323-324.

[30] Lehman, A., Dumpert, J., Wood, N., Redden, L., Visty, A., Farritor, S., Varnell, B., Oleynikov, D. 2009. Natural orifice cholecystectomy using a miniature robot. Surgical Endoscopy, 23(2): 260-266.

[31] McCormick, R.M., Wortman, T.D. Retrieved July 2010. Personal communication.

[32] Hiroshi Yamada. Strength of Biological Materials. 155-157.

[33] Oleynikov, D. Retrieved Oct 2009. Personal communication.

[34] Portaview-LF Tracheal Intubation Fiberscope Olympus LF-GP/TP/DP. Retrieved February 2011 from http://www.olympusamerica.com/msg_section/ 
download_brochures/DPTPGP_SalesLiterature.pdf.

[35] Faraz, A., Payandeh, S. 1997. Synthesis and workspace study of endoscopic extenders with flexible stem. Transactions of ASME Journal of Mechanical Design, 119(3): 412-414.

[36] Da Vinci Surgical Robot. Retrieved February 2011 from http://www.davincisurgery.com/. February 2011.

[37] John J. Craig. Introduction to Robotics Mechanics and Control $3^{\text {rd }}$ Edition. 101-128.

[38] Eugene A. Avallone, Theodore Baumeister III, Ali M. Sadegh. Marks' Standard Handbook for Mechanical Engineers $11^{\text {th }}$ Edition. 3-23.

[39] Michael D. Greenburg. Advanced Engineering Mathematics $2^{\text {nd }}$ Edition. 10201026.

[40] Haim Baruh. Analytical Dynamics. 8-10. 


\section{Appendix A. Drive Mechanism Design Supporting Materials}




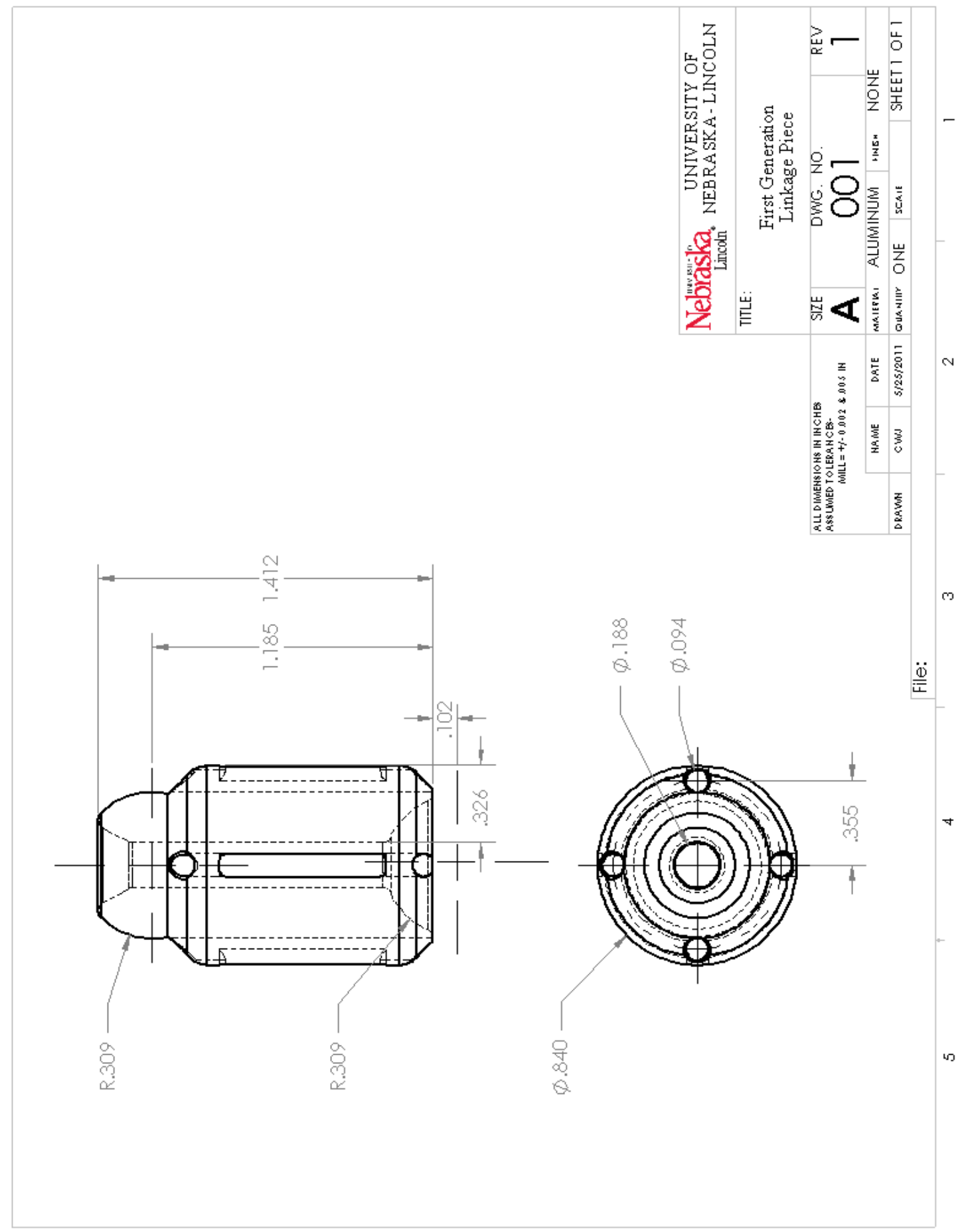



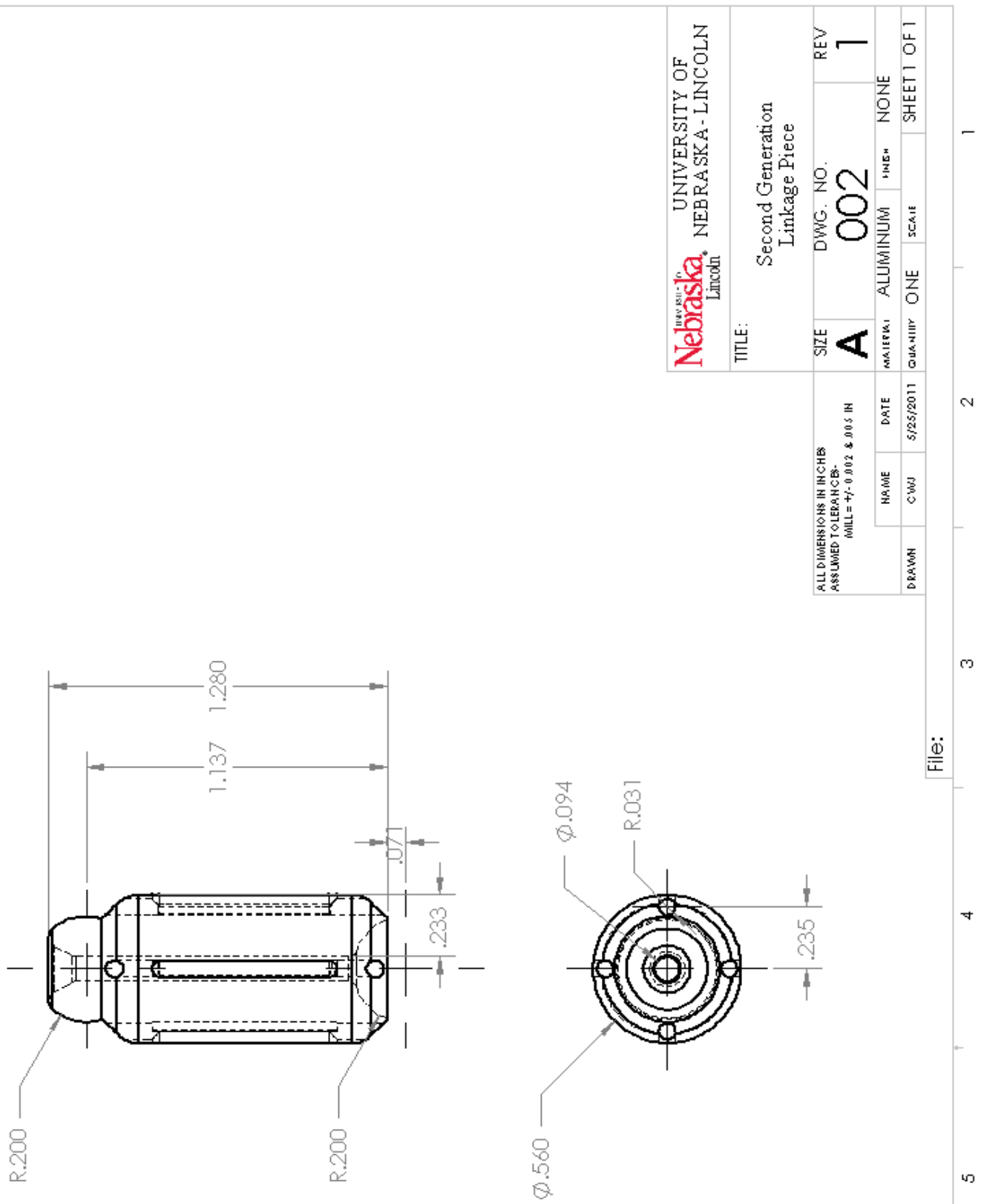


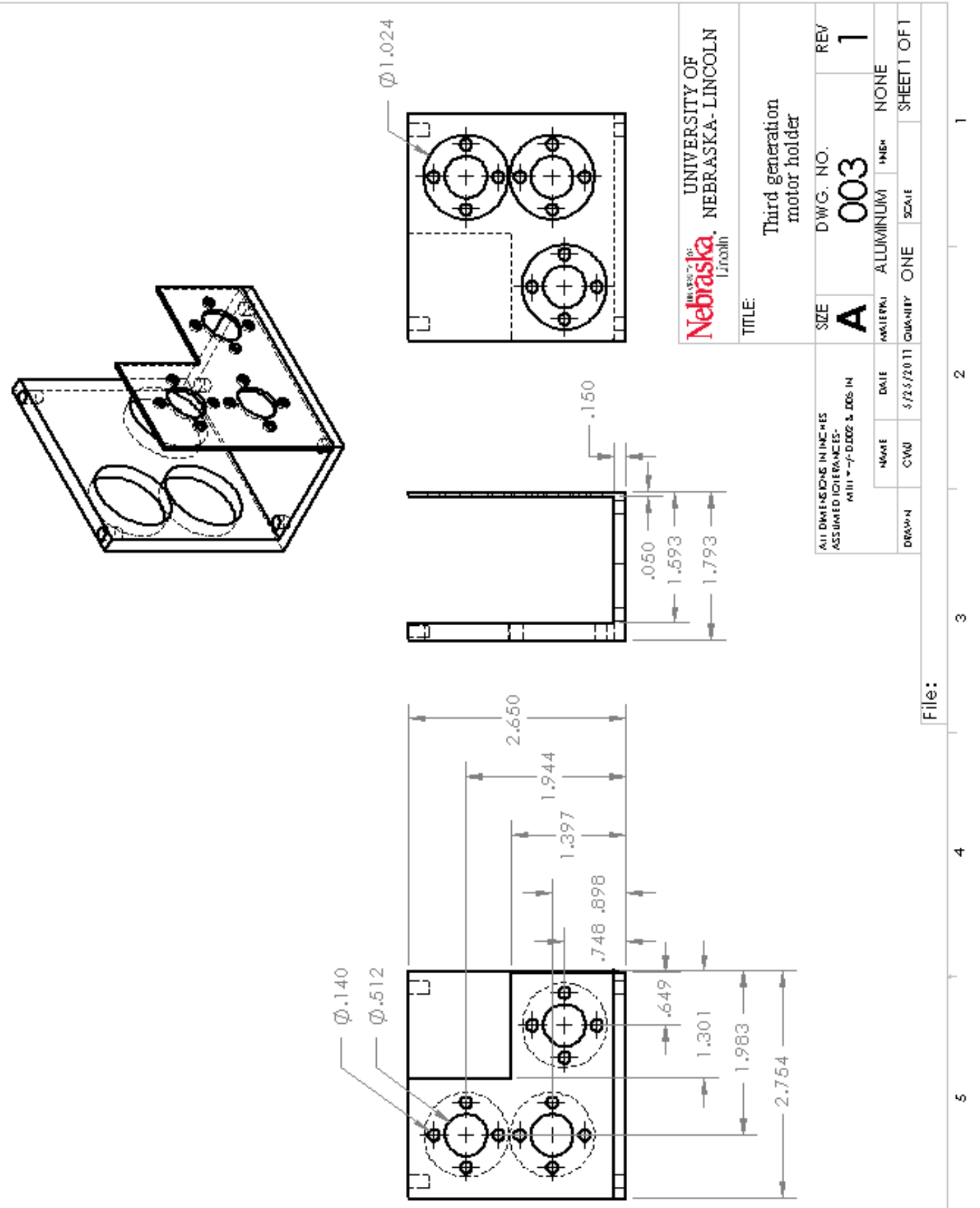



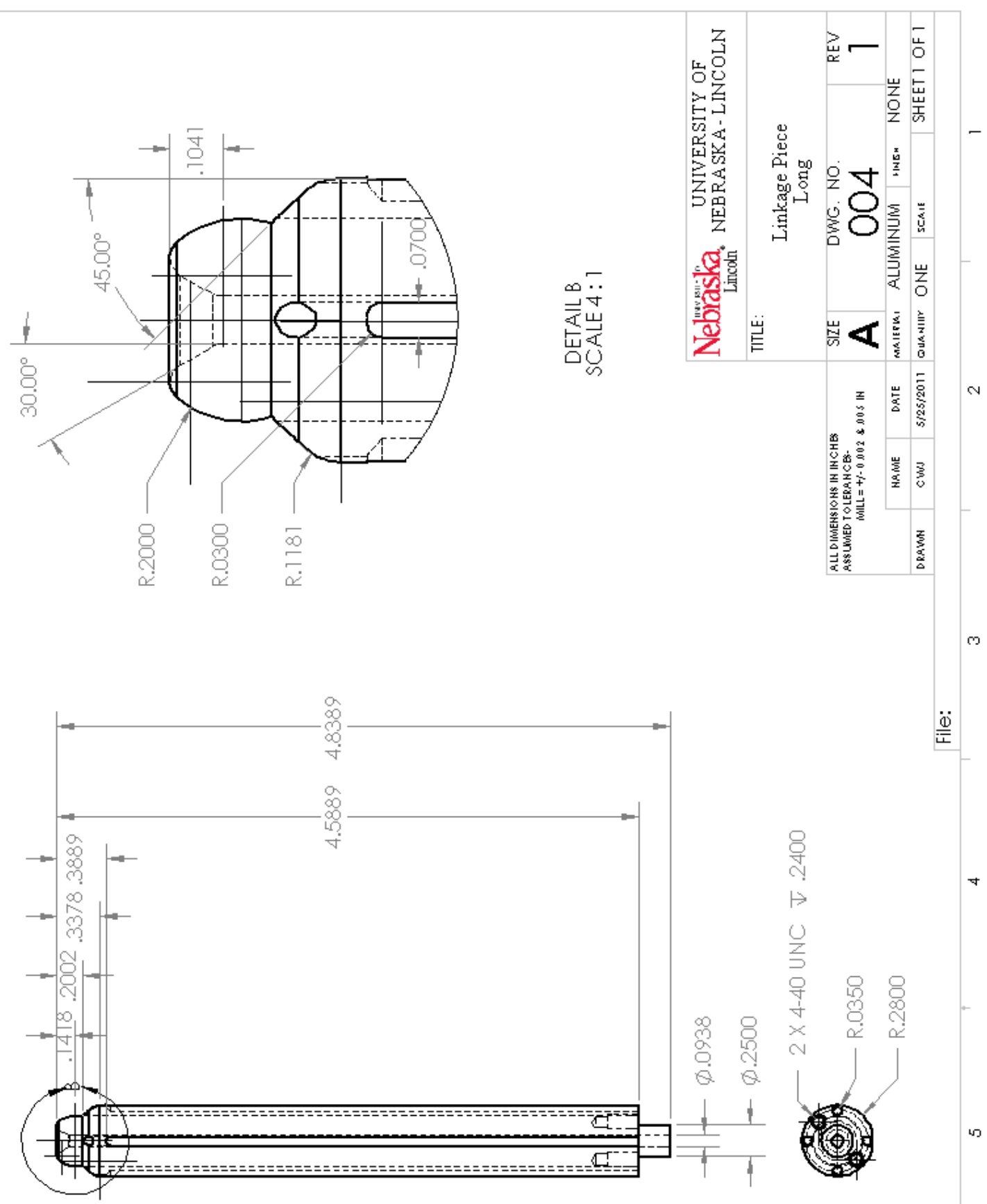


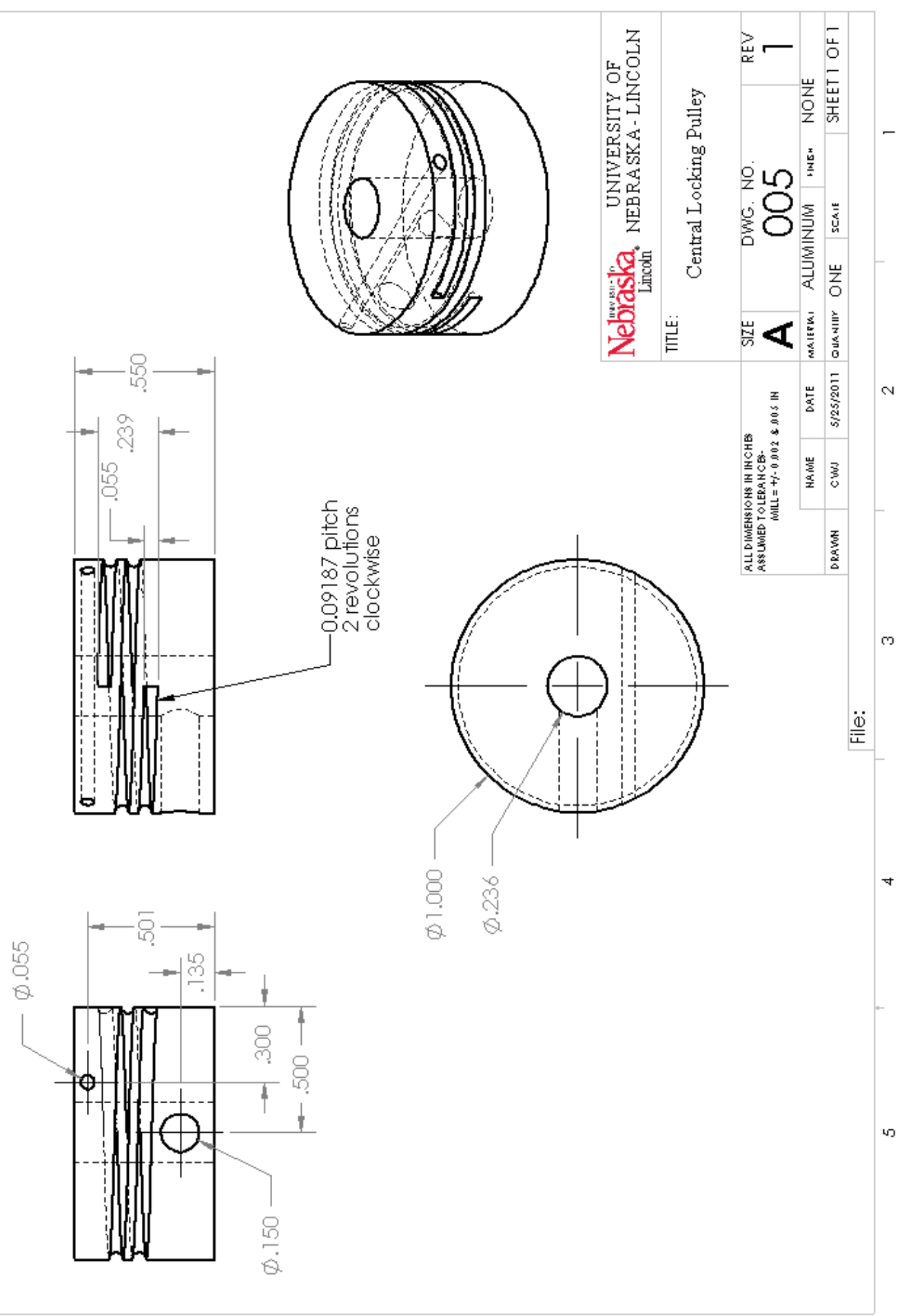




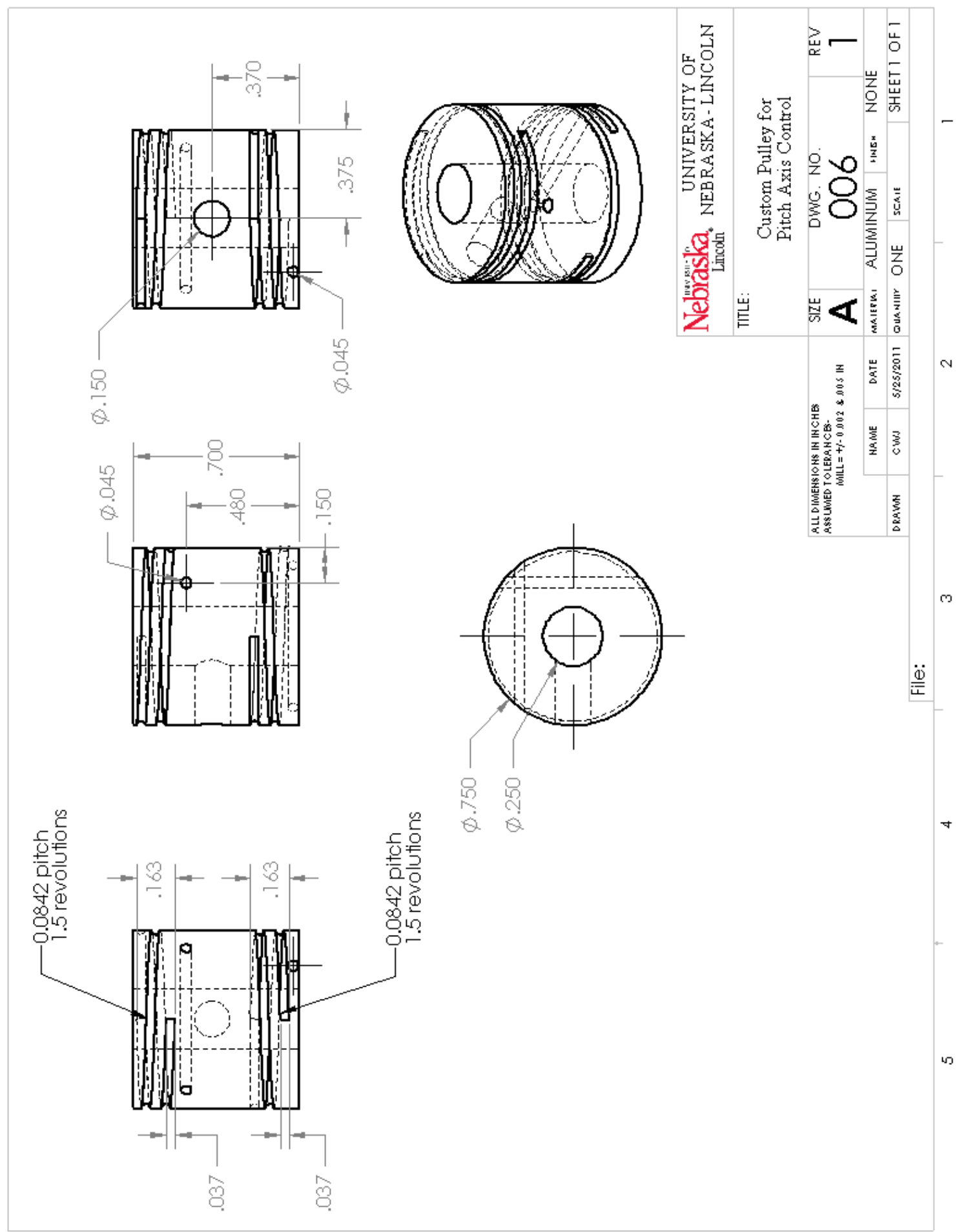




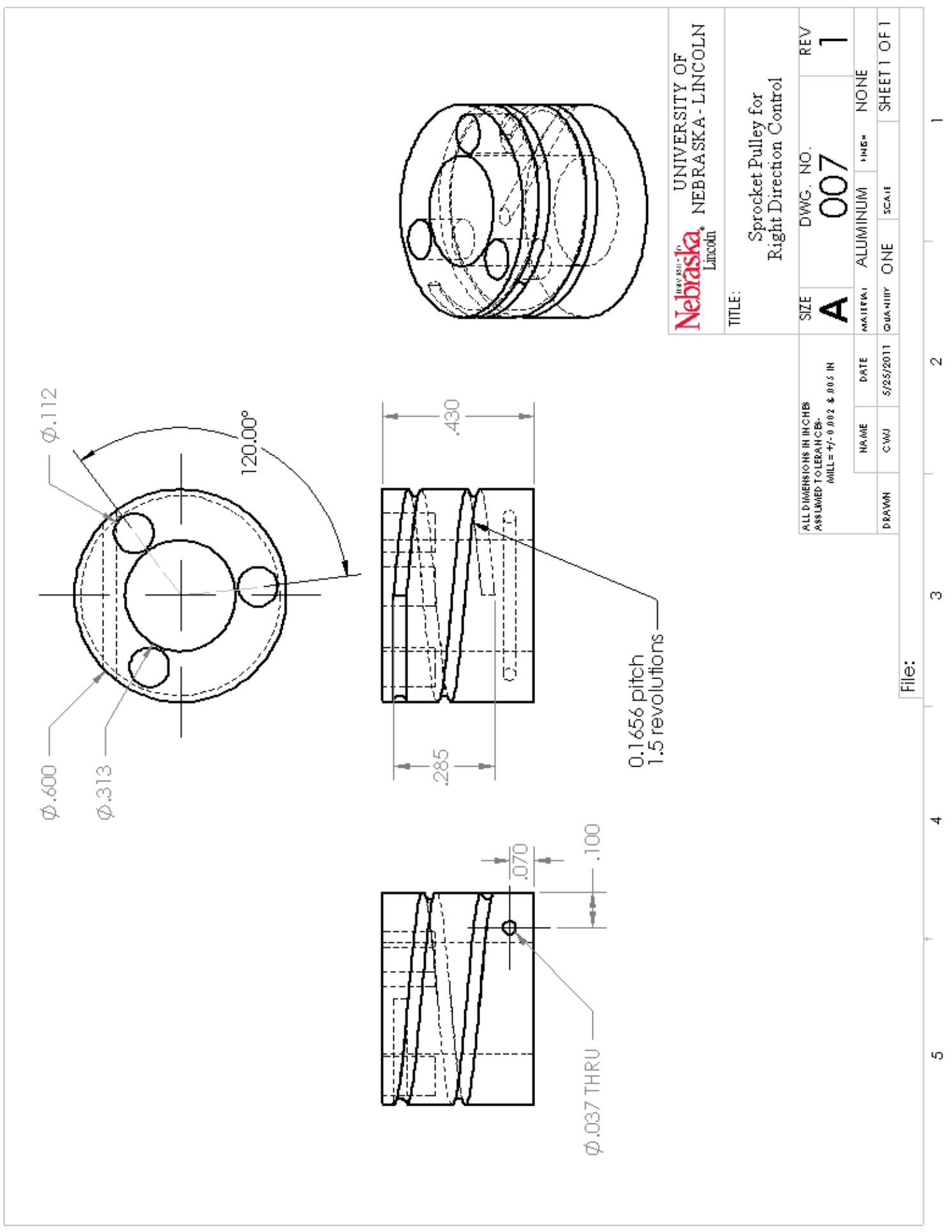




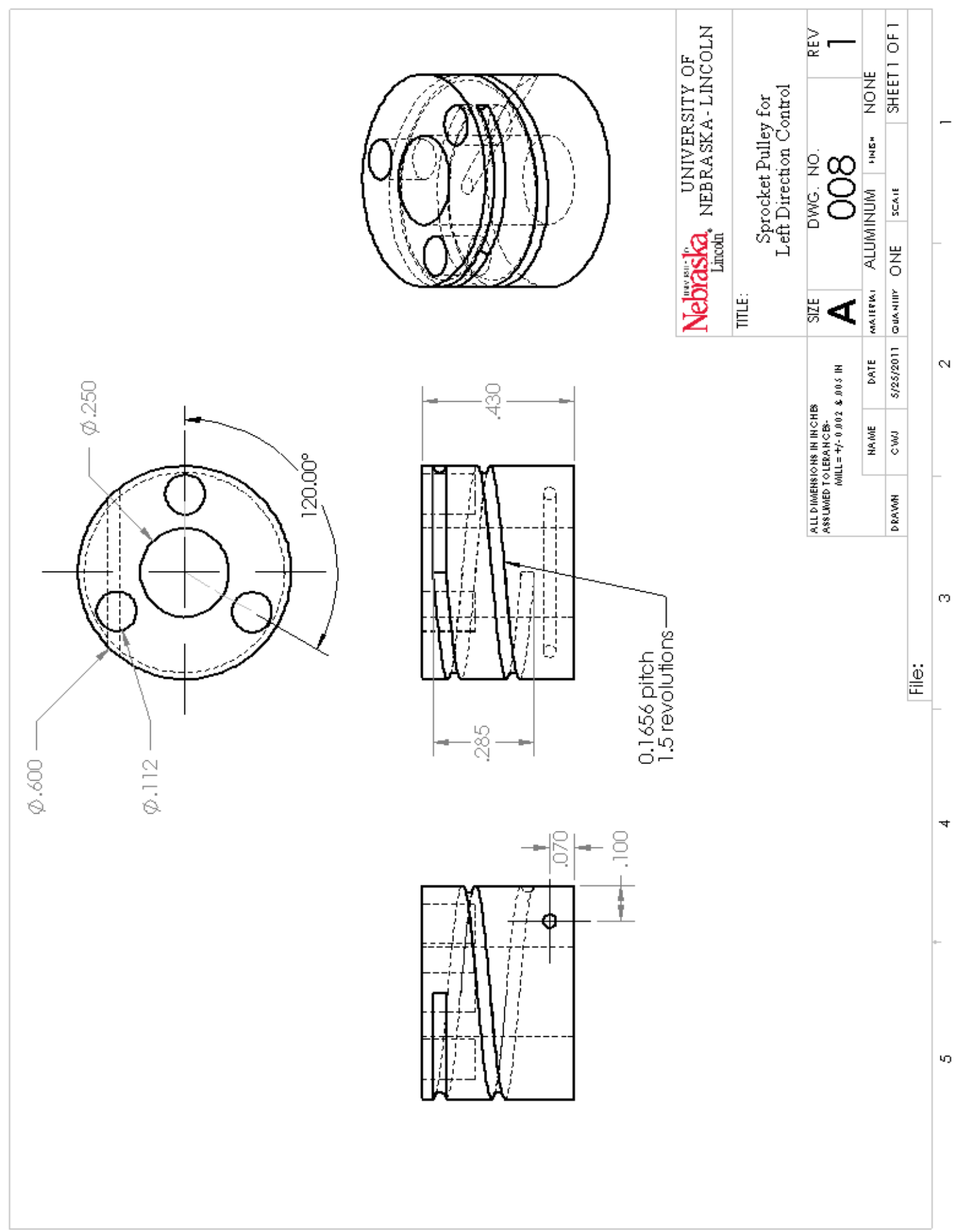




\section{Appendix B. Matlab® Workspace Codes}




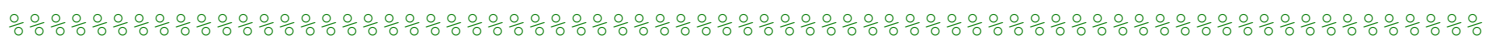

Workspace Code for Articulated Drive Mechanism (3 linkage pieces)

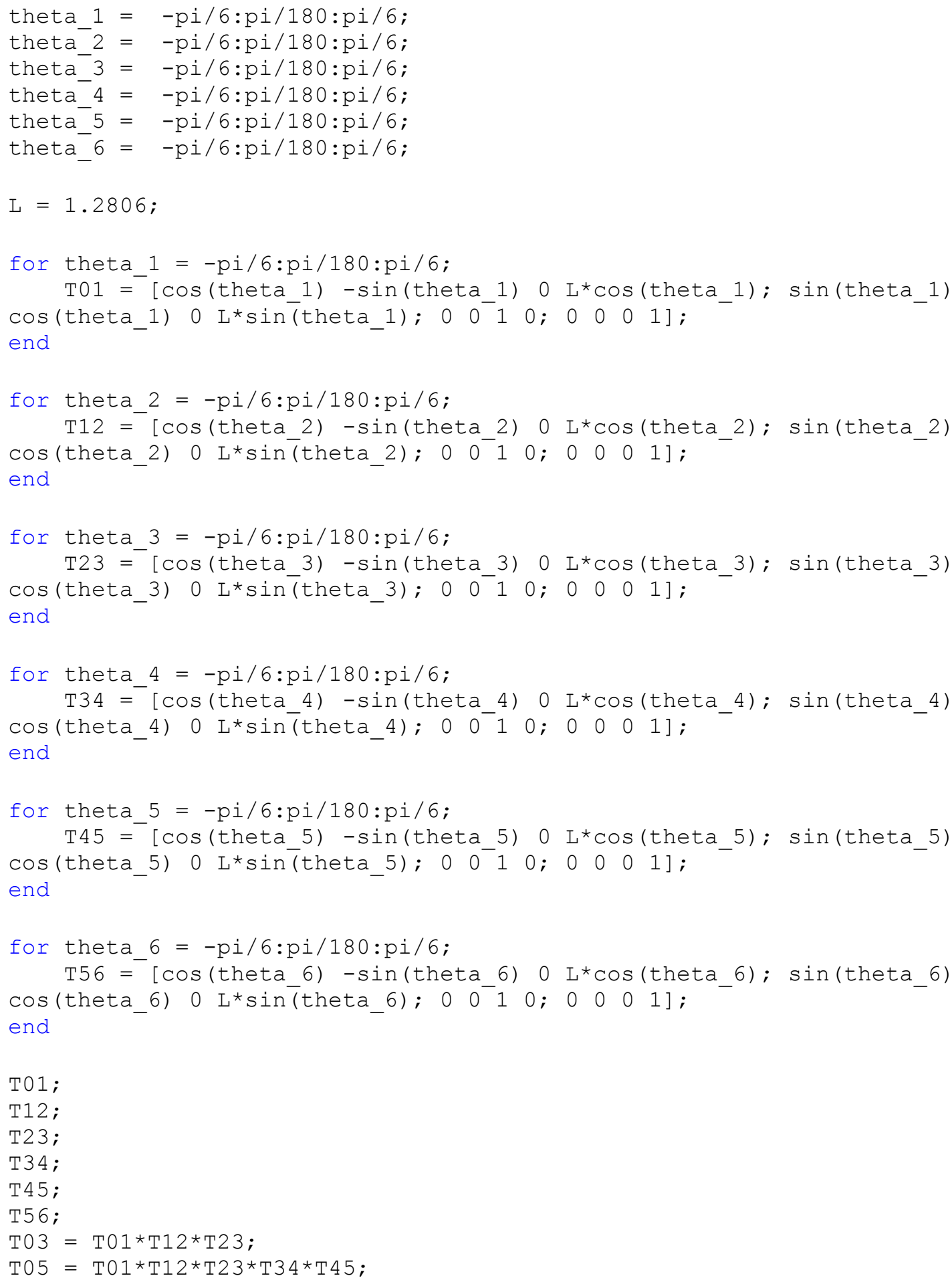




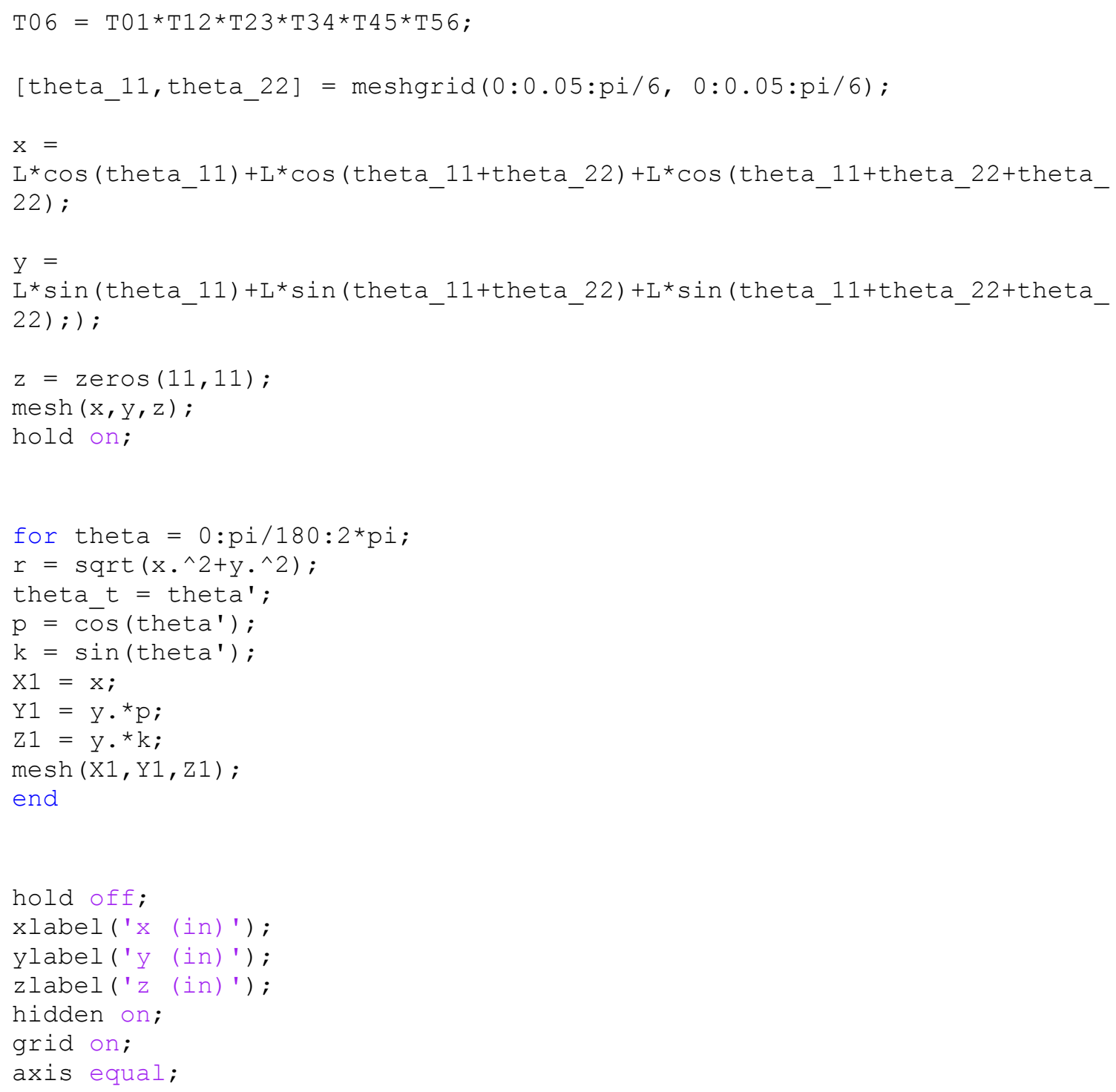




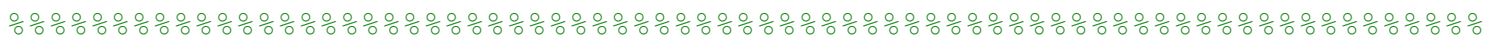

Code for Theoretical and Actual Workspace Comparison

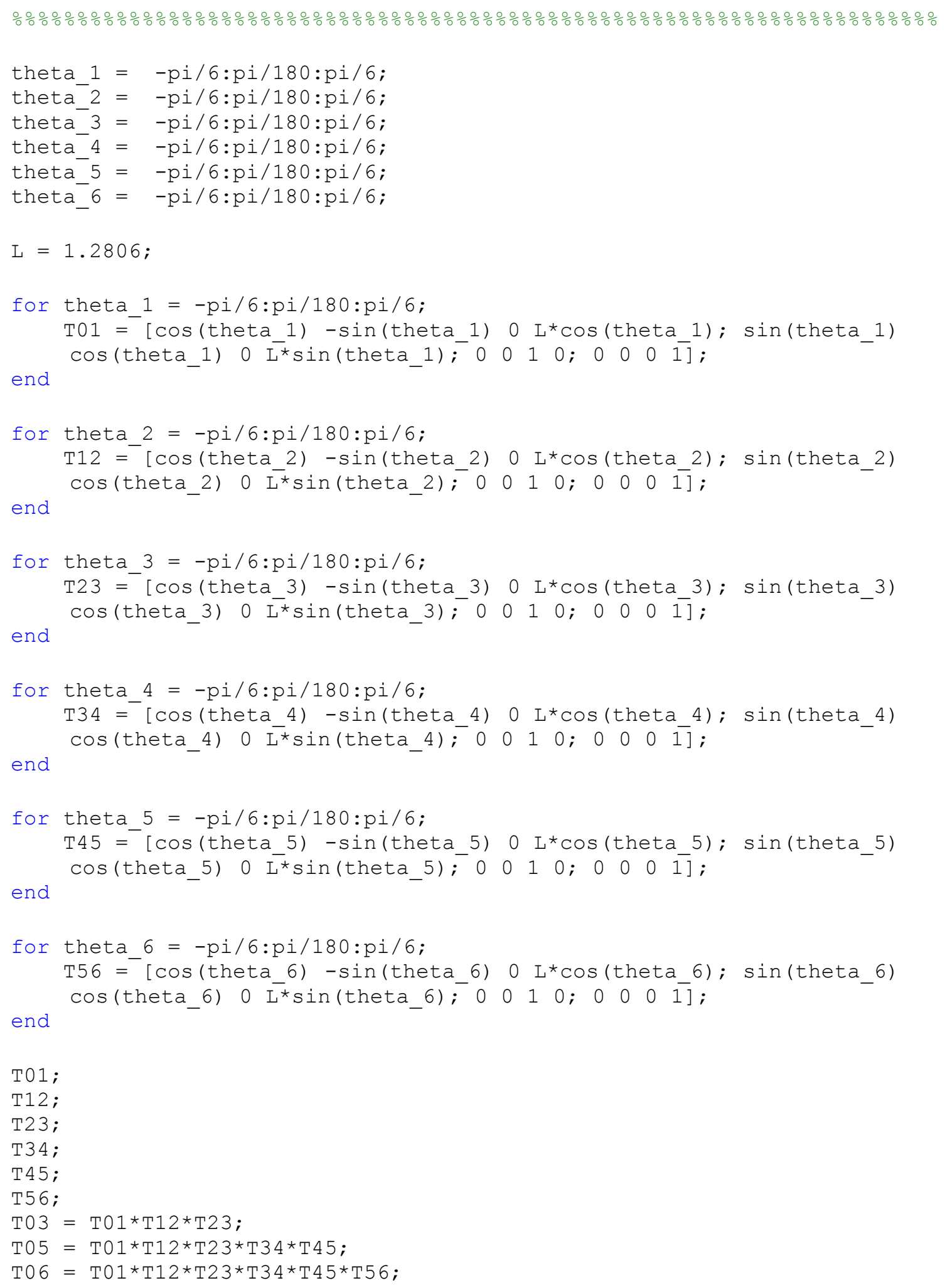


[theta_77, theta_88] = meshgrid $(0: 0.05:$ pi/6, 0:0.05:pi/6);

$\mathrm{x}=$

$\mathrm{L}^{*} \cos ($ theta 77$)+\mathrm{L}{ }^{*} \cos ($ theta $77+$ theta 88$)+\mathrm{L}{ }^{*} \cos ($ theta $77+$ theta $88+$ theta $88)+\mathrm{L}^{*} \cos ($ theta $77+$ theta $88 \overline{+}$ theta $88 \overline{+}$ theta 88$)+\mathrm{L}^{*} \cos$ (theta $77 \overline{+}$ theta $88 \overline{+}$

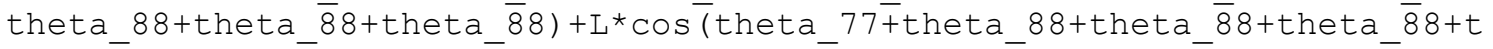
heta_$\overline{8} 8+$ theta_ 8 ();

$\mathrm{y}=$

L* $\sin ($ theta 77) $+\mathrm{L} * \sin ($ theta $77+$ theta 88) $+\mathrm{L} * \sin ($ theta $77+$ theta $88+$ theta

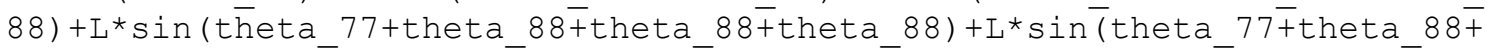

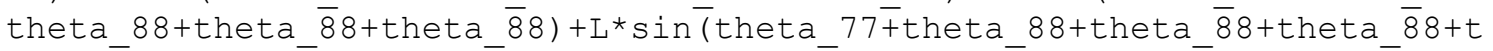
heta_$\overline{8} 8+$ theta_ 8 ) ;

$\mathrm{z}=\operatorname{zeros}(11,11) ;$

$\operatorname{mesh}(\mathrm{x}, \mathrm{y}, \mathrm{z})$;

hold on;

[theta_11, theta_22] = meshgrid $(0: 0.04125:(13 * \mathrm{pi} / 90)$,

$0: 0.03 \overline{6} 49:(23 * \mathrm{p} \overline{\mathrm{i}} / 180))$;

[theta_33, theta_44] = meshgrid $(0: 0.05870:(37 * \mathrm{pi} / 180)$,

$0: 0.04 \overline{6} 01:(29 * \mathrm{p} \overline{\mathrm{i}} / 180))$;

[theta_55, theta_66] = meshgrid $(0: 0.000001586: 0.00001745$,

$0: 0.06 \overline{1} 87:(39 * \mathrm{p} \overline{\mathrm{i}} / 180))$;

$\mathrm{x}=$

$L^{\star} \cos \left(\right.$ theta_11) $+L^{*} \cos ($ theta_11+theta_22) +L*cos (theta_11+theta_22+theta

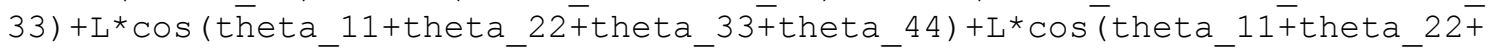
theta_33+theta_ $44+$ theta_ 55$)+\mathrm{L} * \cos$ (theta_11 + theta_22+theta_ $33+$ theta_ $44+t$ heta_$\overline{5} 5+$ theta_ $\overline{6} 6)$;

$\mathrm{y}=$

$\mathrm{L}^{*} \sin ($ theta_11) $+\mathrm{L} * \sin ($ theta_11+theta_22) $+\mathrm{L} * \sin ($ theta $11+$ theta $22+$ theta

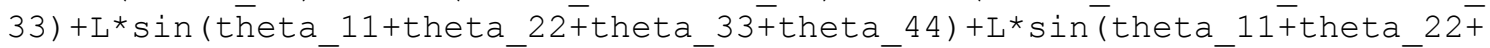
theta_33+theta_ $44+$ theta_ 55$)+\mathrm{L} * \sin ($ theta_11 + theta_22+theta_ $33+$ theta_ $44+t$ heta_$\overline{5} 5+$ theta_$\overline{6} 6)$;

$z=\operatorname{zeros}(12,12) ;$

$\operatorname{surf}(\mathrm{x}, \mathrm{y}, \mathrm{z})$;

hold on;

hold off;

figure (1);

xlabel ('X [inches]');

ylabel ('y [inches]');

zlabel ('Z [inches]');

hidden on;

grid on;

axis equal; 


\section{Appendix C. Matlab ${ }^{\circledR}$ Curvature Code}




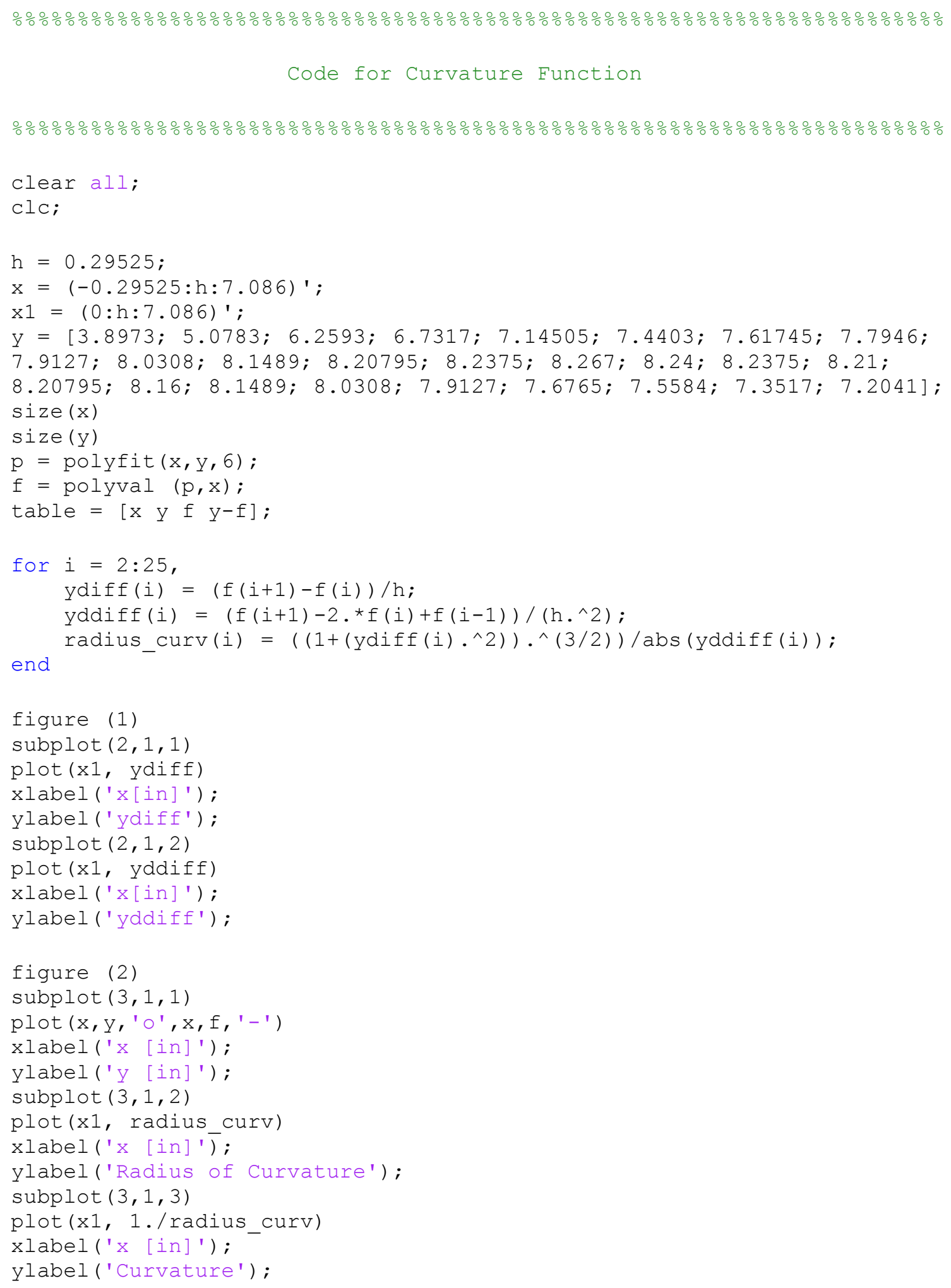




\section{Appendix D. Faulhaber Motor Data Sheet}




\section{FAULHABER}

DC-Micromotors Precious Metal Commutation

Series 2232 ... SR

\begin{tabular}{|c|c|c|c|c|c|c|c|c|c|}
\hline & & 22320 & 006 SR & $009 \mathrm{SR}$ & $012 \mathrm{SR}$ & $015 \mathrm{SR}$ & $018 \mathrm{SR}$ & 024 SR & \\
\hline 1 & Nominal voltage & $\mathrm{UN}_{\mathrm{N}}$ & 6 & 9 & 12 & 15 & 18 & 24 & $\mathrm{~V}$ \\
\hline 2 & Terminal resistance & R & 0,81 & 2,14 & 4,09 & 6,61 & 9,04 & 16,4 & $\Omega$ \\
\hline 3 & Output power & $P_{2 \max }$ & 11 & 9,35 & 8,7 & 8,41 & 8,86 & 8,68 & w \\
\hline 4 & Efflclency, max. & $\eta_{\max }$ & 87 & 86 & 86 & 85 & 86 & 86 & $\%$ \\
\hline 5 & No-load speed & na & 7100 & 7400 & 7100 & 7100 & 7100 & 7100 & rpm \\
\hline 6 & No-load current (with shaft o $2 \mathrm{~mm}$ ) & lo & 0,035 & 0,0241 & 0,0175 & 0,0139 & 0,0116 & 0,0087 & A \\
\hline 7 & Stall torque & Mu & 59,2 & 48,3 & 46,8 & 45,2 & 47,6 & 46,7 & $\mathrm{mNm}$ \\
\hline 8 & Friction torque & $\mathrm{Ma}$ & 0,28 & 0,28 & 0,28 & 0,28 & 0,28 & 0,28 & $\mathrm{mNm}$ \\
\hline 9 & Speed constant & $\mathrm{K}_{\mathrm{n}}$ & 1190 & 827 & 595 & 476 & 397 & 298 & $\mathrm{rpm} / \mathrm{N}$ \\
\hline 10 & Back-EMF constant & $\mathrm{ki}$ & 0,84 & 1,21 & 1,68 & 2,1 & 2,52 & 3,36 & miv/rpm \\
\hline 11 & Torque constant & kM & 8,03 & 11,5 & 16 & 20,1 & 24,1 & 32,1 & $\mathrm{mNm} / \mathrm{A}$ \\
\hline 12 & Current constant & k & 0,125 & 0,087 & 0,062 & 0,05 & 0,042 & 0,031 & $\mathrm{~A} / \mathrm{mNm}$ \\
\hline 13 & Slope of $n-M$ curve & $\Delta \mathrm{N} / \Delta \mathrm{M}$ & 120 & 153 & 152 & 157 & 149 & 152 & $\mathrm{rpm} / \mathrm{m} / \mathrm{Nm}$ \\
\hline 14 & Rotor Inductance & & 45 & 90 & 180 & 280 & 400 & 710 & \\
\hline 15 & Mechanical time constant & $\tau_{m}$ & 6 & 6 & 6 & 6 & 6 & 6 & $\mathrm{~ms}$ \\
\hline 16 & Rotor Inertla & J & 4,8 & 3,8 & 3,8 & 3,8 & 3,8 & 3,8 & $g a n^{2}$ \\
\hline 17 & Angular acceleration & $\alpha \operatorname{mon}$ & 120 & 120 & 120 & 120 & 120 & 120 & $-109 \mathrm{rad} / \mathrm{s}^{2}$ \\
\hline 18 & Thermal resistance & $\operatorname{Rin} 1 / \operatorname{Ran} 2$ & \multicolumn{6}{|l|}{$4 / 13$} & $\mathrm{KN} W$ \\
\hline 19 & Thermal time constant & $\tau=/ \tau \omega$ & \multicolumn{6}{|l|}{$7 / 340$} & 5 \\
\hline \multirow[t]{3}{*}{20} & Operating temperature range: & & \multirow{3}{*}{\multicolumn{6}{|c|}{$\begin{array}{c}-30 \ldots \\
+125\end{array}$ (optional version $-55 \ldots+125$ ) }} & \\
\hline & - motor & & & & & & & & ${ }^{\circ} \mathrm{C}$ \\
\hline & - rotor, max, permissible & & & & & & & & ${ }^{\circ} \mathrm{C}$ \\
\hline \multirow{6}{*}{22} & Shaft bearings & & \multicolumn{2}{|c|}{ sintered bearings } & \multicolumn{2}{|c|}{ ball bearings } & \multicolumn{2}{|c|}{ ball bearings, preloaded } & \\
\hline & Shaft load max.: & & \multirow{2}{*}{\multicolumn{2}{|c|}{$\begin{array}{l}\text { (standard) } \\
2\end{array}$}} & \multirow{2}{*}{\multicolumn{2}{|c|}{ (optional version) }} & \multicolumn{2}{|c|}{ (optional version) } & \\
\hline & - with shaft dlameter & & & & \multirow{2}{*}{\multicolumn{2}{|c|}{$\begin{array}{l}2 \\
8\end{array}$}} & \multirow{2}{*}{\multicolumn{2}{|c|}{$\begin{array}{l}2 \\
8\end{array}$}} & $\mathrm{~mm}$ \\
\hline & - radlal at $3000 \mathrm{rpm}$ (3 mm from bearing) & & \multicolumn{2}{|c|}{1,5} & & & & & $\mathrm{~N}$ \\
\hline & - axlal at $3000 \mathrm{rpm}$ & & \multicolumn{2}{|l|}{0,2} & \multicolumn{2}{|l|}{0,8} & \multicolumn{2}{|l|}{0,8} & $\mathrm{~N}$ \\
\hline & - axlal at standstill & & \multicolumn{2}{|l|}{20} & \multicolumn{2}{|l|}{10} & \multicolumn{2}{|l|}{10} & $\mathrm{~N}$ \\
\hline \multirow{3}{*}{23} & Shaft play & & & & & & & & \\
\hline & - radial & $\leq$ & \multicolumn{2}{|l|}{0,03} & \multicolumn{2}{|l|}{0,015} & \multicolumn{2}{|l|}{0,015} & $\mathrm{~mm}$ \\
\hline & $-a x j a l$ & $\leq$ & \multicolumn{2}{|l|}{0,2} & 0,2 & & & & $\mathrm{~mm}$ \\
\hline 24 & Housing material & & steel, bl: & coated & & & & & \\
\hline 25 & Welght & & 62 & & & & & & g \\
\hline 26 & Direction of rotation & & clockwis & llewed tro & the front & & & & \\
\hline & & & & & & & & & \\
\hline 27 & Speed up to & ne max & 8000 & 8000 & 8000 & 8000 & 8000 & 8000 & rpm \\
\hline 28 & Torque up to & Monnir & 10 & 10 & 10 & 10 & 10 & 10 & $\mathrm{mNm}$ \\
\hline 29 & Current up to (thermal IImits) & lorven & 1,87 & 1,3 & 0,94 & 0,74 & 0,63 & 0,46 & A \\
\hline
\end{tabular}

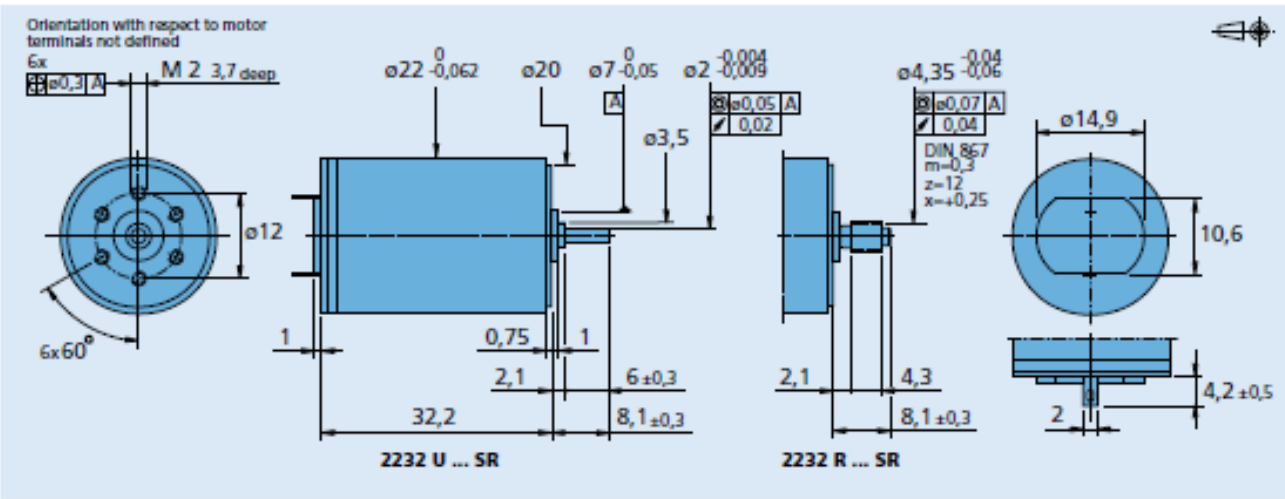

For notes on tachnical data and litsetime performance refor to "Tochrical intormation".

O DR. FAITZ FAULHABER GMSH 8 CO. KG Edition 2011 - 2012

\section{$10 \mathrm{mNm}$}

For combination with

Gearheads:

Encoders:

IE2-1024, IE2-16
$20 / 1,22 / 2,22 / 5,22 \pi, 22 \mathrm{E}, 22 \mathrm{EKV}, 22 \mathrm{~F}, 23 / 1,26 \mathrm{~A}$ 


\section{Appendix E. Faulhaber Planetary Gearhead Data Sheet}


FAULHABER

\section{Planetary Gearheads}

\section{$1 \mathrm{Nm}$}

For combination with

DC-Micromotors

Brushless DC-Motors

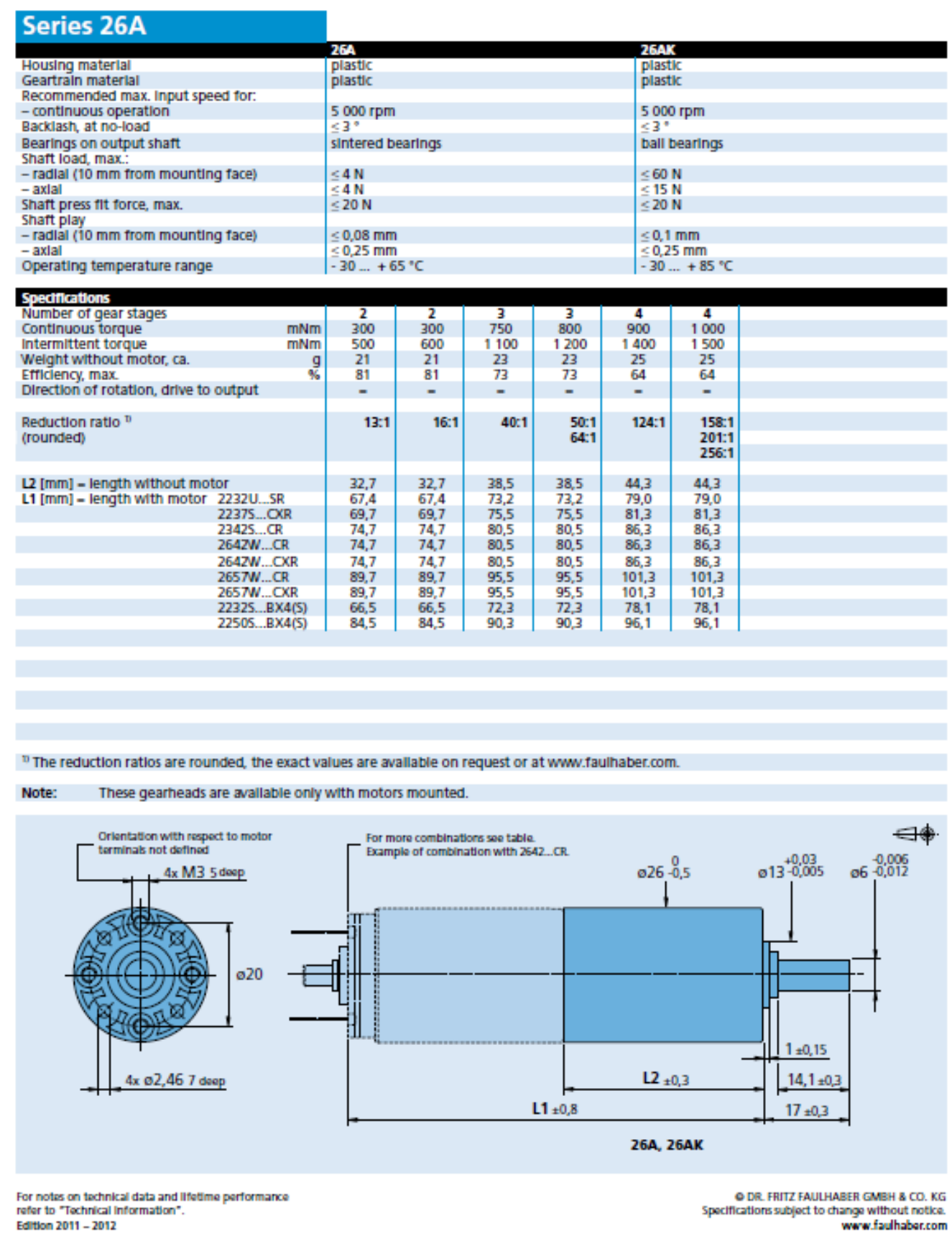

